A integração de Testes Adaptativos
Informatizados e Ambientes
Computacionais de Tarefas para o
aprendizado do inglês instrumental 



\section{A integração de Testes Adaptativos Informatizados e Ambientes Computacionais de Tarefas para o aprendizado do inglês instrumental}

Jean Piton Gonçalves

Orientadora: $\operatorname{Prof}^{a} \operatorname{Dr}^{a}$ Sandra Maria Aluísio

Dissertação apresentada ao Instituto de Ciências Matemáticas e de Computação, ICMC/USP, como parte dos requisitos necessários à obtenção do título de Mestre em Ciências de Computação e Matemática Computacional.

USP - São Carlos

Fevereiro/2004

\footnotetext{
${ }^{1}$ Trabalho realizado com auxílio financeiro do CNPq.
} 



\section{Dedicatória}

A todos educadores e pesquisadores que acreditam na mudança do cenário da Educação e do uso da Tecnologia no Brasil. 



\section{Agradecimentos}

Agradeço, em um primeiro momento, aos espíritos amigos por terem proporcionado saúde e inspiração durante a trajetória de dois anos no mestrado. Agradeço a todas as pessoas que estiveram nesse tempo envolvidas, direta ou indiretamente comigo. E agradeço especialmente:

- Ao meu irmão Joffer pela amizade e por estar ao meu lado nos bons e maus momentos;

- A orientadora Professora Sandra Maria Aluísio, por proporcionar o conhecimento, seu tempo e sua dedicação na pesquisa;

- Aos amigos do laboratório da pós-graduação (lab 160) Waldo, Bruno, Leonardo, Eduardo, Tanaka, Jacqueline, Jorge Teles, ... , pela amizade e dicas de computação;

- Aos funcionários da portaria, da secretaria de pós-graduação, da limpeza e do STI do $\mathrm{ICMC}$;

- Aos Professores Rosana Miskulin e Osvaldo Oliveira (Chú) pelas contribuições no Exame de Qualificação;

- Ao CNPq pelo apoio financeiro, fundamental para manter-me em São Carlos;

- Ao professor Dilvan por ter me aceito inicialmente no programa; 

Esse documento foi elaborado com o formatador de textos $\mathrm{LT}_{\mathrm{E}} \mathrm{X}$.

No sistema de citações de referências bibliográficas utilizou-se chicago_url (é uma reformulação realizada pelo autor dessa monografia do pacote chicago para aceitar links nas referências), e nas citações do texto utiliza-se o estilo natbib.

Para a elaboração de alguns esquemas gráficos, utilizou-se o software Inspiration 2

\author{
(C) Copyright 2004 por Jean Piton Gonçalves \\ jpiton@yahoo.com \\ http://www.jpiton.da.ru \\ Todos os direitos reservados.
}

${ }^{2}$ http://www.inspiration.com/home.cfm 



\section{Resumo}

A necessidade de jovens pesquisadores lerem correta e rapidamente uma grande quantidade de textos escritos em inglês, que é a língua franca da ciência, representa uma barreira considerável para eles. Dada essa necessidade, em 2001, o programa de mestrado em Ciências da Computação e Matemática Computacional do ICMC-USP passou a avaliar a proficiência em inglês dos alunos quanto à habilidade de reconhecerem o gênero de textos científicos em inglês, com as convenções que lhe são características. O site do Exame de Proficiência em Inglês (EPI) disponibiliza Exames Modelos com correção automatizada para os alunos saberem antecipadamente como será o exame formal, também informatizado. Porém, a prática com o Exame Modelo fornece apenas um relatório com o escore do aluno, não oferecendo meios para ele relembrar seus conhecimentos, receber instrução ou ainda rever conceitos errôneos. Uma possível solução para essa lacuna é um ambiente computacional que propicie um contexto favorável à aprendizagem do inglês instrumental. Na perspectiva de favorecer tal aprendizado e auxiliar os alunos a estudarem para o EPI é que essa pesquisa propôs um Ambiente Computacional de Aprendizagem (ACA) para o inglês instrumental. O ACA desenvolvido, denominado Computer-Aided Learning of English for Academic Purposes (CALEAP-Web), é fruto da integração de um Teste Adaptativo Informatizado (TAI), denominado de Adaptive English Proficiency Test for the Web (ADEPT), e um Ambiente Computacional de Tarefas (ACT), denominado de Computer-Aided Task Environment for Scientific English (CATESE). Um TAI consiste em itens (questões) selecionados de acordo com o nível de habilidade estimado do aluno, gerando um teste individualizado. Já o ACT fornece tarefas pré-determinadas para o aprendizado do aluno. Para o ADEPT foram realizados dois experimentos com alunos de mestrado em Ciências da Computação e Matemática Computacional do ICMC-USP e com o CALEAP-Web, como um todo, foram realizadas simulações para a verificação de sua operacionalidade. Embora o ACA tenha sido desenvolvido para apoiar os alunos do programa de mestrado do ICMC-USP, ele é suficientemente genérico para ser usado em outros programas de mestrado que avaliam o inglês instrumental e por jovens pesquisadores que desejam conhecer as convenções do gênero de textos científicos em inglês. 



\section{Abstract}

The need to read correctly and rapidly a huge amount of scientific papers, that is predominantly in English as the lingua franca for science, represents a considerable barrier for novice non-native English researchers. Due to this need, in 2001, the MSc. program in Computer Science and Computational Maths at ICMC-USP proposed a new type of proficiency exam to evaluate students' competence in terms of the demands of highly standardized research articles written in English. The English proficiency exam website makes available simulated tests for the students to be aware of the contents and scoring procedure and to practice before applying for the formal exam, which is also automatically corrected. However, practice with simulated tests only provides a report with the student's score. There is no support to correct student's misconceptions, to instruct or to refresh prerequisite knowledge. A possible solution to fulfil this gap is to provide a computer-based environment designed to arouse students' consciousness about the conventions in English usage in research papers. The purpose of this research was to propose such an environment. The computer-based environment developed, called ComputerAided Learning of English for Academic Purposes (CALEAP-Web), is the result of the integration of an adaptive test, named Adaptive English Proficiency Test for the Web (ADEPT), and a task based environment called Computer-Aided Task Environment for Scientific English (CATESE). An adaptive test consists of items (questions) selected according to the estimated ability level of the student, providing an individualized test. A task based environment provides predefined tasks to ensure student's learning in a certain issue. Two evaluation experiments with students from the MSc. program in Computer Science and Computational Maths at ICMC-USP were carried out with ADEPT; with CALEAP-Web simulations were designed to verify functionality and robustness. Although CALEAP-Web was developed to support students from the MSc. program in Computer Science and Computational Maths at ICMC-USP, it is sufficiently generic to be used in other master programs which assess instrumental English and by novice researchers who need to know the demands of highly standardized research articles written in English. 



\section{Sumário}

Resumo ............................. . . . . . . . .

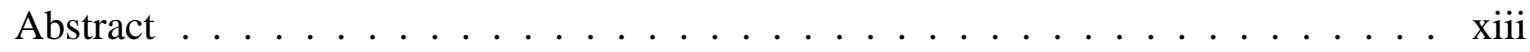

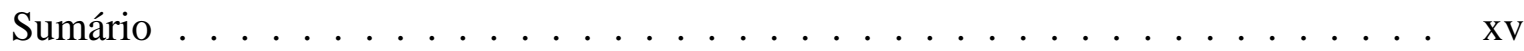

Lista de Figuras $\ldots \ldots \ldots \ldots \ldots \ldots \ldots \ldots \ldots \ldots \ldots$. . . . . . . . . . . . . . . . .

Lista de Tabelas . . . . . . . . . . . . . . . . . . . . . xix

Lista de Abreviaturas . . . . . . . . . . . . . . . . . . . . . xxii

Nomenclatura . . . . . . . . . . . . . . . . . . . . . xxiii

1 Introdução 1

1.1 Motivação . . . . . . . . . . . . . . . . . . . . . 3

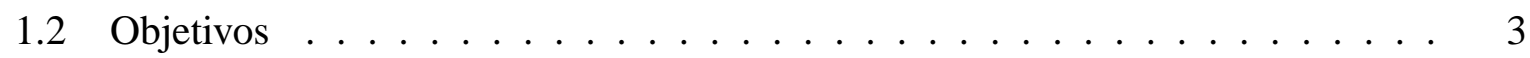

1.3 Organização do Texto $\ldots \ldots \ldots \ldots \ldots \ldots \ldots \ldots \ldots$

\begin{tabular}{|lll|}
\hline 2 & Abordagens de Ambientes Computacionais de Aprendizagem & $\mathbf{7}$
\end{tabular}

2.1 Classificação de Ambientes Computacionais de Aprendizagem quanto ao tipo

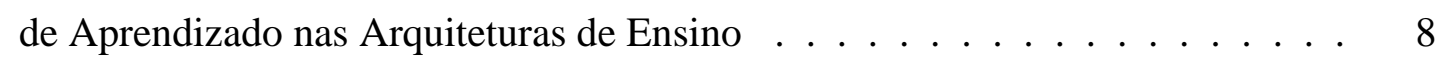

2.1 .1 Simulação Baseada em Aprender-Fazendo. . . . . . . . . . . . . . . 10

$2.1 .2 \quad$ Aprendizado Incidental . . . . . . . . . . . . . . . . . . . . 10

2.1 .3 Aprendizado por Reflexão $\ldots \ldots \ldots \ldots$. . . . . . . . 10

2.1 .4 Ensino Baseado em Casos . . . . . . . . . . . . . . . . . . . . . . . . 11

2.1 .5 Aprendizado por Exploração . . . . . . . . . . . . . . . . . . . 12

2.2 Classificação de Ambientes Computacionais de Aprendizagem quanto ao Pro-

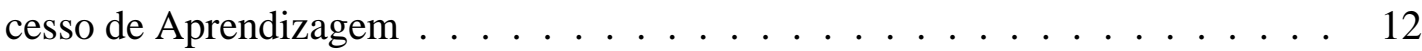

$2.2 .1 \quad$ Enfoque Algorítmico . . . . . . . . . . . . . . . . . . . 12

2.2 .2 Enfoque Heurístico . . . . . . . . . . . . . . . . . . . 12

2.3 Classificação de Ambientes Computacionais de Aprendizagem quanto ao Agente da Interação . . . . . . . . . . . . . . . . . . . . . . . 13

2.3 .1 Aluno no Comando . . . . . . . . . . . . . . . . . . . . . . 13

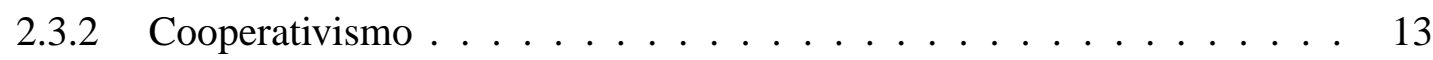


2.3 .3 Colaborativismo . . . . . . . . . . . . . . . . . . . 14

2.3 .4 Tutor no Comando . . . . . . . . . . . . . . . . . . . . . . . . 14

2.4 Classificação de Ambientes Computacionais de Aprendizagem quanto à Forma de Aquisição de Conhecimento . . . . . . . . . . . . . . . . . . 15

2.4 .1 Baseados em Simulação . . . . . . . . . . . . . . . . . . 15

2.4 .2 Sistemas Tutores . . . . . . . . . . . . . . . . . . . . 16

2.4 .3 Hipertexto e Hipermídia . . . . . . . . . . . . . . . . . . . . 16

2.4 .4 Prática por Repetição $\ldots \ldots \ldots \ldots \ldots \ldots$

2.4 .5 Sistemas Informativos . . . . . . . . . . . . . . . . . . 16

2.4 .6 Aprendizagem à Distância $\ldots \ldots \ldots \ldots$

2.4 .7 Sistemas Híbridos $\ldots \ldots \ldots \ldots \ldots$

2.5 Considerações Finais $\ldots \ldots \ldots \ldots \ldots \ldots \ldots$

$\begin{array}{lll}3 & \text { Visão Geral sobre Avaliação e Teste } & 19\end{array}$

3.1 Classificação da Avaliação quanto à Dimensão Pedagógica . . . . . . . . . . . . 19

3.1 .1 Avaliação como Medida . . . . . . . . . . . . . . . . . . 20

3.1 .2 Avaliação como Distância . . . . . . . . . . . . . . 20

3.1 .3 Avaliação como Interpretação $\ldots \ldots \ldots \ldots \ldots \ldots$

3.2 Classificação da Avaliação quanto ao Propósito . . . . . . . . . . . . . . . 21

3.2 .1 Avaliação Diagnóstica . . . . . . . . . . . . . . . . . . . 21

3.2 .2 Avaliação Formativa . . . . . . . . . . . . . . . . . . 21

3.2 .3 Avaliação Somativa ou Final . . . . . . . . . . . . . . . . 22

3.3 Classificação da Avaliação quanto à Pontuação . . . . . . . . . . . . . . . 22

3.3 .1 Critério da Medida de Referência . . . . . . . . . . . . . 22

3.3 .2 Normalização da Medida de Referência . . . . . . . . . . . . . . 23

3.4 Alguns Esclarecimentos sobre Avaliação e Teste . . . . . . . . . . . . . . 23

3.5 Categorias de Testes Objetivos . . . . . . . . . . . . . . . . . . . . 24

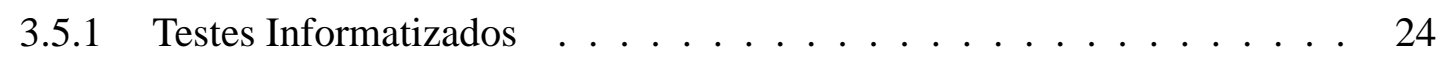

3.5 .2 Vantagens e Desvantagens dos Testes Informatizados . . . . . . . . 26

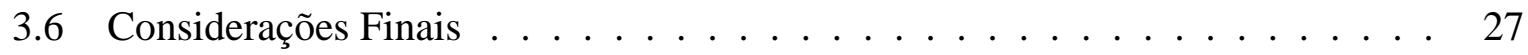

4 Testes Adaptativos Informatizados 29

$4.1 \quad$ Elementos dos Testes Adaptativos Informatizados . . . . . . . . . . . . . . . . 29

4.2 Principais Modelos de Testes Adaptativos $\ldots \ldots \ldots \ldots \ldots \ldots$

4.3 Testes Adaptativos Baseados na Teoria de Resposta ao Item . . . . . . . . . . . 32

4.3 .1 Parâmetros do Banco de Itens $\ldots \ldots \ldots \ldots \ldots \ldots$

4.3 .2 Calibração dos Itens $\ldots \ldots \ldots \ldots \ldots \ldots$ 
4.4 Modelos Logísticos . . . . . . . . . . . . . . . . . . . . . . . 33

4.4 .1 Modelo Logístico de Um Parâmetro . . . . . . . . . . . . . . . 33

4.4 .2 Modelo Logístico de Dois Parâmetros . . . . . . . . . . . . . . . 34

4.4 .3 Modelo Logístico de Três Parâmetros . . . . . . . . . . . . . . . 34

4.4 .4 Modelo Logístico de Quatro Parâmetros . . . . . . . . . . . . . . . 35

4.5 Banco de Itens e a Estimativa de Parâmetros . . . . . . . . . . . . . . . 35

4.6 Estimativa da Habilidade do Aluno . . . . . . . . . . . . . . . . . . 36

4.7 Função de Informação de um Item . . . . . . . . . . . . . . . . . . . 36

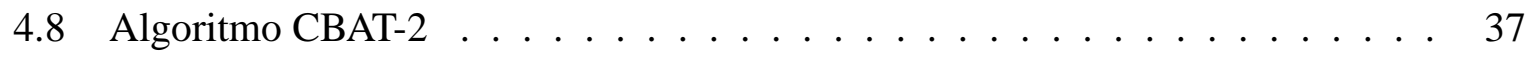

4.8 .1 Gerenciamento de Conteúdo . . . . . . . . . . . . . . . . . 38

$4.8 .2 \quad$ Seleção das Questões . . . . . . . . . . . . . . . . . . . . . . . . . 39

4.8 .3 Estimativa da Habilidade no CBAT-2 $\ldots \ldots \ldots \ldots \ldots \ldots$. . . . 41

4.8 .4 Pontuação e a Decisão Mestra . . . . . . . . . . . . . . . . . . . 41

4.9 Potencialidades dos Testes Adaptativos Informatizados $\ldots \ldots \ldots \ldots$. . . . . 41

4.10 Considerações Finais $\ldots \ldots \ldots \ldots \ldots$. . . . . . . . . . . 42

5 Integração de Testes Adaptativos Informatizados e Ambientes Computacionais de Tarefas 43

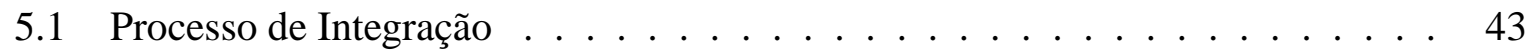

5.2 Exemplos de Ambientes de Integração $\ldots \ldots \ldots \ldots \ldots$. . . . . . . . 44

$5.2 .1 \quad$ Projeto TREE $\ldots \ldots \ldots \ldots \ldots \ldots \ldots \ldots \ldots$

5.2 .2 Sistema INSPIRE $\ldots \ldots \ldots \ldots \ldots \ldots$. . . . . . . . . . . . 47

5.3 Considerações Finais $\ldots \ldots \ldots \ldots \ldots \ldots \ldots$

6 Implementação de um Teste Adaptativo Informatizado para o Inglês Instrumental 49

6.1 Arquitetura do ADEPT $\ldots \ldots \ldots \ldots \ldots \ldots \ldots$

$6.1 .1 \quad$ Banco de Itens do ADEPT . . . . . . . . . . . . . . . . . 52

6.1 .2 Critérios de Parada do Teste . . . . . . . . . . . . . . . . 56

6.1 .3 Cálculo da Nota Final do Aluno . . . . . . . . . . . . . . . . . 57

6.2 Alterações Realizadas no CBAT-2 . . . . . . . . . . . . . . . . . . . 57

6.2 .1 Seleção dos Itens no ADEPT . . . . . . . . . . . . . . . . . . 57

6.2 .2 Estimativa da Habilidade do Aluno $\ldots \ldots \ldots \ldots \ldots \ldots$

6.2 .3 Expansão do ADEPT $\ldots \ldots \ldots \ldots \ldots \ldots \ldots \ldots$

6.3 Experimentos Realizados com o ADEPT $\ldots \ldots \ldots \ldots \ldots \ldots \ldots$

6.3 .1 Experimento Número $1 \ldots \ldots \ldots \ldots \ldots$

6.3 .2 Experimento Número $2 \ldots \ldots \ldots \ldots$

6.3 .3 Resultados Comparativos - Experimentos Número 1 e 2 . . . . . . 66 
6.4 Discussão dos Resultados $\ldots \ldots \ldots \ldots$. . . . . . . . . . . . . 71

6.5 Considerações Finais $\ldots \ldots \ldots \ldots$. . . . . . . . . . . . . . 72

7 Implementação de um Ambiente Computacional de Aprendizagem para o Inglês Instrumental $\quad \mathbf{7 3}$

$7.1 \quad$ Arquitetura do CALEAP-Web . . . . . . . . . . . . . . . . 73

7.1 .1 Ambiente Computacional de Tarefas CATESE . . . . . . . . . . 75

7.1 .2 Funcionamento do Sistema . . . . . . . . . . . . . . . . . 76

7.2 Projetos que Apoiaram o desenvolvimento do CATESE . . . . . . . . . . . 78

$7.2 .1 \quad$ Ferramenta de Suporte à Escrita do AMADEUS $\ldots . . . . . .78$

7.2.2 SciPo: uma Ferramenta de Suporte à Escrita em Português . . . . . . . 81

7.2.3 CALESE: uma Ferramenta de Suporte à Escrita em Inglês . . . . . . . 81

7.3 Avaliação da Operacionalidade do CALEAP-Web . . . . . . . . . . . . . . 83

7.3.1 Interação do Aluno com o CALEAP-Web na Tarefa 1. . . . . . . . . . 83

7.3 .2 Interação do Aluno com o CALEAP-Web na Tarefa 2 . . . . . . . . . . 89

7.3 .3 Interação do Aluno com o CALEAP-Web na Tarefa 4 . . . . . . . . . . 93

7.3.4 Interação do Aluno com o CALEAP-Web na Tarefa 3 . . . . . . . . . . 97

7.4 Discussão dos Resultados . . . . . . . . . . . . . . . . . . . . . . . . . . . 100

7.5 Considerações Finais $\ldots \ldots \ldots$. . . . . . . . . . . . . . . . . 101

\begin{tabular}{lll}
\hline Conclusão & 103
\end{tabular}

8.1 Contribuições . . . . . . . . . . . . . . . . . . . . . . . . . . . 104

8.2 Limitações . . . . . . . . . . . . . . . . . . . . . . . . 105

8.3 Trabalhos Futuros $\ldots \ldots \ldots \ldots$. . . . . . . . . . . . . . . . . . . . . .

\begin{tabular}{ll}
\hline Referências Bibliográficas & 106
\end{tabular}

\begin{tabular}{ll}
\hline Apêndice & 111
\end{tabular}

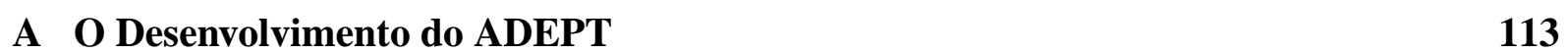

A.1 Etapa 1 - Seleção da Questão ao Aluno . . . . . . . . . . . . . . . . . . . . . . 113

A.2 Etapa 2 - Resposta à Questão . . . . . . . . . . . . . . . . . . . . . . . . . . . 114

A.3 Etapa 3 - Calibração do Parâmetro $b$ da Questão . . . . . . . . . . . . . . . . . 114

A.4 Etapa 4 - Estimativa da Habilidade do Aluno . . . . . . . . . . . . . . . . . . 115

A.5 Ciclo das Etapas . . . . . . . . . . . . . . . . . . . . . . . . . 116 


\section{Lista de Figuras}

$3.1 \quad$ Avaliação durante o ciclo $\ldots \ldots \ldots \ldots \ldots$

3.2 Relação temporal da Avaliação Diagnóstica. . . . . . . . . . . . . . . . 21

3.3 Relação temporal da avaliação no fim do período . . . . . . . . . . . . 22

3.4 Tela com uma introdução de um artigo científico da área de computação no

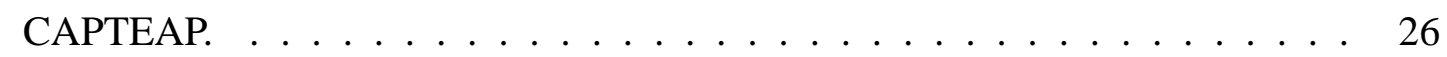

3.5 Tela com uma questão sobre a estrutura de introdução apresentada na Figura 3.4|no CAPTEAP. . . . . . . . . . . . . . . . . . . . . 27

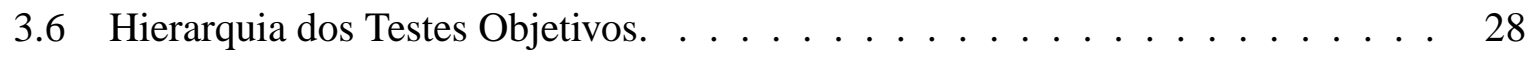

4.1 Registro de resposta de um aluno no Binet Test $\ldots \ldots \ldots \ldots \ldots$. . . . . 31

4.2 Registro de resposta de um aluno no Teste Adaptativo Estratificado . . . . . . . 32

4.3 Áreas do conteúdo e questões em uma Hierarquia de Currículo . . . . . . . . . 38

5.1 Integração entre Módulos de Teste e de Aprendizado. . . . . . . . . . . . . . 44

5.2 Arquitetura geral do SIETTE $\ldots \ldots \ldots \ldots \ldots \ldots \ldots$

5.3 A estrutura do TREE. . . . . . . . . . . . . . . . . . . . . 46

5.4 Componentes e interações com o aluno. . . . . . . . . . . . . . . . 48

$6.1 \quad$ Arquitetura do ADEPT. . . . . . . . . . . . . . . . . 50

6.2 A estrutura e funcionamento do ADEPT. . . . . . . . . . . . . . . . . 51

6.3 Tela de uma questão do ADEPT da Parte Gap. . . . . . . . . . . . . . . . 53

6.4 Tela de uma questão do ADEPT da Parte Setting. . . . . . . . . . . . . . . 54

6.5 Tela de uma questão do ADEPT da Parte Comprehension. . . . . . . . . . . . 54

6.6 Continuação da tela de uma questão do ADEPT da Parte Comprehension. . . . 55

6.7 Tela de uma questão do ADEPT da Parte Introduction. . . . . . . . . . . . 55

6.8 Seqüência de apresentação dos Módulos do EPI ao usuário no experimento 1. . 60

6.9 Sequiência de apresentação dos Módulos do EPI ao usuário no experimento 2. . 64

6.10 Diagrama de conteúdo do EPI. . . . . . . . . . . . . . . . . 67

7.1 Esquema da integração no CALEAP-Web. . . . . . . . . . . . . . . . . 74 
7.2 Seqüência de aprendizado para o CATESE. … . . . . . . . . . . 75

7.3 Tela inicial do CALEAP-Web. . . . . . . . . . . . . . . . . . . . 77

7.4 Esquema de funcionamento do CALEAP-Web. . . . . . . . . . . . . 77

7.5 Tela de escolha de componentes e estratégias da Ferramenta de Suporte à escrita do AMADEUS. . . . . . . . . . . . . . . . . . . . . . . . . . . . 79

7.6 Tela da recuperação de casos da Ferramenta de Suporte à escrita do AMADEUS. 80

7.7 Tela de revisão de um artigo científico da Ferramenta de Suporte à escrita do

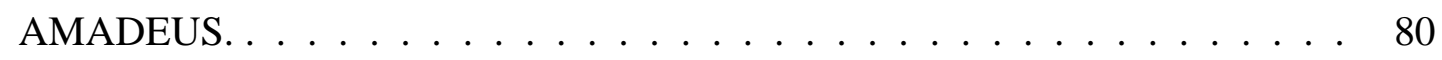

7.8 Tela da escolha de componentes e estratégias no CALESE. . . . . . . . . . . 82

7.9 Continuação da tela para a escolha de componentes e estratégias no CALESE. . 82

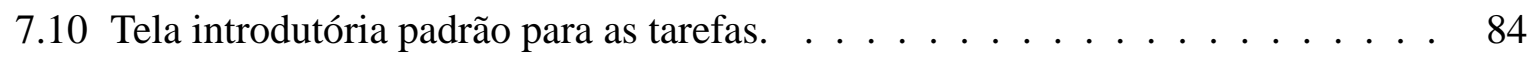

7.11 Tela com as instruções da Tarefa 1. . . . . . . . . . . . . . . . . 84

7.12 Tela com as explicações sobre Gap da Tarefa 1. . . . . . . . . . . . . . 85

7.13 Tela da Tarefa 1 com os exemplos de Gap recuperados. . . . . . . . . . . . 86

7.14 Tela de navegação dos exemplos recuperados de Gap da Tarefa 1. . . . . . . . 87

7.15 Tela com as explicações sobre Purpose da Tarefa 1. . . . . . . . . . . . . 88

7.16 Tela da Tarefa 1 com os exemplos recuperados de Purpose. . . . . . . . . 88

7.17 Tela com as instruções da Tarefa $2 . \ldots \ldots \ldots \ldots \ldots$. . . . . . . . 89

7.18 Tela com as explicações da Tarefa $2 . \ldots \ldots \ldots$. . . . . . . . 90

7.19 Tela da Tarefa 2 para a escolha de estratégias para a escrita de introduções. . . . 91

7.20 Tela com a recuperação de casos da Tarefa $2 . \ldots \ldots \ldots$. . . . . . 91

7.21 Tela 1 com a exibição do caso $t s f 4$ para a Tarefa $2 . \ldots \ldots \ldots$. . . . . . 92

7.22 Tela 2 com a exibição do caso $t s f 4$ para a Tarefa $2 . \ldots \ldots$. . . . . . . 92

7.23 Tela com as instruções da Tarefa $4 . \ldots \ldots \ldots$. . . . . . . . . 93

7.24 Tela com as explicações de Setting da Tarefa 4. . . . . . . . . . . . . . . 94

7.25 Tela da Tarefa 4 com os exemplos de Setting recuperados. . . . . . . . . . 95

7.26 Tela com as explicações sobre Review of Literature da Tarefa 4. . . . . . . . . . 96

7.27 Tela da Tarefa 4 com os exemplos recuperados de Review of Literature. . . . . 96

7.28 Tela com as instruções da Tarefa 3. . . . . . . . . . . . . . . . . . . 97

7.29 Tela com as explicações da Tarefa $3 . \ldots \ldots \ldots$. . . . . . . . . . 98

7.30 Tela com os marcadores da função contraste/oposição da Tarefa 3. . . . . . . . 99

7.31 Tela com os marcadores da função conseqüência/resultado da Tarefa 3. . . . . . 99

7.32 Término do uso do CALEAP-Web. . . . . . . . . . . . . . . . . . 100

A.1 Ciclo das Etapas para o desenvolvimento do ADEPT. . . . . . . . . . . 116 


\section{Lista de Tabelas}

2.1 Classificações dos Ambientes Computacionais de Aprendizagem. . . . . . . . 17

3.1 Classificações da avaliação. . . . . . . . . . . . . . . . . . . . . 28

$6.1 \quad$ Número de questões armazenadas na base de dados do ADEPT. . . . . . . . . 56

6.2 Peso de cada módulo para o TAI. . . . . . . . . . . . . . . . 57

6.3 Tabela das classes do parâmetro $b . \ldots \ldots$. . . . . . . . . . 60

6.4 Quantidade de questões calibradas por Módulo e Parte no experimento 1. . . . 61

6.5 Diferença absoluta entre o parâmetro $b$ das questões iniciais e calibradas no

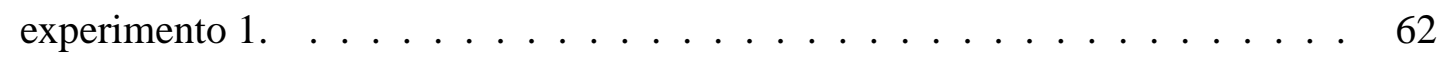

6.6 Dados de cada aluno no experimento $1 . \ldots \ldots \ldots$. . . . . . . 63

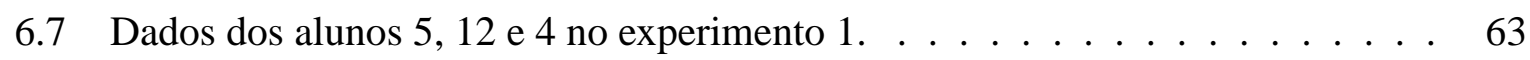

6.8 Valores máximos e mínimos do teste referentes aos alunos envolvidos no experimento 1. . . . . . . . . . . . . . . . . . . 64

6.9 Quantidade de questões calibradas por Módulo e Parte no experimento 2. . . . 65

6.10 Diferença absoluta entre o parâmetro $b$ do experimento $1\left(\omega_{0}\right)$ e experimento 2

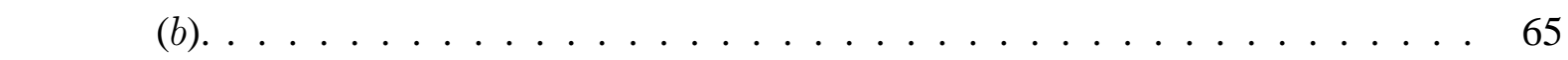

6.11 Dados de cada aluno no experimento $2 . \ldots \ldots \ldots 6 . \ldots \ldots 6$

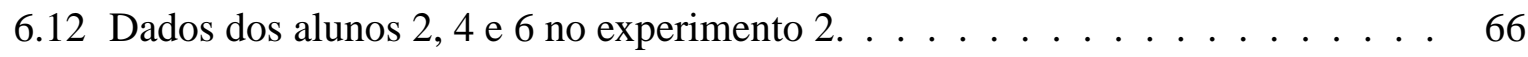

6.13 Valores máximos e mínimos do teste referentes aos alunos envolvidos no expe-

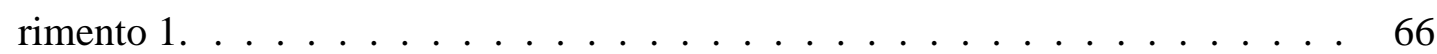

6.14 Questões que os alunos responderam totalmente corretas e totalmente incorretas. $\omega_{0}$ é o $b$ inicial, anterior ao experimento $1 . \ldots \ldots . \ldots 68$

6.15 Número de questões calibradas do experimento 1 e experimento 2 por Parte em cada Módulo do EPI. . . . . . . . . . . . . . . . . . . . . . 68

6.16 Resultados globais da base de questões final. . . . . . . . . . . . . . . . 69

6.17 Dados dos grupos dos testlets no experimento $2 . \ldots \ldots$. . . . . . . 69

6.18 Valores máximos e mínimos do teste referentes aos alunos envolvidos em ambos experimentos. . . . . . . . . . . . . . . 70 
7.1 Tarefas sugeridas ao aluno e seus conteúdos ministrados. . . . . . . . . . 76

7.2 Dados do aluno 1 no ADEPT para o Módulo 1 do EPI. . . . . . . . . . . 83

7.3 Dados do aluno 2 no ADEPT para o Módulo 2 do EPI. . . . . . . . . . . . 89

7.4 Dados do aluno 4 no ADEPT para o Módulo 4 do EPI. . . . . . . . . . . . . 93

7.5 Dados do aluno 3 no ADEPT para o Módulo 3 do EPI. . . . . . . . . . . . 97 


\section{Lista de Abreviaturas}

ACA Ambiente Computacional de Aprendizagem

ACA's Ambientes Computacionais de Aprendizagem

ACT Ambiente Computacional de Tarefas

ACT's Ambientes Computacionais de Tarefas

ADEPT Adaptive English Proficiency Test for the Web

BI Banco de Itens

CALEAP-Web Computer-Aided Learning of English for Academic Purposes

CALESE Computer-Aided Learning Tool for Scientific Writing in English

CATESE Computer-Aided Task Environment for Scientific English

CAPTEAP Computer Assisted Proficiency Test of English for Academic Purposes

CBAT-2 Content-Balanced Adaptive Testing

CCI Curva Característica de um Item

CMR Critério da Medida de Referência

EPI Exame de Proficiência em Inglês

EXP1 Experimento 1

EXP2 Experimento 2

FII Função de Informação de um Item

IA Inteligência Artificial

IAC Instrução Auxiliada por Computador 
MPA Medida de Probabilidade Admissível

ML1P Modelo Logístico de Um Parâmetro

ML2P Modelo Logístico de Dois Parâmetros

ML3P Modelo Logístico de Três Parâmetros

ML4P Modelo Logístico de Quatro Parâmetros

NMR Normalização da Medida de Referência

NR método de Newton-Raphson iterativo modificado

RBC Raciocínio Baseado em Casos

TA Teste Adaptativo

TA's Testes Adaptativos

TAI Teste Adaptativo Informatizado

TAI's Testes Adaptativos Informatizados

TI Teste Informatizado

TI's Testes Informatizados

TRI Teoria de Resposta ao Item

SciPo Scientific Writing in Brazilian Portuguese

STI Sistema Tutor Inteligente

STI's Sistemas Tutores Inteligentes 


\section{Glossary}

$I(\theta)$ Função de Informação do Item da TRI

$P^{\prime}(\theta)$ Derivada de primeira ordem da função $P(\theta)$

$P(\theta)$ Probabilidade de um aluno com habilidade $\theta$ acertar a questão

$\Phi_{i} \quad$ Dificuldade acumulada por cada questão $Q_{i}$ no CBAT-2

$\Upsilon_{i} \quad$ Probabilidade da seleção do $i$-ésimo componente $C_{i}$ no CBAT-2

$\mu_{i} \quad$ Nível de dificuldade da questão $Q_{i}$ no CBAT-2

$\theta \quad$ Estimador de habilidade do aluno

a Parâmetro discriminação da TRI

$b \quad$ Parâmetro dificuldade da TRI

c Parâmetro adivinhação da TRI

d Parâmetro lentidão da TRI 



\section{Capítulo 1}

\section{Introdução}

A apropriação de saberes é um processo complexo, que em muitos casos pode ser facilitado com o uso do computador. Para isso existem softwares de aprendizagem com os quais é possível obter o conhecimento de um determinado domínio. Nessa perspectiva tem-se os Ambientes Computacionais de Aprendizagem (ACA's) que propiciam cenários para o aprendizado de um dado conteúdo. Exemplos de ACA's são o ambiente de aprendizado do projeto TREE (Conejo et al. 1999, 2000, 2001) e o sistema INSPIRE (Papanikolaou et al., 2001; Gouli et al., 2001).

Com a rápida expansão do número de estudantes dada a necessidade acentuada da educação continuada neste novo milênio, as instituições de Ensino Superior estão usando o computador para resolver os problemas associados a essa nova demanda. Além do uso do computador para a aquisição do conhecimento e como suporte no aprendizado de alunos, ele tem sido usado na construção e administração de testes e exames. Avaliação é um componente importante de processos educacionais ou de treinamento, para a admissão em programas educacionais, ou para processos classificatórios (ou eliminatórios) de várias naturezas.

Existem sistemas que realizam a avaliação em larga escala por intermédio do computador, como é o caso do Test of English as a Foreign Language (TOEFL) ${ }^{1}$ que é de caráter adaptativo, ou seja, se o aluno responder corretamente a uma questão, a seguinte terá um grau de dificuldade superior, caso contrário (resposta incorreta) terá uma questão de um grau de dificuldade inferior.

No Brasil, a Fundação Carlos Chagas tem um projeto em andamento, que tem como proposta principal a Educação para o Trânsitð² Para fortalecer a formação de condutores e pedestres são aplicados exames diretamente no computador em que as perguntas são ministradas segundo um banco de dados calibrado. Além dos candidatos receberem tipos de provas diferentes, o sistema permite rapidez e segurança na geração automática de pontuações, resultados e boletins de desempenho dos futuros condutores. O Ministério da Educação e Cultura (MEC)

\footnotetext{
${ }^{1}$ http://www.toefl.org

${ }^{2}$ http://www.fcc.org.br/servlets/apresentacao/apresentacao?pg=transito.html
} 
criou o Sistema Nacional de Avaliação da Educação Básica (Saeb) ${ }_{3}^{3}$, que vem aplicando testes a cada dois anos, sendo possível colocar em uma mesma escala os alunos das três séries envolvidas na avaliação. Para a avaliação, são utilizadas provas elaboradas com um grande número de itens distribuídos em vários cadernos de provas, o que permite uma ampla cobertura dos conteúdos e das habilidades em todas as séries avaliadas. Já o Laboratório de Fundamentos da Computação (LFC) ${ }^{4}$ da Universidade Federal do Rio Grande do Sul (UFRGS) criou dois tipos de provas 5 para alunos via computador: a Prova Eletrônica Convencional que consiste na resolução de questões de múltipla escolha pela WWW, sendo possível ao final da prova, obter imediatamente o resultado final da prova; e a Prova Eletrônica Adaptativa cujas provas estão classificadas em áreas de estudo com questões de múltipla-escolha de diferentes níveis de dificuldade. Quando o aluno escolhe a área, é apresentada uma questão de nível médio. No caso de acertar a questão, o aluno passa para uma outra questão de maior dificuldade. Se errar a resposta da questão, o aluno passa para uma questão de menor nível de dificuldade. Esses exemplos de sistemas de avaliação e aprendizagem mostram instituições preocupadas em obter resultados eficientes, rápidos e precisos.

Com o aumento de textos científicos e da facilidade de acesso a eles devido à WWW, cada vez mais torna-se necessário que alunos de mestrado leiam e interpretem bem e com rapidez os artigos científicos de suas áreas de pesquisa. Nessa perspectiva, até o início do ano 2000, os alunos que ingressavam no programa de mestrado do ICMC-USP ${ }^{6}$ eram avaliados com relação à proficiência em inglês mediante exames preparados a cada semestre por um professor diferente, que decidia o conteúdo, extensão e duração dos exames. Em agosto de 2000, foi proposto um novo tipo de EPI instrumental automatizado, composto por questões objetivas, isto é, requisitam do aluno uma resposta a uma questão cuja resposta correta é pré-determinada (McKenna \& Bull, 1999). Tal exame avalia a compreensão do texto e a habilidade de reconhecer o gênero de textos científicos em inglês, com a estrutura e convenções da língua que lhes são características, por meio de quatro módulos: Convenções da Língua Inglesa para Textos Científicos, Estrutura de Textos Científicos, Compreensão de Texto e Estratégias de Escrita (Aquino, 2001). O Exame de Proficiência em Inglês (EPI) para o Mestrado do ICMC-USP tenta sanar os problemas de custo, tempo, falta de padronização e a falta de adequação dos exames anteriores.

Segundo Aquino (2001), a Taxonomia de Bloom foi utilizada para auxiliar no esclarecimento dos objetivos educacionais envolvidos no exame e na identificação de habilidades que estão sendo avaliadas. Para solucionar o problema do "chute" e estabelecer uma pontuação coerente com o conhecimento do estudante, foi utilizada a técnica de Medida de Probabilidade Admissível (MPA), usando questões de três alternativas. Esse método possibilita ao aluno ex-

\footnotetext{
${ }^{3}$ http://www.inep.gov.br/basica/saeb/default.asp

${ }^{4} \mathrm{http}: / /$ teia.inf.ufrgs.br

${ }^{5}$ http://teia.inf.ufrgs.br/e-exams.php

${ }^{6}$ http://www.icmc.usp.br
} 
pressar o grau de certeza ou incerteza em relação as suas respostas, podendo escolher como resposta da questão uma opção dentre as letras $\mathrm{A}$ até $\mathrm{M}$ dispostas em um triângulo eqüilátero. Cada resposta está associada a uma pequena região de probabilidades que representam a crença dele na escolha de alguma alternativa.

Em abril de 2001, foi utilizado o primeiro exame informatizado para o EPI através do sistema Computer Assisted Proficiency Test of English for Academic Purposes (CAPTEAP) 7 , que tenta estabelecer uma análise de resultados mais justa, utilizando critérios que permitem a classificação do aluno em aprovado ou refazer, fornecendo ao final do exame um relatório de seu desempenho nos vários módulos e com indicação explícita em qual critério o aluno foi aprovado (existem três critérios de aprovação). O CAPTEAP disponibiliza Exames Modelos com correção automatizada para os alunos saberem antecipadamente como será o exame formal conteúdo, sistema de pontuação e formato.

\subsection{Motivação}

No projeto do CAPTEAP não foi previsto nenhum ambiente computacional que propicie um contexto de aprendizagem aos alunos ingressantes no mestrado em Ciências da Computação e Matemática Computacional do ICMC-USP, disponibilizando somente Exames Modelos com correção automatizada para os alunos antecipadamente terem ciência de como será o exame formal.

Nesse contexto, o CAPTEAP não fornece meios para o aluno relembrar seus conhecimentos, receber instrução ou ainda rever conceitos errôneos sobre as convenções do gênero de textos científicos em inglês, como por exemplo em um artigo científico: resumo, metodologia, conclusão, etc.

\subsection{Objetivos}

O propósito dessa pesquisa de mestrado foi verificar se a integração de um teste informatizado e um ambiente que fornece tarefas ao aluno, resultaria em um ambiente capaz de propiciar o aprendizado do inglês instrumental. Para validar a hipótese projetou-se, desenvolveu-se e avaliou-se a integração de um Teste Adaptativo Informatizado (TAI) - que consiste em itens (questões) selecionados de acordo com o nível de habilidade estimado do aluno, gerando um teste individualizado com poucas questões - e um Ambiente Computacional de Tarefas (ACT) - que fornece tarefas bem elaboradas a partir das convenções do gênero de textos científicos.

\footnotetext{
${ }^{7}$ http://www.nilc.icmc.usp.br/capteap
} 
Da integração do TAI e do ACT surge um Ambiente Computacional de Aprendizagem (ACA) que poderá auxiliar alunos de mestrado que realizarão o EPI do programa de mestrado em Ciências da Computação e Matemática Computacional do ICMC-USP, e também auxiliar alunos de iniciação científica, de mestrado ou doutorado envolvidos com pesquisas científicas a conhecerem melhor o gênero de textos científicos em inglês.

O ACA desenvolvido, denominado Computer-Aided Learning of English for Academic Purposes (CALEAP-Web), foi baseado na abordagem Aprender-Fazendo que propicia um contexto favorável para o aprendizado do inglês instrumental. Para o TAI foram realizados dois experimentos com alunos do mestrado em Ciências da Computação e Matemática Computacional do ICMC-USP e com o CALEAP-Web, como um todo, foram realizadas simulações para a verificação de sua operacionalidade.

\subsection{Organização do Texto}

Por essa pesquisa tratar de três grandes áreas do conhecimento: Ciência da Computação, Educação e Lingüística/Escrita Técnica, o Capítulo 2 consiste em quatro abordagens de ACA's ( Classificação quanto ao Aprendizado nas Arquiteturas de Ensino, quanto ao Processo de Aprendizagem, quanto ao Agente da Interação e quanto à Forma de Aquisição de Conhecimento) que possibilitaram a escolha da abordagem Aprender-Fazendo para o ambiente proposto.

O Capítulo 3 mostra-se três visões sobre avaliação de alunos: pedagógica, objetivo/propósito e enquanto medida do conhecimento. Nesse capítulo faz-se também algumas considerações sobre Testes Objetivos Informatizados.

No Capítulo 4 são detalhados os Testes Adaptativos Informatizados (TAI's) e levantados os elementos principais que compõem um TAI baseado na Teoria de Resposta ao Item (TRI), que permite a individualização e consideração da habilidade do aluno em um determinado teste. Aborda-se também o Content-Balanced Adaptive Testing (CBAT-2), que apresenta-se como uma solução de TAI's para pequenas instituições, como é o caso do ICMC-USP - comparado com o exame TOEFL aplicado mundialmente. A TRI e o CBAT-2 foram os modelos escolhidos para a implementação do TAI.

Dois exemplos de ACA's resultantes da integração entre dois ou mais sistemas são apresentados no Capítulo 5. O projeto TREE e o sistema INSPIRE são resultados da integração entre TAI's e Ambientes Computacionais de Tarefas (ACT's) (são ambientes que fornecem tarefas para propiciar o aprendizado do aluno em um dado domínio).

A arquitetura e experimentos realizados com o TAI baseado no CBAT-2 estão no Capítulo 6. A arquitetura e validação da operacionalidade do ACT e do CALEAP-Web estão descritos no Capítulo 7 
Encerra-se com o Capítulo 8, ressaltando as limitações da pesquisa e dos ambientes desenvolvidos, as contribuições do pesquisador e da pesquisa e a proposta de trabalhos futuros. $\mathrm{O}$ Apêndice A mostra o algoritmo do TAI desenvolvido nessa pesquisa. 


\section{Capítulo 2}

\section{Abordagens de Ambientes Computaci- onais de Aprendizagem}

Ambientes Computacionais de Aprendizagem (ACA's) são aqueles que fornecem subsídios para que o aluno possa aprender algum conhecimento via uso do computador, sempre por meio de processos de ensino/aprendizagem. Por essa razão faz-se necessário um breve resgate sobre algumas concepções e teorias relacionadas com os processos de ensino/aprendizagem de alunos. Como o objetivo final desses ambientes é propiciar ao aluno o aprendizado, então três terminologias são importantes para a compreensão das teorias de aprendizagem: Educação, Aprendizagem e Ensino.

A palavra Educação, originária do latim educationis, é atualmente concebida por alguns estudiosos como um conjunto de experiências pessoais ativas, dinâmicas e mutáveis, pelas quais a pessoa seleciona, absorve e incorpora informações, relacionando-as com as que já possui e reorganiza-as para criar novas informações (Neto, 1987).

Aprendizagem consiste em uma mudança de comportamento resultante de prática ou experiência anterior. É pelo processo de aprendizagem que adquirimos o conhecimento, mas o conhecimento resultante do processo não se confunde com a aprendizagem (Witter \& Romônaco, 1984). Os processos de aprendizagem envolvem muitas variáveis, que sofrem influências de fatores externos e internos, individuais e sociais.

Neto (1987) afirma que o Ensino é uma relação de ajuda ou auxílio interpessoal, na qual o professor (ou tutor), tendo mais experiência e mais conhecimento do que o aprendiz, influenciandoo de várias maneiras: orienta, leciona, mostra, explica, demonstra, estimula, corrige, dirige, pergunta, responde, debate, supervisiona, esclarece, prepara, propõe e guia; com o uso adequado de materiais e recursos, fornecendo os preceitos ou fundamentos de uma ciência, técnica, arte ou habilidade. Em outras palavras, ensinar é proporcionar a aprendizagem aos alunos (Neto, 1987). 
O propósito desse capítulo é apresentar ao leitor quatro abordagens de ACA's. Os critérios utilizados para a classificação das abordagens são:

Como dá-se o aprendizado do aluno: a ênfase é o aprendizado pelo aluno com o uso de Arquiteturas de Ensino, isto é, como dá-se o aprendizado com o uso de ambientes computacionais baseados em cada arquitetura. As arquiteturas de ensino encontram-se na Seção 2.1 ,

Aprendizagem quanto ao processo de aprendizagem: a ênfase é o software, segundo os processos de aprendizagem do aluno. A referida classificação é apresentada na Seção 2.2 ;

Quem é o agente da interação: consiste em quem está no comando do ambiente computacional, em outras palavras, quem é o agente da interação. A referida classificação encontra-se na Seção 2.3 ,

Forma de aquisição de conhecimento: a ênfase dessa última abordagem é a forma de aquisição de conhecimento, ou seja, como pode dar-se o conhecimento. A referida classificação é mostrada na Seção 2.4

\subsection{Classificação de Ambientes Computacionais de Apren- dizagem quanto ao tipo de Aprendizado nas Arqui- teturas de Ensino}

No Institute of the Learning Sciences da Northwestern University 1 , Roger Schank $\aleph^{2}$ coordenou conjuntamente com mais de 130 pessoas, projetos de desenvolvimento de softwares de alta qualidade que permitem o Aprendizado no Momento Certo (Just-in-Time). Schank, um dos pesquisadores mais importantes da Inteligência Artificial (IA), diz que "humanos são naturalmente aprendizes", ou seja, que o ser humano está constantemente imerso em situações novas de aprendizado e por meio do uso do computador, pode-se criar situações individuais de ensino, diferentemente do atual cenário de massificação e homogeneidade do ensino escolar tradicional.

Para Schank (2002), a melhor forma de aprender é "aprender fazendo", de acordo com o ritmo de aprendizado individual de cada aluno. Para isso, Schank acredita que a única possibilidade de individualizar o ensino é por intermédio do computador, ou seja, no ensino das escolas tradicionais presenciais, para ter-se um ensino individualizado (que adapta-se às necessidades individuais do aluno), deveria existir um professor para cada aluno, o que de fato é excêntrico. John Dewey (1859-1952), filósofo e educador, foi um dos primeiros a reconhecer a importância

\footnotetext{
${ }^{1}$ http://www.northwestern.edu

${ }^{2}$ http://engines4ed.org/hyperbook/misc/rcs.html
} 
de aprender a aprender para a necessidade pessoal. Dewey contrapõe os estudos puramente intelectuais com a experiência prática que produz o conhecimento, o qual intitula "produto da ação" (Silva et al., 2000). Essas concepções fundamentais de Dewey têm como núcleo o caráter insubstituível da experiência, que chamou de Aprender-Fazendo e acredita que é por intermédio da ação que se concebe o verdadeiro conhecimento.

Nessa perspectiva, a abordagem Aprender-Fazendo é estudada por pesquisadores das áreas de Psicologia, Educação, Ciências Cognitivas e Ciências da Computação, tanto no Brasil como no mundo, existindo concordância quanto à perspectiva do estudante poder aprender um conceito ou um conteúdo "fazendo" as tarefas. Exemplos de Aprender-Fazendo: pedalar uma bicicleta, falar, cozinhar, conduzir um veículo e jogar futebol. Cada exemplo está inserido em um contexto específico de aprendizado, sendo que no caso da pesquisa de Schank (2002), o contexto são os computadores.

O mais importante nessa abordagem é que o sujeito vai construindo o conhecimento pelo processo do fazer, ou em outras palavras, "colocando a mão na massa". Schank (2002) enfatiza ainda que os pais ensinam os filhos por meio deste paradigma, e não fornecendo-lhes uma série de leituras de preparação para andar, falar, correr, brincar ou mesmo aprender a pensar. No processo de aprender fazendo o sujeito coloca em ação suas hipóteses acerca de um determinado conhecimento e, com a retroalimentação do computador, poderá constatar, refletir e modificar seu pensamento e conhecimento na ação, ou seja, sem a reflexão não configura o processo de aprendizagem. Grande parte do aprendizado dos seres humanos é de origem natural, ou seja, é o aprendizado que ocorre naturalmente, sendo denominado Aprendizado Natural. Como exemplos tem-se aprender a jogar futebol, aprender diversas técnicas de conversação, aprender estratégias políticas para chefiar repartições. No Aprendizado Natural, Schank (2002) exemplifica uma situação ocorrida entre ele e seus alunos graduandos e graduados, em que os primeiros mostraram-se "inexperientes" enquanto os segundos já possuíam uma maior "experiência". A esse fato Schank denominou de Aprendizado por Experiência. A experiência é um fator que favorece a aprendizagem, que permite a uma pessoa, segundo sua experiência pessoal, selecionar o melhor modo de assimilar o conhecimento, podendo distinguir o que é ou não essencial para si.

No hiperlivro de Schank (2002), a partir do Aprendizado Natural e da experiência do aluno são descritos cinco Arquiteturas de Ensino: a Simulação Baseada em Aprender-Fazendo (SimulationBased Learning-by-Doing), o Aprendizado Incidental (Incidental Learning), o Aprendizado por Reflexão (Learning by Reflection), o Ensino Baseado em Casos (Case-Based Teaching) e o Aprendizado por Exploração (Learning by Exploring). O professor pode ter o papel de tutor (apenas guiar/instruir o aluno) ou professor-mediador (que utiliza-se dessas arquiteturas para complementar ou auxiliar em sua aulas presenciais). Segue nas próximas seções os detalhes de cada arquitetura. 


\subsubsection{Simulação Baseada em Aprender-Fazendo}

A simulação Baseada em Aprender-Fazendo parte do pressuposto que, para aprender a realizar alguma tarefa, é necessário fazê-la, ou seja, aprender pela ação. Tais ações podem ser realizadas por simulações no computador, que a priori pode simular situações que propiciam o aprendizado. Nesse caso, as simulações baseadas em Aprender-Fazendo demonstram maior interatividade entre aluno e computador e mostram-se capazes de gerar contextos favoráveis para o aprendizado de um domínio de conhecimento. Esses contextos causam nos alunos motivação, permitindo em muitos casos a ocorrência do Aprendizado Natural.

Um exemplo de ambiente dessa arquitetura é o Dustin (Schank, 2002), que consiste em uma simulação simples que ajuda os estudantes a aprenderem um novo idioma, por meio de um cenário apresentado com histórias. O ambiente ajusta-se as situações que o aluno encontrará na vida real, permitindo que demonstre suas competências, e com isso aprendendo somente o necessário para si.

\subsubsection{Aprendizado Incidental}

Para Schank (2002), nem todo o aprendizado é interessante e divertido. Assim surge a Arquitetura de Aprendizado Incidental, que consiste em um método ligado à descoberta de tarefas interessantes de realizar-se no computador. Uma das idéias da arquitetura do Aprendizado Incidental é a criação de tarefas cujo resultado final seja interessante - sendo utilizado para repassar ao aluno informações enfadonhas.

Seja a seguinte situação: um grupo de estudantes deseja saber quais são as respectivas capitais de cada estado brasileiro, e haja estudantes interessados em futebol. É possível que os alunos possam por meio do futebol aprender geografia? E se os alunos desejam saber onde a cidade de Campinas está e houvesse alguns que fossem torcedores do Guarani, junto a isso, dar-lhes um carro e um mapa para chegarem à Campinas? Esse é um exemplo de uma situação propícia para a arquitetura baseada no Aprendizado Incidental. O Road Trip (Schank, 2002) é um outro exemplo de ambiente que ensina estudantes de uma escola americana nas aulas de geografia dos Estados Unidos, permitindo que os alunos realizem viagens simuladas pelo país.

\subsubsection{Aprendizado por Reflexão}

Existem casos que o aluno desconhece um determinado assunto, mas precisa saber como perguntá-lo. Algumas vezes, o estudante tem uma idéia do que deseja cogitar; em outras o aluno tem um problema e precisa achar um caminho para solucioná-lo; ou talvez o estudante, ao chegar no fim de um projeto, deseje pensar como melhorá-lo. Nesses casos, o trabalho do professor é guiar os alunos para novas condutas e caminhos, ajudando-os a articularem as 
situações que possibilitam gerar novos caminhos e com isso avançarem nas tarefas, nos projetos e nos estudos.

A todo momento o aluno está superando seu próprio conhecimento através dessa arquitetura. Segundo Schank (2002), o papel do professor durante o processo de questionamento é ajudar o aluno a localizar as deficiências em suas idéias e encontrar alternativas, hipóteses errôneas e algumas eventualidades não consideradas. O trabalho do professor, nessa abordagem, é de meditar conjuntamente com o aluno.

Um exemplo de ambiente dessa arquitetura é o Sounding Board (Schank, 2002), o qual consiste em um sistema de perguntas e respostas que podem levar o estudante a um Aprendizado por Reflexão, permitindo que o aluno crie representações detalhadas de seu pensar, em um processo reflexivo. A idéia da "caixa de ressonância" é obter a captura de uma parte da estrutura do pensamento do aluno, e incitá-lo com perguntas críticas sobre essa parte.

\subsubsection{Ensino Baseado em Casos}

Schank (2002) diz que a Arquitetura do Ensino Baseado em Casos parte de duas idéias: os especialistas são repositórios de casos e os bons professores são bons "contadores de histórias". O papel dessa arquitetura é indicar aos alunos exatamente o que eles necessitam saber quando eles precisarem saber. A partir do Raciocínio Baseado em Casos (RBC) é que as decisões são tomadas, sempre baseadas em experiências similares anteriores do aluno. Aprender com os erros também faz parte desta abordagem, pois nesse ponto novamente poderá ocorrer um aprendizado (Schank, 2002). Conseqüentemente, tal falha não ocorrerá novamente se o aluno aprender e entender a própria falha, buscando alternativas de solução para não mais falhar.

O projeto denominado Creanimate (Schank, 2002) insere o divertimento que acompanha a investigação científica em uma experiência educacional eficaz. Os cientistas pensam sobre perguntas difíceis, não resolvidas, desenvolvem explicações possíveis, armazenam dados e revisam suas explanações, sempre trabalhando com outros cientistas, escutando e ensinando suas teorias. Dessa forma, o ambiente Creanimate permite que crianças executem esse tipo de atividades em um nível adequado para elas, que conectem o fascínio natural dos animais na biologia com a oportunidade de gerar hipóteses criativas, de considerar as suas hipóteses examinando perguntas, e de praticar o raciocínio sobre os casos. O ambiente é como um filme da National Geographid ${ }^{3}$ (Schank, 2002), sendo que a diferença é que a seqüencia das cenas (vídeos) é explorada segundo os interesses dos alunos, que podem explorar as diversas maneiras que os animais sobrevivem na natureza, sendo guiados por um tutor de biologia.

\footnotetext{
${ }^{3}$ http://www.nationalgeographic.com
} 


\subsubsection{Aprendizado por Exploração}

Essa última arquitetura está direcionada para fornecer respostas no formato de uma conversa, ou seja, durante o desenvolvimento e resolução das tarefas pelos alunos - que estão envolvidos com a atividade - questões são geradas e os alunos devem estar prontos para aprender essas questões. Dessa forma, um método importante de ensino é responder às questões dos estudantes no momento em que forem geradas, levando a uma conversa para chegarem às respostas das perguntas.

Um exemplo dessa arquitetura é o ambiente $A S K$ (Schank, 2002), um ambiente hipermídia que consiste em uma conversa com especialistas (baseada em metáforas). $\mathrm{O}$ aluno fornece as perguntas e o sistema responde. Em uma conversação real, ambos os participantes influenciam o fluxo da discussão. Já no $A S K$, o aluno influencia no fluxo selecionando as questões, e o sistema influencia no fluxo das respostas fornecidas.

\subsection{Classificação de Ambientes Computacionais de Apren- dizagem quanto ao Processo de Aprendizagem}

Em uma outra perspectiva, tem-se uma classificação dos softwares segundo os processos de aprendizagem do aluno, a qual Ramos (1996) propõe os enfoques Algorítmico e Heurístico. Segue a descrição de ambos.

\subsubsection{Enfoque Algorítmico}

Predomina a ênfase na transmissão do conhecimento do sujeito que sabe, para o sujeito que deseja aprender. Nessa abordagem é o programa quem decidirá (inteligentemente ou não) as tarefas para o aprendizado do aluno. Assim, o controle total dos processos de ensino/aprendizagem está em poder do projetista de software, que deverá de antemão modelar as rotas para o aprendizado do aluno. Essa abordagem é eficiente para o treinamento de habilidades específicas e aprendizado de conteúdos já sistematizados. O enfoque Algorítmico é eficiente e útil quando os critérios de análise forem quantitativos: portabilidade, controle dos resultados, custos, tempo, normalização de procedimentos, etc. Nessa abordagem estão os softwares do tipo Tutoriais ou de Instrução Auxiliada por Computador (IAC) (Ramos, 1996).

\subsubsection{Enfoque Heurístico}

No enfoque Heurístico existe uma valorização do aprendizado experimental, no qual o software deve-se mostrar capaz de criar cenários para propiciar o levantamento de conjecturas pelos 
alunos. Os softwares desenvolvidos nessa abordagem não devem trazer atividades programadas, mas gerar conflitos cognitivos nos alunos, indicando uma ampliação significativa do aprendizado dos conteúdos propostos. Na abordagem Heurística estão as simulações, os jogos, as linguagens de programação e os Sistemas Especialistas. Um exemplo fundamental de software inserido na abordagem Heurística é o LOGO, sendo visto como uma linguagem de programação interpretada - o aprendizado dá-se por meio dos "passos da tartaruga" (Gonçalves, 2001). Nos alunos, em termos de aprendizagem, são observadas abstrações, formulação de estratégias computacionais e matemáticas, resolução de problemas, depuração, desenvolvimento de raciocínio e processos reflexivos (Gonçalves, 2001).

\subsection{Classificação de Ambientes Computacionais de Apren- dizagem quanto ao Agente da Interação}

Essa classificação tem como principal critério quem é o agente da interação dos processos de ensino/aprendizagem entre computador e aluno, ou seja, existem momentos em que o comando do processo está com o aluno, em outros momentos com o sistema ou poderá estar compartilhado com ambos (usuário e computador). Nessa classificação existem quatro possibilidades: Aluno no Comando, Cooperativismo, Colaborativismo e Tutor no Comando.

\subsubsection{Aluno no Comando}

É definida pelas ações do aluno no computador, as quais são apenas de caráter unilateral, isto é, o computador apenas exercerá suas tarefas se o aluno requisitar. O papel do computador é apenas de gerenciar o conhecimento e suas próprias execuções. Como exemplo, a Ferramenta de Referência (Reference Tool), apresentada por Aluísio et al. (1993), está inserida nessa abordagem. A ferramenta de referência é uma base lexical para consulta, composta por sentenças que possuem lacunas no lugar do material factual, agrupadas de acordo com a estrutura de artigos científicos: resumo, introdução, revisão da literatura, metodologia, resultados, discussão e conclusão; de acordo com as estratégias retóricas de escrita, como definições, argumentações, classificações, etc. Também expressões comuns da escrita científica como paper, objective, results, etc.

\subsubsection{Cooperativismo}

O Cooperativismo envolve a divisão do trabalho em tarefas, sendo que cada um é responsável por concluir sua parte. Por exemplo, suponha um grupo de quatro estudantes que necessitam realizar uma pesquisa sobre Aristóteles, contendo os temas postulados, hipóteses, axiomas 
e silogismo. Eles, no cooperativismo, dividiriam exatamente os temas em partes iguais, e na monografia final, os temas seriam "colados", sendo que um aluno não teria ciência da parte do trabalho dos outros. Em outras palavras, o trabalho é "dividido" e ao fim todos são "somados", obtendo um trabalho "modularizado". Existe uma parceria sem compartilhamento de objetos, isto é, (co-labore) trabalho com co-autores. Um exemplo de ambiente computacional cooperativo é a Ferramenta de Suporte do ambiente AMADEUS (Aluísio \& Jr, 1995; Aluísio \& Gantenbein, 1997; Aluísio et al. 2003) - detalhes na Seção 7.2 do Capítulo 7 .

\subsubsection{Colaborativismo}

Segundo Blandford (1994), Colaboração é definida como uma série de atividades sincronizadas e coordenadas, com o objetivo de compartilhar os resultados e processos de um problema. Dessa forma, os alunos irão trabalhar juntos para solucionarem metas comuns, cada um atuando na tarefa do outro. Os objetivos são negociados e resignificados no coletivo e compartilhados nas estratégias e ações do grupo colaborativo.

É certo que alguns autores consideram cooperação e colaboração o mesmo conceito, mas percebe-se que em Blandford (1994) existem sutis diferenças entre ambos. Utilizando o exemplo da pesquisa sobre Aristóteles da Seção 2.3.2, segundo a perspectiva colaborativa, os alunos reuniriam-se para comutarem as idéias e desenvolverem a pesquisa, e conseqüentemente, produzirem conjuntamente a monografia final. Como exemplos de um ambientes colaborativos para suporte à escrita científica, tem-se a Ferramenta de Crítica do AMADEUS (Aluísio et al., 2001) e a ferramenta Scientific Writing in Brazilian Portuguese (SciPo) (Feltrim \& Teufel, 2004) detalhes na Seção 7.2 do Capítulo 7 .

\subsubsection{Tutor no Comando}

Um Sistema Tutor possui o objetivo de agir como professor ou tutor guiando o usuário. Desde a década de 60, pesquisas vêm sendo desenvolvidas sobre processos de ensino/aprendizagem mediados por computador (Turine, 1994). Da Instrução Programada (que divide o material a ser ensinado em módulos) derivou a IAC, caracterizada por uma psicologia comportamentalista. Porém, no decorrer dos anos, percebeu-se a necessidade dos sistemas de IAC terem maior flexibilidade, maior individualização do ensino e uma retroalimentação mais significativa (Turine, 1994). Então, uma solução possível para estes problemas foi a inserção da IA em sistemas de IAC. Nesse contexto surge na década de 70 os Sistemas Tutores Inteligentes (STI's). 


\section{Sistemas Tutores Inteligentes}

Um Sistema Tutor Inteligente (STI) utiliza técnicas de IA para apresentar as regras definidas por um tutor que media os processos de ensino/aprendizagem. Não existem padrões para um STI, porém, aceita-se uma arquitetura básica para um STI, composta por quatro componentes (Turine, 1994):

1. Módulo do Domínio: também conhecido como Módulo do Especialista, abrange o domínio do conhecimento a ser ministrado, sendo esse armazenado na base de conhecimento. A representação desse conhecimento é determinada pelo domínio e pela manipulação a ser realizada pelo STI;

2. Modelo do Estudante: abrange as informações sobre o aluno. Esse modelo representa o estado atual do conhecimento e do desempenho do estudante no domínio proposto, com atualização dinâmica dos dados, fornecendo a situação do aluno. Ou seja, cria-se um modelo de aluno para que o tutor possa "conhecer quem é o aluno";

3. Módulo Tutorial: também conhecido como Módulo Pedagógico, abrange as estratégias de ensino (regras tutoriais), planejando e administrando as interações com o aluno. A explicitação do conhecimento nesse módulo possibilita uma adaptação do sistema e melhorias em suas estratégias de ensino;

4. Módulo de Comunicação: realiza a interação entre o sistema e o aluno pela interface. É importante nesse módulo uma adequação da interface na interação usuário-computador, possibilitando a facilidade de diálogo, fornecendo suporte ao aluno e rapidez de resposta do sistema. Esse módulo também monitora as interações entre sistema-aluno e sistemaprofessor.

\subsection{Classificação de Ambientes Computacionais de Apren- dizagem quanto à Forma de Aquisição de Conhe- cimento}

Schar \& Krueger (2000) sugere sete abordagens que são classificadas segundo as diferentes formas de aquisição de conhecimento: Baseados em Simulação, Sistemas Tutores, Hipertexto e Hipermídia, Prática por Repetição, Sistemas Informativos, Aprendizagem à Distância e Sistemas Híbridos. 


\subsubsection{Baseados em Simulação}

São ambientes ativos e, estudantes, nesses ambientes, envolvem-se em simular fenômenos reais e imaginários. Eles podem processar entradas, variáveis, planejar ações, analisar problemas, tomar decisões, monitorar os progressos e coordenar seus esforços para alcançarem os objetivos delineados (Miskulin, 1999). Esses ambientes podem reproduzir as condições de ações e reações de eventos do "mundo real". Os estudantes podem gerar hipóteses necessárias para expandir suas próprias intuições. O aprendizado pode ser por tentativa e erro.

\subsubsection{Sistemas Tutores}

O aprendizado dá-se de forma objetiva e o conhecimento verificado por intermédio de testes, avaliações, correções e sugestões. Um ambiente tutor é distinguido por ter módulos de aprendizado, que possuem, de modo geral, níveis, passos e testes finais - requisito do translado para os demais módulos. Os detalhes sobre os STI's encontram-se na Seção 2.3.4.

\subsubsection{Hipertexto e Hipermídia}

Há uma organização do material didático em ligações e nós, sendo que no último (nós) pode-se ter textos, gráficos, audio e vídeo. O aprendizado dá-se num contexto de hiperespaço, onde o aluno estabelece estratégias de acesso e necessidades individuais, trazendo à tona os benefícios similares da simulação.

\subsubsection{Prática por Repetição}

Do inglês Drill and Practice, é caracterizado pelo aprendizado por meio de perguntas e respostas - as corretas são motivadas com estímulo/resposta, ou seja, há uma "recompensa" às respostas corretas. $\mathrm{O}$ computador apresenta aos alunos problemas específicos e eles trabalham nesse problema até alcançarem um certo nível de eficiência. A partir daí, eles mudam para problemas de natureza diferente ou mais complexa (Miskulin, 1999). Os ambientes baseados na Prática por Repetição são propícios para o aprendizado de materiais que necessitem de mais memorização do que entendimento profundo.

\subsubsection{Sistemas Informativos}

Conhecidos como Information Systems, têm como objetivo o aprendizado de caráter informativo. Possum uma estrutura simples, baseada em consultas à banco de dados, por exemplo. Um dicionário digital, um atlas são exemplos de Sistemas Informativos. 


\subsubsection{Aprendizagem à Distância}

Os ACA's à distância são caracterizados pelos estudos realizados remotamente, concebida pela ação e não pela forma. Como principais características tem-se a utilização de apresentações com o uso de projetores multimídia, o armazenamento e coleta de dados via correio eletrônico, a correspondência entre o professor e o aluno, a utilização de video-conferências, etc. Exemplos de ambientes para a Aprendizagem à Distância: Teleduc 4 , Aulanet ${ }^{5}$, WebCT ${ }^{6}$, entre outros.

\subsubsection{Sistemas Híbridos}

Como o próprio nome sugere, são ambientes formados pelas diversas combinações dentre os demais ambientes destacados anteriormente. Pode-se obter junções, por exemplo, entre Sistemas Tutores e Simulações, com a proposta de minimizar as desvantagens de cada um. A combinação entre dois ambientes poderá transmitir os benefícios de ambos.

\subsection{Considerações Finais}

A Tabela 2.1 mostra as principais abordagens de ACA's, agrupados pelos critérios estabelecidos nesse capítulo:

Tabela 2.1: Classificações dos Ambientes Computacionais de Aprendizagem.

\begin{tabular}{|c|c|}
\hline Tipo I & Tipo II \\
\hline Simulação Baseada em Aprender-Fazendo & Algorítmico \\
\hline Aprendizado Incidental & Heurístico \\
\hline Aprendizado por Reflexão & \\
\hline Ensino Baseado em Casos & \\
\hline Aprendizado por Exploração & \\
\hline
\end{tabular}

\begin{tabular}{|c|c|}
\hline Tipo III & Tipo IV \\
\hline Aluno no Comando & Baseado em Simulação \\
\hline Cooperativismo & Sistemas Tutores \\
\hline Colaborativismo & Hipertexto e Hipermídia \\
\hline Tutor no Comando & Prática por Repetição \\
\hline & Sistemas Informativos \\
\hline & Aprendizagem à Distância \\
\hline & Sistemas Híbridos \\
\hline
\end{tabular}

\footnotetext{
${ }^{4}$ http://hera.nied.unicamp.br/teleduc/

${ }^{5}$ http://asgard.les.inf.puc-rio.br/aulanet/

${ }^{6} \mathrm{http}: / / w w w . w e b c t . c o m /$
} 
- Classificação de ACA's quanto ao Aprendizado nas Arquiteturas de Ensino ou Tipo I;

- Classificação de ACA's quanto ao Processo de Aprendizagem ou Tipo II;

- A Classificação de ACA’s quanto ao Agente da Interação ou Tipo III;

- A Classificação de ACA’s quanto à Forma de Aquisição de Conhecimento ou Tipo IV.

Algumas características comuns são percebidas dentre as quatro principais classificações, podendo-se cruzar as abordagens de cada classificação da seguinte maneira:

1. Os ambientes baseados na abordagem Aprender-Fazendo são: Simulação Baseada em Aprender-Fazendo, Baseado em Simulação e Heurístico;

2. Os ambientes baseados em STI's são: Tutor no Comando, Sistemas Tutores e Algorítmico;

3. Os ambientes que estão preocupados somente na "apresentação do conteúdo" são: Aluno no Comando e Sistemas Informativos;

4. Observa-se que os ambientes Hipertexto e Hipermídia permitem o Aprendizado por Exploração.

Foram descritas nesse capítulo as abordagens Tipo I, II, III e IV relacionadas com ACA's. O Capítulo 3 trata da visão geral sobre avaliação, com destaque ao processo de avaliar alunos mediado por computador. 


\section{Capítulo 3}

\section{Visão Geral sobre Avaliação e Teste}

Foram descritas e classificadas no Capítulo 2 as abordagens dos ACA's, que podem propiciar aos alunos o aprendizado de um determinado conhecimento. Confirmar a ocorrência do aprendizado é de suma importância tanto para o professor (ou tutor) quanto para o aluno. Por meio de uma avaliação do aprendizado é possível obter medidas e resultados, realizar análises e estabelecer metas para a aquisição de conhecimento do aluno. Toda avaliação é realizada direta ou indiretamente, por um especialista de domínio, que pode ser uma pessoa ou sistema.

Nas Seções 3.1, 3.2 e 3.3 são tratados três critérios relacionados com a avaliação:

1. Quanto à pedagogia da avaliação: uma visão da avaliação por uma dimensão pedagógica;

2. Quanto ao seu objetivo/propósito da avaliação: uma classificação segundo os fins (objetivos) da avaliação da aprendizagem do aluno;

3. Quanto à pontuação do aluno: classifica-se segundo os critérios de pontuação absoluto (valor pré-estabelecido) e relativo (valor normalizado de acordo com o grupo de alunos).

\subsection{Classificação da Avaliação quanto à Dimensão Pe- dagógica}

Em uma dimensão pedagógica da avaliação de alunos, Abrantes (1995) distingue três significados distintos atribuídos à avaliação: Avaliação como Medida, Avaliação como Distância e Avaliação como Interpretação. 


\subsubsection{Avaliação como Medida}

Nessa perspectiva, o processo de aprendizagem está ligado à memorização e possui ênfase nos resultados. Tem como referência o modelo do professor segundo a maneira da reprodução do conhecimento pelo aluno. O conhecimento é medido por uma nota normalizada - segundo a média da turma - realizada no fim de um período, que pode ser um ano ou o curso. A Avaliação como Medida serve para informar pais e escola, dizendo pouco sobre o processo de aprendizagem do aluno.

\subsubsection{Avaliação como Distância}

Em 1956, Benjamin Bloom publicou sua taxonomia de objetivos educacionais separados em três domínios: Cognitivo, Afetivo e Motor. Com ela, pode-se medir com rigor e objetividade o conhecimento do aluno sem a subjetividade do professor, deixando de considerar o modelo do professor e tomando como referência um conjunto de objetivos educacionais, fazendo com que o resultado da avaliação seja visto como uma medida da distância entre a resposta do aluno e o objetivo educacional. Dessa visão comportamentalista emerge a Pedagogia por Objetivos, a qual introduz a Avaliação Diagnóstica e a Avaliação Formativa (Abrantes, 1995) (ambas na Seção 3.2. A Figura 3.1 mostra que os ciclos de ensino são seguidos por momentos formais de avaliação:

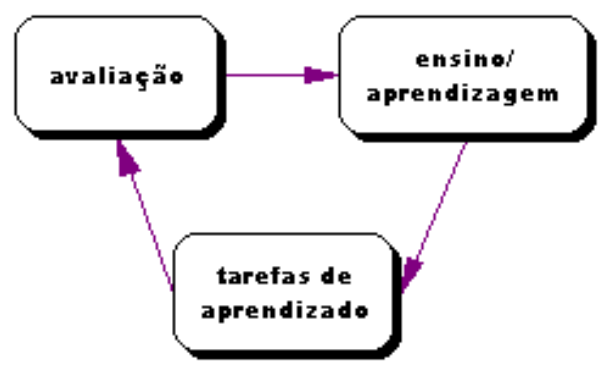

Figura 3.1: Avaliação durante o ciclo (adaptada de Abrantes (1995)).

\subsubsection{Avaliação como Interpretação}

Mais do que medir o desvio em relação a comportamentos previamente determinados, é necessário compreender as razões do erro (Abrantes, 1995). Portanto, na avaliação como interpretação, o erro é uma fonte de aprendizado e a avaliação é contínua, ocorrendo ao longo dos processos de ensino/aprendizagem. O objetivo da avaliação não é medir informação, mas sim interpretá-la e comunicá-la. 


\subsection{Classificação da Avaliação quanto ao Propósito}

Varandas (2000) afirma que os processos de ensino/aprendizagem possuem três fases: Planificação (elaboração), Execução (ação) e Avaliação (análises finais). Miller et al.(1998) também propõe três abordagens de avaliação quanto ao propósito: Avaliação Diagnóstica, Avaliação Formativa e Avaliação Somativa ou Final. Considerando a ligação entre os processos de ensino/aprendizagem e avaliação, Varandas (2000) estabelece correspondências entre o processo (aprendizagem) e o produto (aprendizado) da seguinte maneira: a fase de Planificação está associada à Avaliação Diagnóstica, a fase de Execução está associada à Avaliação Formativa e a fase de Avaliação associada à Avaliação Somativa. Seguem nas próximas seções os esclarecimentos das três abordagens de avaliação quanto ao propósito, com base em Haydt (1988), Miller et al. (1998), Varandas (2000) e Aquino (2001).

\subsubsection{Avaliação Diagnóstica}

A Avaliação Diagnóstica verifica a presença ou ausência de pré-requisitos necessários para o aluno inserir-se em um novo contexto de aprendizado. A Avaliação Diagnóstica pode detectar as dificuldades específicas de aprendizagem, tentando identificar suas causas. Esse tipo de avaliação é realizado no início de um curso (ver Figura 3.2), período letivo ou unidade de ensino, possibilitando ao professor elaborar melhor seu plano de ensino. Para obter os dados necessários para uma Avaliação Diagnóstica, podem ser necessárias, segundo Varandas (2000): entrevistas, provas (escritas e orais), auto-avaliação, etc.

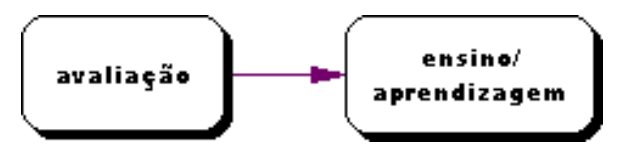

Figura 3.2: Relação temporal da Avaliação Diagnóstica.

\subsubsection{Avaliação Formativa}

A idéia da Avaliação Formativa é contribuir para o aprendizado do aluno durante o processo, tendo como função regular seu aprendizado. Pode-se constatar se os objetivos pré-estabelecidos foram alcançados pelos alunos e, caso não tenham sido atingidos, deve-se fornecer conhecimento do domínio para aperfeiçoar sua aprendizagem. A Avaliação Formativa é um processo contínuo presente durante todo o ciclo de estudo\$ ${ }^{1}$ (ver Figura 3.1). Ressalta-se que essa avaliação não tem um caráter de "finalização", sendo valorizada como um meio de melhoria da aprendizagem dos alunos (Varandas, 2000).

\footnotetext{
${ }^{1}$ Exemplos: uma disciplina, um ano letivo, um curso.
} 


\subsubsection{Avaliação Somativa ou Final}

A principal característica da Avaliação Somativa é ser realizada após um ciclo de estudos (ver Figura 3.3), julgando os resultados de aprendizagem alcançados pelos alunos, de acordo com níveis de aperfeiçoamento pré-estabelecidos. A Avaliação Final está restrita a avaliar o produto final dos alunos, visando a promoção de um nível para outro ou classificação segundo uma escala, sendo sempre realizada no final de um ciclo de estudos.

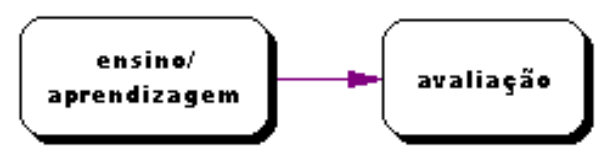

Figura 3.3: Relação temporal da avaliação no fim do período (adaptada de Abrantes (1995)).

\subsection{Classificação da Avaliação quanto à Pontuação}

Miller et al. (1998) propõe uma classificação baseada segundo o critério estabelecido para medir a pontuação das avaliações: o Critério da Medida de Referência (CMR) e a Normalização da Medida de Referência (NMR). Nas próximas seções seguem detalhes de cada uma.

\subsubsection{Critério da Medida de Referência}

O CMR verifica se o aluno atingiu ou não o nível pré-especificado de desempenho, segundo um valor absoluto de qualidade, que independe dos valores de outros alunos. Esse critério é adequado para:

1. Avaliar programas de aprendizado individuais;

2. Diagnosticar as dificuldades dos estudantes;

3. Estimar habilidades num campo especifico do conhecimento;

4. Medir o que o estudante aprendeu;

5. Certificar a competência;

6. Controlar o ingresso em unidades de ensino;

7. Ser utilizado quando um assunto é preocupação principal;

8. Ser utilizado quando existe seleção por cotas.

Algumas críticas são levantadas em relação ao CMR: 
1. Não fornece o grau de excelência ou deficiência do aluno em relação aos outros estudantes;

2. Não é clara a definição de conhecimento e entendimento, dificultando estabelecer os critérios adequados de desempenho;

3. Encoraja os alunos a fornecerem as soluções corretas e incorretas somente, não estimulando a resolução de problemas.

\subsubsection{Normalização da Medida de Referência}

Na NMR mede-se o desempenho comparativamente com os resultados obtidos por terceiros, ou seja, comparam-se os resultados de cada aluno com um determinado grupo que realizou a mesma avaliação. Esse critério é adequado para:

1. Classificar os estudantes;

2. Selecionar os estudantes por cotas fixas requeridas;

3. Tomar decisões relacionadas ao aprendizado do aluno segundo comparações com outros estudantes.

Algumas críticas são levantadas em relação à NMR:

1. A nota final recebida pelos alunos oculta as dificuldades e interpretações errôneas, habilidades inadequadas e limitações potenciais em um dado conteúdo;

2. Uma nota significa a quantidade efetiva de conhecimento, sendo pouco relevante para o conteúdo do teste;

3. Há diminuição do grau de motivação quando os estudantes estão expostos continuamente à NMR;

4. A NMR oculta a qualidade de cursos e professores, por definir padrões diferentes.

\subsection{Alguns Esclarecimentos sobre Avaliação e Teste}

Avaliar é um processo complexo que, em muitos casos, é confundido com outras idéias. Por essa razão Haydt (1988) faz algumas considerações sobre os termos testar, medir e avaliar, em relação a pessoas:

Testar: é o mesmo que verificar um desempenho mediante situações previamente organizadas; 
Avaliar: é um processo de interpretação de dados quantitativos e qualitativos com o objetivo de obter um parecer ou julgamento de valor, tendo por base padrões ou critérios;

Medir: descreve um fenômeno do ponto de vista quantitativo, o qual tem por base um sistema de medidas.

A avaliação engloba o testar e o medir. Testar não significa o mesmo que realizar um teste, pois esse é um tipo de avaliação, ou seja, o teste é um dos instrumentos de avaliação (Ponte et al., 1997). Ponte et al. (1997) ainda afirma que existem outros instrumentos de avaliação, tais como teste em duas fases, apresentação oral, questionários, entrevistas, relatórios e dissertações.

\subsection{Categorias de Testes Objetivos}

Uma forma de avaliar o aprendizado de alunos é por meio de Testes Objetivos, que requisitam do aluno uma resposta a uma questão cuja resposta correta é pré-determinada (McKenna \& Bull, 1999). Segundo Olea et al. (1999), os testes objetivos podem ser classificados da seguinte maneira:

Teste Objetivo Tradicional: tem a principal característica de realizar o teste via lápis e papel. Nessa classificação está a maioria dos testes aplicados nas instituições de ensino. $\mathrm{O}$ professor ou o responsável autorizado aplica e corrige o teste;

Teste tipo Fichas: estão inseridos nessa classificação os testes que são realizados com lápis e papel, mas corrigidos pelo computador (por meio de leitoras óticas, por exemplo). Um exemplo é o vestibular da Fundação Universitária para o Vestibular ${ }^{2}$ (FUVEST), que realiza seu vestibular por meio de questões impressas em papel, mas as respostas são preenchidas em cartões de respostas que são posteriormente verificados pelo computador;

Teste Informatizado (TI) ou Teste Objetivo Informatizado: é totalmente automatizado, sendo que o computador tem o papel de fornecer as questões e os resultados relativos ao aluno por meio de tabelas, gráficos ou números, isto é, o computador aplica e corrige o teste.

\subsubsection{Testes Informatizados}

Com o auxilio do computador é possível elaborar testes de várias maneiras (por exemplo, com recursos multimídia), mostrando-se útil e eficaz para testes que envolvam procedimentos e cálculos estatísticos. Segundo Aquino (2001), uma outra forma de auxílio é a elaboração de um Banco de Itens (BI), no qual estão armazenadas as questões do teste. Em um TI todo o processo

\footnotetext{
${ }^{2}$ http://www.fuvest.br
} 
é realizado pelo computador (exposição das questões, análise e resultados), podendo ser categorizado segundo dois critérios: forma de pontuação (certo/errado ou avaliação do conhecimento parcial) e elenco de questões (mesmo número e/ou mesmas questões e/ou variação no número de questões). Dessa maneira, destaca-se dois métodos de Testes Informatizados (TI's):

1. Métodos Convencionais Informatizados. São aqueles em o número de questões é mesmo para todos os alunos participantes e cujas opções de resposta são certo/errado, isto é, não avalia o conhecimento parcial;

2. Métodos Alternativos Informatizados. Medem o conhecimento parcial do aluno, ou se adaptam à habilidade de cada aluno, podendo gerar um elenco de questões diferente para cada aluno. Dentre os métodos alternativos informatizados destacam-se:

- A MPA é um método utilizado no EPI do mestrado do ICMC-USP, que possibilita ao aluno expressar seu conhecimento parcial acerca das questões por meio do uso de um triângulo com 3 alternativas cujos vértices correspondem às alternativas $A, B, C$. Existem outras opções de $D$ a $M$ que podem ser utilizadas para expressar incerteza quanto às alternativas. Se o aluno estiver totalmente certo/seguro usa as opções $A$, $B$ ou $C$. Se estiver totalmente incerto/inseguro usa a opção $M$. Se uma das três opções $A, B$ e $C$ parecerem definitivamente erradas, escolhe entre as cinco opções da linha oposta. Indica a preferência entre duas opções $A, B$ ou $C$ escolhendo as opções $D, F, G, I, J$ ou $L$. Se duas das opções $A, B$, ou $C$ parecem iguais escolhe as opções $E, H$, ou $K$. Esse método possibilita obter um grau de certeza para as respostas dadas. As Figuras 3.4 e 3.5 mostram respectivamente uma introdução de um artigo científico e a questão sobre ela, na qual há o triângulo com as 13 respostas possíveis. A questão é pontuada com uma das 6 seguintes classes relativas ao conhecimento do estudante: Totalmente Informado (alternativa correta), Quase Informado, Parcialmente Informado, Mal Informado e Desinformado. Um estudo detalhado sobre a MPA encontra-se em Aquino (2001);

- O TAI baseia-se na seleção de itens realizada pelo computador, compondo um teste que mais se adapta ao nível de habilidade do aluno. Assim, cada aluno que participa da avaliação pode ter um teste diferente, dependendo de sua competência. Subjacente ao modelo adotado, o item selecionado será aquele que fornecer mais informação, dada a habilidade de um indivíduo. Uma descrição completa desse tipo de teste encontra-se no Capítulo 4. 


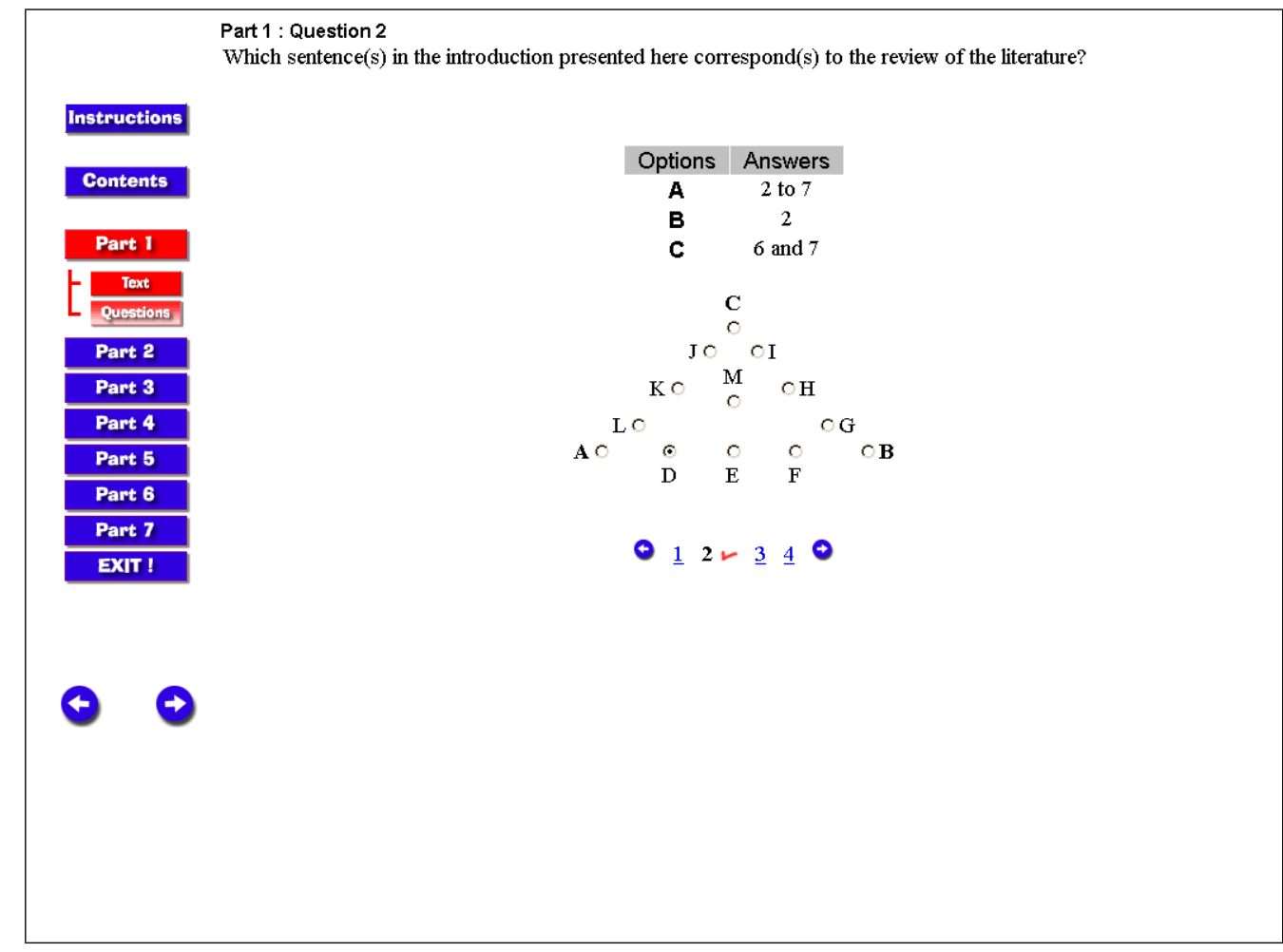

Figura 3.4: Tela com uma introdução de um artigo científico da área de computação no CAPTEAP.

\subsubsection{Vantagens e Desvantagens dos Testes Informatizados}

São percebidas algumas vantagens dos TI's, que garantem sua escolha (Oliveira, 2002):

1. A correção automática reduz o tempo de correção das respostas, diminuindo assim o trabalho dos professores e a redução da ocorrência de erros nesse processo;

2. Os sistemas informatizados de testes podem fornecer uma retroalimentação imediata de informações (em tempo de execução);

3. Todas as tarefas, procedimentos e resultados podem gerar relatórios individuais ou do grupo de alunos que realizaram o teste;

4. Os testes podem ser controlados e monitorados. Por exemplo, controlar o tempo de resposta do teste e fornecer ajuda ao aluno.

Algumas desvantagens também são percebidas:

1. Quanto às características e condições, um computador com uma configuração insatisfatória, ou seja, um "computador lento", poderá comprometer a robustez e tempo de teste; 


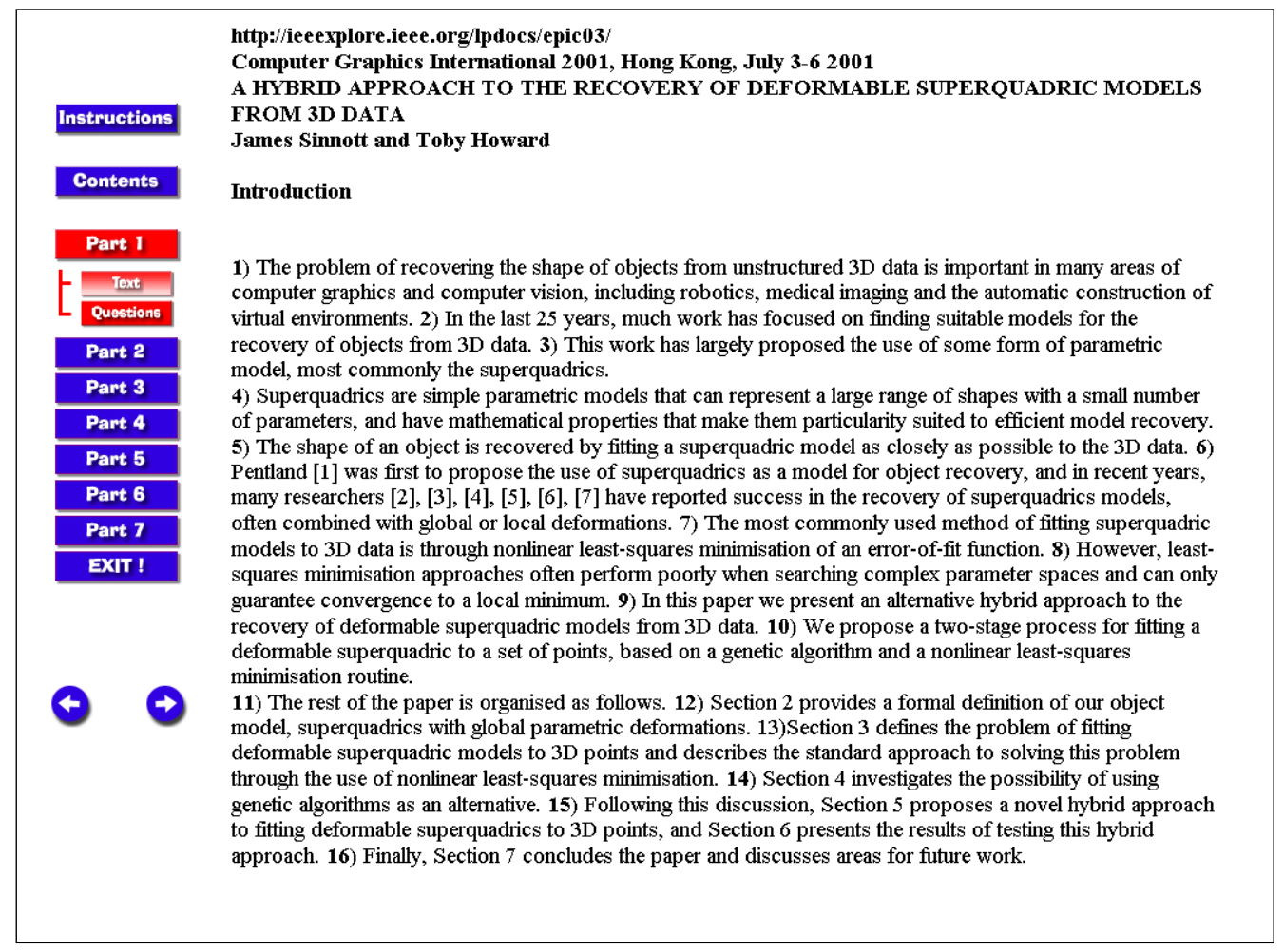

Figura 3.5: Tela com uma questão sobre a estrutura de introdução apresentada na Figura 3.4 no CAPTEAP.

2. A implementação de um teste pode ser uma tarefa difícil e dispendiosa. No desenvolvimento de um teste, por exemplo, pode haver a necessidade de equipes de projetistas, de especialistas de domínio e de engenheiros de software; e até mesmo matemáticos e estatísticos no caso do TAI baseado na TRI (detalhes no Capítulo 4);

3. No caso de um teste realizado na WWW, as condições da velocidade da rede e segurança na transmissão e armazenamento dos dados são muito importantes para a eficiência e confiança no teste. Com uma deficiência em qualquer um desses fatores o teste poderá estar comprometido.

\subsection{Considerações Finais}

A Tabela 3.1 mostra as principais abordagens de avaliação de alunos, agrupadas pelos critérios estabelecidos nesse capítulo:

- Classificação da avaliação quanto à dimensão pedagógica ou Classe I;

- Classificação da avaliação quanto ao propósito ou Classe II;

- Classificação da Avaliação quanto à pontuação ou Classe III. 
Tabela 3.1: Classificações da avaliação.

\begin{tabular}{|c|c|c|}
\hline Classe I & Classe II & Classe III \\
\hline Medida & Diagnóstica & CMR \\
\hline Distância & Formativa & NMR \\
\hline Interpretação & Somativa & \\
\hline
\end{tabular}

Algumas características comuns são percebidas dentre as principais classificações de avaliação, podendo-se cruzar as abordagens de cada classificação da seguinte maneira:

1. Quando a avaliação é realizada no fim do curso: Avaliação como Medida e Avaliação Somativa;

2. Quando aplica-se a avaliação durante o período de aprendizado: Avaliação como Distância e Avaliação Formativa. O ACA proposto por essa pesquisa está inserido na perspectiva de avaliação durante a aprendizagem do aluno;

3. O CMR e a NMR auxiliam nas medidas referentes aos alunos em todas as abordagens das Classes I e II;

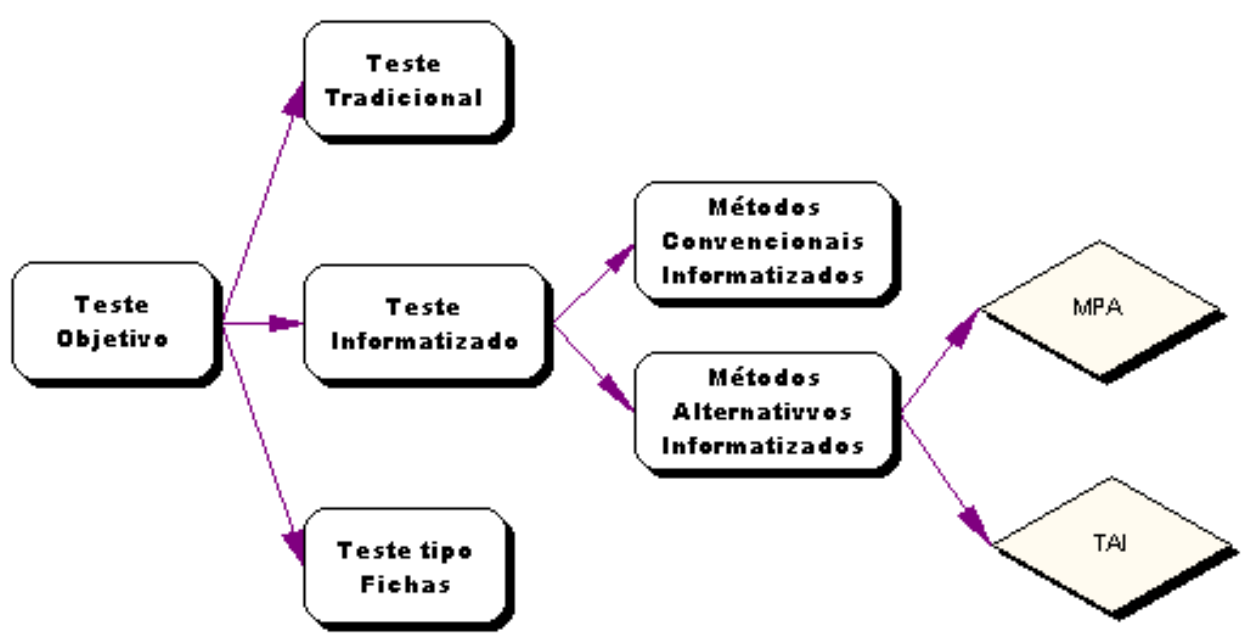

Figura 3.6: Hierarquia dos Testes Objetivos.

A Figura 3.6 mostra a hierarquia da classificação dos Testes Objetivos abordados nesse capítulo, onde foram resgatados as abordagem das Classes I, II, III. Foram levantados alguns esclarecimentos sobre classificações de TI's e suas vantagens e desvantagens.

O Capítulo 4 trata dos TAI's, que trabalham segundo as necessidades de aprendizado individuais e as habilidades de cada aluno. 


\section{Capítulo 4}

\section{Testes Adaptativos Informatizados}

A partir da década de 50, deu-se início a uma nova forma de avaliar alunos mediante testes, os quais caracterizavam-se por selecionarem as questões para o aluno, segundo os níveis estimados de habilidade. Mediante um conjunto de questões, o Teste Adaptativo (TA) tem a principal característica de "individualizar um teste", ou seja, cada aluno participante recebe um elenco de diferentes questões, estabelecidas segundo o critério de habilidade do aluno, interpretada aqui como grau de conhecimento por um aluno em um certo domínio. Testes Adaptativos (TA’s) são suportado por uma família de caracterizações matemáticas de respostas do teste. Na perspectiva da informática, tem-se os Testes Adaptativos Informatizados (TAI's), os quais “automatizam” o processo do TA, que anteriormente era computado via lápis e papel.

Esse capítulo está dividido da seguinte maneira: uma introdução aos elementos principais dos TA’s é apresentada na Seção 4.1, com detalhes de cada um nas Seções 4.5, 4.6 e 4.7. Um resgate histórico dos TAI's é apresentado na Seção 4.2. O Teste Adaptativo Informatizado (TAI) baseado na Teoria de Resposta ao Item (TRI) - que considera a habilidade individual do aluno em um teste, conjuntamente com algumas informações pré-estabelecidas das questões, está descrito na Seção 4.3, por meio de quatro Modelos Logísticos que dão suporte a ele. Uma descrição detalhada do algoritmo CBAT-2 caracterizado pela ausência de uma pré-calibração dos itens está na Seção 4.8 .

\subsection{Elementos dos Testes Adaptativos Informatizados}

A surgimento do TAI está diretamente ligado com a discussão sobre a eficácia e inconvenientes dos Testes Tradicionais. Os TAI's mostram maior flexibilidade, adaptabilidade, redução de tempo de teste, resultados imediatos e maior precisão em relação aos Testes Objetivos Tradicionais (Olea et al., 1999). Segundo Conejo et al. (2001), os TAI's são compostos por alguns elementos básicos: 
Modelo de Resposta ao Item: esse modelo descreve como o aluno examinado responde ao item, segundo seu nível de conhecimento. Quando faz-se medidas do nível de conhecimento, espera-se que o resultado obtido não dependa do instrumento usado, como por exemplo o computador ou lápis e papel;

Banco de Itens (BI): é um dos elementos fundamentais para a criação de um TAI, o qual define um banco de questões que devem abranger parte ou todo o domínio do conhecimento abordado pelo teste. Uma vez especificado o conteúdo do teste, o BI deve ser composto por itens que tratem de tal conteúdo;

Nível de Conhecimento Inicial: deve-se escolher de forma adequada o nível de dificuldade da primeira questão, para possibilitar uma sensível redução do tempo de teste;

Método de Seleção dos Itens: um TAI seleciona o item seguinte que será apresentado, em cada momento, em função do nível estimado do conhecimento do aluno e da resposta do item previamente ministrado. Selecionar o melhor item pode melhorar a precisão na estimativa desse nível, e com isso, reduzir o tempo de teste;

Critério de Parada: é o término do teste. Pode-se utilizar diferentes critérios de parada, tais como o alcance de um nível pré-estabelecido de habilidade, quantidade máxima de itens em um teste, tempo de teste, etc.

\subsection{Principais Modelos de Testes Adaptativos}

Ao longo de todo o processo evolutivo dos TA's, muitos modelos estão em constante criação e reestruturação, com o objetivo de fornecer subsídios para melhor avaliar alunos em um dado domínio. Weiss (1985) traz alguns tipos de TA's:

Binet Test: trata-se de um teste de inteligência baseado em níveis de dificuldade, criado por Alfred Binet. Esse teste foi desenvolvido para o diagnóstico do nível de inteligência de uma criança em comparação com sua idade cronológica, analisando a idade mental. As questões são classificadas segundo níveis, e se todos os itens de um determinado nível forem respondidos corretamente são fornecidos itens de um nível mais alto até que todos eles sejam respondidos incorretamente (Nível Superior); caso contrário, se todos os itens de um certo nível forem respondidos incorretamente, são disponibilizados itens de um nível mais baixo até que todos eles sejam respondidos corretamente (Nível Inferior). Quando o Nível Superior e o Nível Inferior são identificados, termina o teste. A Figura 4.1 mostra o procedimento da seleção de itens no teste, onde os símbolos $+\mathrm{e}-$ significam respectivamente questão respondida corretamente e questão respondida incorretamente. 
O aluno inicia o teste na primeira questão $1+$ e segue até a décima questão 10+. Após verificado seu desempenho, ele é levado a um novo conjunto de dez questões, em um segundo nível (idade mental 8,5), seguindo até o nível inferior $(7,5)$. Após responder todas as questões corretamente, será levado ao nível superior. Assim é ministrado um Binet Test.

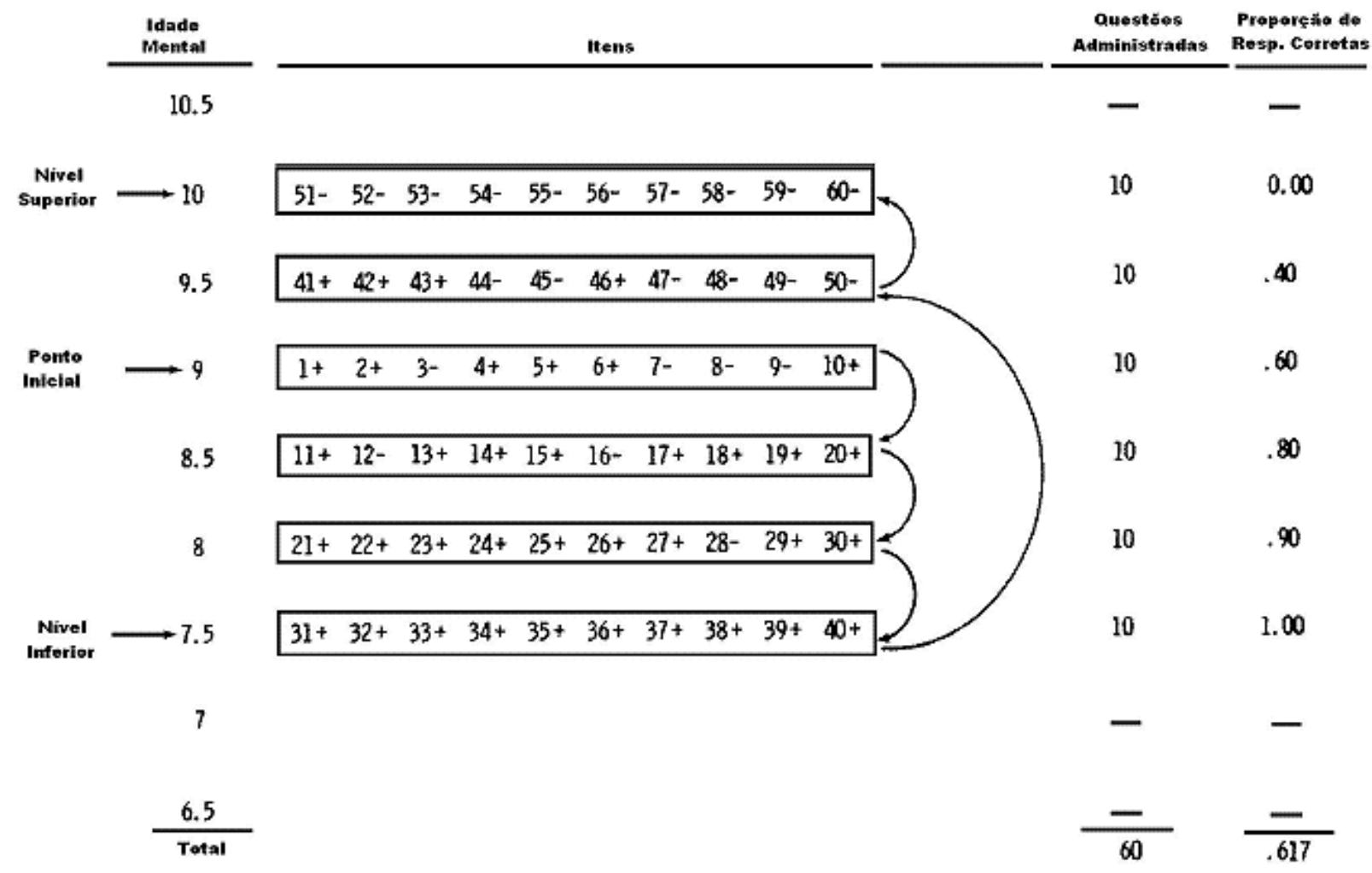

Figura 4.1: Registro de resposta de um aluno no Binet Test (adaptado de Weiss (1985)). Os símbolos $+\mathrm{e}-$ significam respectivamente questão respondida corretamente e questão respondida incorretamente.

Teste Adaptativo de Dois Estágios (Two-Stage Adaptive Testing): é dividido basicamente em dois sub-testes de menor dificuldade (Routing Test) e maior dificuldade (Measurement Test). Segundo as respostas corretas e incorretas obtidas no Routing Test, selecionam-se as questões do Measurement Test;

Teste Adaptativo Estratificado (Stratified Adaptive Test): é uma melhoria do Binet Test, sendo diferenciado pela eleição de um próximo item logo após cada um ser respondido. A Figura 4.2 ilustra o procedimento de seleção dos itens. Quando o aluno responde corretamente uma questão, a próxima é de uma dificuldade maior. Por outro lado, quando o aluno responder incorretamente uma questão, a próxima questão é de uma dificuldade menor. O aluno inicia na questão $1+$, respondendo-a corretamente. Conforme ocorrem 
acertos (+), o nível de dificuldade das questões vai se elevando. No caso de errar uma questão (-), o aluno será levado a uma questão de um nível de dificuldade menor. O teste termina quando for identificado o Nível Superior (nível de dificuldade no qual nenhuma questão foi respondida corretamente);

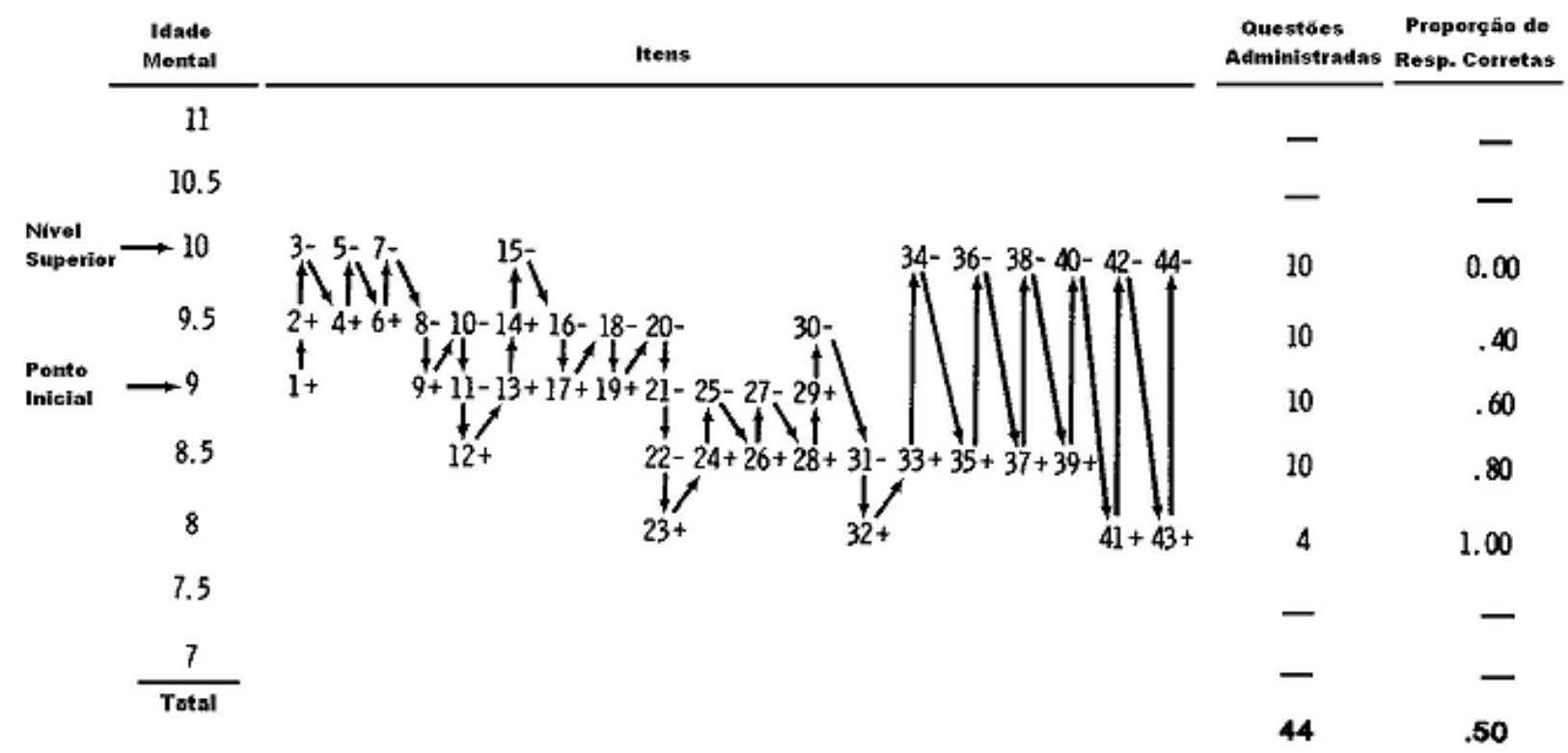

Figura 4.2: Registro de resposta de um aluno no Teste Adaptativo Estratificado (adaptado de Weiss (1985)). Os símbolos $+\mathrm{e}-$ significam respectivamente questão respondida corretamente e questão respondida incorretamente.

Teste Adaptativo baseado na Teoria de Resposta ao Item: tal teoria permite o desenvolvimento e calibração dos itens conjuntamente com o BI, acrescentando parâmetros referentes a cada item. Seguem os detalhes na Seção 4.3 .

\subsection{Testes Adaptativos Baseados na Teoria de Resposta ao Item}

A Teoria de Resposta ao Item (TRI) assume algumas relações entre a habilidade do aluno e as questões do teste, fundamentadas por modelos estatísticos. Os modelos inerentes à TRI dão suporte à teoria e são compostos essencialmente por estimadores de habilidade e parâmetros, métodos e processos estatísticos. A diferenciação entre esses modelos está relacionada com objetivo do teste, o tamanho da BI e a forma de aprendizado do aluno. 


\subsubsection{Parâmetros do Banco de Itens}

O TAI baseado na TRI apresenta no mínimo um parâmetro, que pode medir algumas informações sobre o item. Os parâmetros são (Oliveira, 2002; Huang, 1996a b; Wang \& Hanson, 2001):

Discriminação (a): determina o grau de discriminação de um item, ou seja, descreve como um item pode diferenciar os alunos de baixa habilidade dos alunos de alta habilidade;

Dificuldade (b): o nível de dificuldade de um item é dado por esse parâmetro;

Adivinhação $(c)$ : representa a probabilidade de ter-se uma resposta correta, mediante uma baixa habilidade estimada do examinado (chute). Como o próprio nome diz, mede quão a questão é "adivinhável”;

Lentidão $(d)$ : é a estimativa de tempo para a resolução de um item, isto é, $d$ é o tempo esperado que um aluno utilize para encontrar uma solução para o item.

Convencionam-se os parâmetros da TRI, com $a, b, c, d \in \mathbb{Q}$ e a estimativa de habilidade é dada por $\theta \in \mathbb{Q}$, estimada pelo TAI ao longo do teste.

\subsubsection{Calibração dos Itens}

Calibrar um item da base significa a especificação dos parâmetros $(a, b, c, d)$ dos itens que compõem um BI, e que futuramente serão selecionados para o uso em um determinado teste (Oliveira, 2002). O número de parâmetros a serem calibrados depende estritamente do modelo para a calibração selecionado. Por fazerem parte da calibração de um item, apresentamos os modelos logísticos na Seção 4.4 .

\subsection{Modelos Logísticos}

Na TRI existem quatro principais Modelos Logísticoß $\coprod^{1}$ de resposta, que são traduzidos por funções que medem o nível de informação de um item, estimam os parâmetros e habilidades e medem erros (Oliveira, 2002). A descrição dos Modelos Logísticos nas seções seguintes foi baseada em Wang \& Hanson (2001), Baker (2001) e Lord (1980).

\subsubsection{Modelo Logístico de Um Parâmetro}

O modelo Rasch (Rasch Model) foi publicado primeiramente pelo matemático dinamarquês Georg Rasch na década de 60, o qual abordou a análise de dados de teste do ponto de vista da

\footnotetext{
${ }^{1}$ Detalhes em http://mathworld.wolfram.com/LogisticEquation.html
} 
Teoria de Probabilidades. Segundo Baker (2001), o Rasch é um modelo com dois parâmetros, mas considera-se como um Modelo Logístico de Um Parâmetro (ML1P) (One Parameter Logistic - $1 P L$ ), pois o parâmetro $a$ (discriminação) é fixo e constante - o que define o número de parâmetros do modelo não é a quantidade de parâmetros, mas sim quais desses parâmetros podem ser variáveis. Já o parâmetro $b$ (dificuldade) pode assumir os valores $-4,0 \leq b \leq 4,0$ (esse intervalo é mais tipicamente usado) e $a=1,0$, com $a, b \in \mathbb{Q}$. A função para o ML1P é dada por:

$$
P(\theta)=\frac{1}{1+e^{-1(\theta-b)}}
$$

onde $P(\theta)$ é a probabilidade de um aluno com habilidade $\theta$ acertar a questão.

\subsubsection{Modelo Logístico de Dois Parâmetros}

O Modelo Logístico de Dois Parâmetros (ML2P) (Two Parameter Logistic, 2PL) trabalha com os parâmetros $a$ e $b$. Ambos podem assumir os valores $-1,0 \leq a \leq 4,0 \mathrm{e}-2,5 \leq b \leq 2,5$, $\operatorname{com} a, b \in \mathbb{Q}$. A função que descreve o modelo é dada por:

$$
P(\theta)=\frac{1}{1+e^{-a(\theta-b)}}
$$

onde $P(\theta)$ é a probabilidade de um aluno com habilidade $\theta$ acertar a questão.

\subsubsection{Modelo Logístico de Três Parâmetros}

Birmbaum, em 1968, modificou o ML2P para incluir um terceiro parâmetro, causando a "perda" de algumas propriedades matemáticas da função logísticą (Baker, 2001). Dessa maneira, surge o modelo Modelo Logístico de Três Parâmetros (ML3P) (Three Parameter Logistic - 3PL), o qual considera os parâmetros $a, b$ e $c$ assumindo valores $-1,0 \leq a \leq 4,0$, $-4,0 \leq b \leq 4,0$ e $0,0 \leq c \leq 1,0, \operatorname{com} a, b, c \in \mathbb{Q}$. A função que descreve o modelo é dada por:

$$
P(\theta)=c+(1-c) \frac{1}{1+e^{-D a(\theta-b)}}
$$

onde $P(\theta)$ é a probabilidade de um aluno com habilidade $\theta$ acertar a questão, e $D$ é uma constante de ajuste da função, que pode assumir os valores 1, 7 para Lord (1980) ou 1, 0 para Baker (2001).

\footnotetext{
${ }^{2}$ Observa-se tal "perda" devido à inserção do fator $(c+(1-c))$.
} 


\subsubsection{Modelo Logístico de Quatro Parâmetros}

Segundo Wang \& Hanson (2001), situações de testes reais sempre têm um limite de tempo, e, com a incorporação de um quarto parâmetro relacionado ao tempo no ML3P, o teste se tornará mais fiel ao medir a habilidade do aluno. No Modelo Logístico de Quatro Parâmetros (ML4P) (Four-Parameter Logistic Response Time - 4PLRT) o acréscimo do tempo está relacionado com outros três parâmetros do modelo: a lentidão do item, lentidão do aluno e o tempo total de teste; respectivamente os parâmetros $d, \rho$ e $t$. Ou seja, $\forall d \in \mathbb{Q}$ significa a estimativa de tempo para uma questão e $\rho$ o tempo que um aluno utilizará para solucionar alguma questão, com $0,0 \leq \rho \leq 10,0$ e $\rho \in \mathbb{Q}$. O tempo total está em $0,0 \leq t \leq \infty$, com $t \in \mathbb{Q}$. A função do ML4P é dada por:

$$
P(\theta)=c+\frac{1-c}{1+e^{-1,7 a\left(\theta-\left(\frac{\rho d}{t}\right)-b\right)}}
$$

onde $P(\theta)$ é a probabilidade de um aluno com habilidade $\theta$ acertar a questão.

\subsection{Banco de Itens e a Estimativa de Parâmetros}

Um BI pode ser definido como um banco de dados cujos dados são as questões necessárias para a execução de um TI. Um requisito é que os itens devem tratar do mesmo domínio do conhecimento e a extração de informações seja facilitada.

Caso um teste trate de vários assuntos, faz-se necessário um Balanceamento de Conteúdo do BI, que consiste em uma divisão do banco em várias seções. Isso permite que em um único exame avaliem-se várias habilidades de cada aluno de forma individual. As seções são definidas pelo professor, garantindo a eficácia e objetivos do teste (Oliveira, 2002). Um exemplo é um teste de Matemática, em que o conteúdo é balanceado da seguinte forma: pode-se ter $30 \%$ de Álgebra Linear, 30\% de Geometria, 20\% de Teoria do Números e 20\% de outros assuntos.

Em um BI estão as variáveis psicométricas ${ }^{3}$ que descrevem numericamente algumas características relacionadas ao item e ao aluno. Para estimar tais variáveis é necessária uma calibração dos itens que pode ser realizada por dois métodos: Estimativa da Máxima Verossimilhança e Método Bayesiano, ambos detalhados em Morettin \& Bussab (2003), Oliveira (2002) e Lord (1980).

O TAI baseado na TRI necessita de um BI pré-calibrado e pré-ajustado, com exceção do CBAT-2 (ver detalhes na Seção 4.8) que autocalibra os parâmetros no decorrer do teste. Detalhes sobre BI e balanceamento de conteúdo encontram-se em Oliveira (2002).

\footnotetext{
${ }^{3}$ No caso da TRI, são os parâmetros, $a, b, c, d$.
} 


\subsection{Estimativa da Habilidade do Aluno}

Existem algumas formas de estimar a habilidade $\theta$ do aluno em um TA: Método da Máxima Verossimilhança, Método Bayesiano (ambos, com detalhes em Morettin \& Bussab (2003); Oliveira (2002); Lord (1980)) e método de Newton-Raphson iterativo modificado (NR) (ver detalhes em (Lord, 1980)). Com destaque ao NR, o modelo é ajustado para estimar a habilidade do aluno, segundo as seguintes funções:

$$
\begin{array}{r}
\theta_{n+1}=\theta_{n}+\frac{\sum_{i=1}^{n} S_{i}\left(\theta_{n}\right)}{\sum_{i=1}^{n} I_{i}\left(\theta_{n}\right)} \\
S_{i}(\theta)=\left[r_{i}-P_{i}(\theta)\right] \frac{P_{i}^{\prime}(\theta)}{P_{i}(\theta)\left[1-P_{i}(\theta)\right]}
\end{array}
$$

onde:

- $\theta_{n}$ é a habilidade estimada após a $n$-ésima questão;

- $I_{i}(\theta)$ é a função A.1;

- $P_{i}(\theta)^{\prime}$ é a derivada da função $P_{i}(\theta)$, que advém da escolha de um modelo apresentado na Seção 4.4 ,

- $r_{i}$ recebe o valor 1 se a $i$-ésima questão estiver correta e 0 caso a questão estiver incorreta. A demonstração do NR está em Ruggiero \& da Rocha Lopes (1997).

\subsection{Função de Informação de um Item}

Segundo Baker (2001), por intermédio da TRI pode-se medir a quantidade de informação fornecida por um item dada a habilidade $\theta$ do aluno. Com isso obtém-se um gráfico denominado Função de Informação de um Item (FII), que quantifica a informação máxima de um item como uma curva padronizada de $P_{i}(\theta)$ por $(\theta)(i=1,2,3, \ldots)$ dada pelas seguintes funções:

$$
\begin{gathered}
I_{i}(\theta)=\frac{\left(P_{i}^{\prime}(\theta)\right)^{2}}{P_{i}(\theta) Q_{i}(\theta)} \\
Q_{i}(\theta)=1-P_{i}(\theta)
\end{gathered}
$$


onde

- $\theta$ é a habilidade estimada do aluno;

- $I_{i}(\theta)$ é a FII do item $i$-ésimo item, dada a habilidade do aluno;

- $P_{i}(\theta)$ é a probabilidade do aluno responder corretamente ao item $i$;

- $P_{i}^{\prime}(\theta)$ é a derivada de primeira ordem da função $P_{i}(\theta)$.

Detalhes do funcionamento da FII encontram-se em Oliveira (2002);

\subsection{Algoritmo CBAT-2}

Uma grande dificuldade de aplicar TAI's é realizar a calibração dos parâmetros dos itens. Huang (1996a) propõe o algoritmo Content-Balanced Adaptive Testing (CBAT-2), que soluciona o problema da calibração dos itens, eliminando um estudo empírico para a calibração de itens do teste. Huang (1996b) propõe que à medida que o aluno responde as questões, o algoritmo ajuste os parâmetros dos itens, isto é, quanto mais vezes o teste é acessado, mais precisa é a calibração dos itens. Algumas características do CBAT-2 são destacadas:

Balanceamento de conteúdo: é assegurado que os itens selecionados podem cobrir todas as áreas do conteúdo (ver Seção 4.8.1);

Autocalibração dos itens de teste selecionados: não requer um estudo empírico para a calibração dos itens do BI;

Seleção dos itens: selecionar itens do teste pode fornecer mais informação para a avaliação, aumentando a eficiência e precisão do teste;

Segurança: a seleção dos itens para teste não forma um padrão. Em uma seleção padrão aquela em que a seleção dos itens são iguais para todos os alunos - existe um aumento das chances de adivinhações e trapaças;

Questões em múltiplas áreas do conteúdo: permite que uma questão seja associada com múltiplas áreas do conteúdo;

Dois níveis de avaliação: fornece informações da avaliação de partes do conteúdo e do conteúdo global no teste.

Para realizar uma calibração com outros métodos, necessita-se de um BI com um grande número de itens. Por essa razão, o CBAT-2 mostra-se uma possível solução da aplicação de TAI's em instituições de pequeno porte, pois requer um BI menor. 


\subsubsection{Gerenciamento de Conteúdo}

Em relação ao Balanceamento de Conteúdo, o CBAT-2 apresenta um sistema gráfico chamado Hierarquia de Currículo (Curriculum Hierarchy) (Huang, 1996b) que faz o mesmo papel de balancear o conteúdo dos itens do BI. Áreas do conhecimento podem ser associadas com as questões, fornecendo uma boa representação do curso por meio de tal hierarquia. Sua representação pode ser vista na Figura 4.3 .

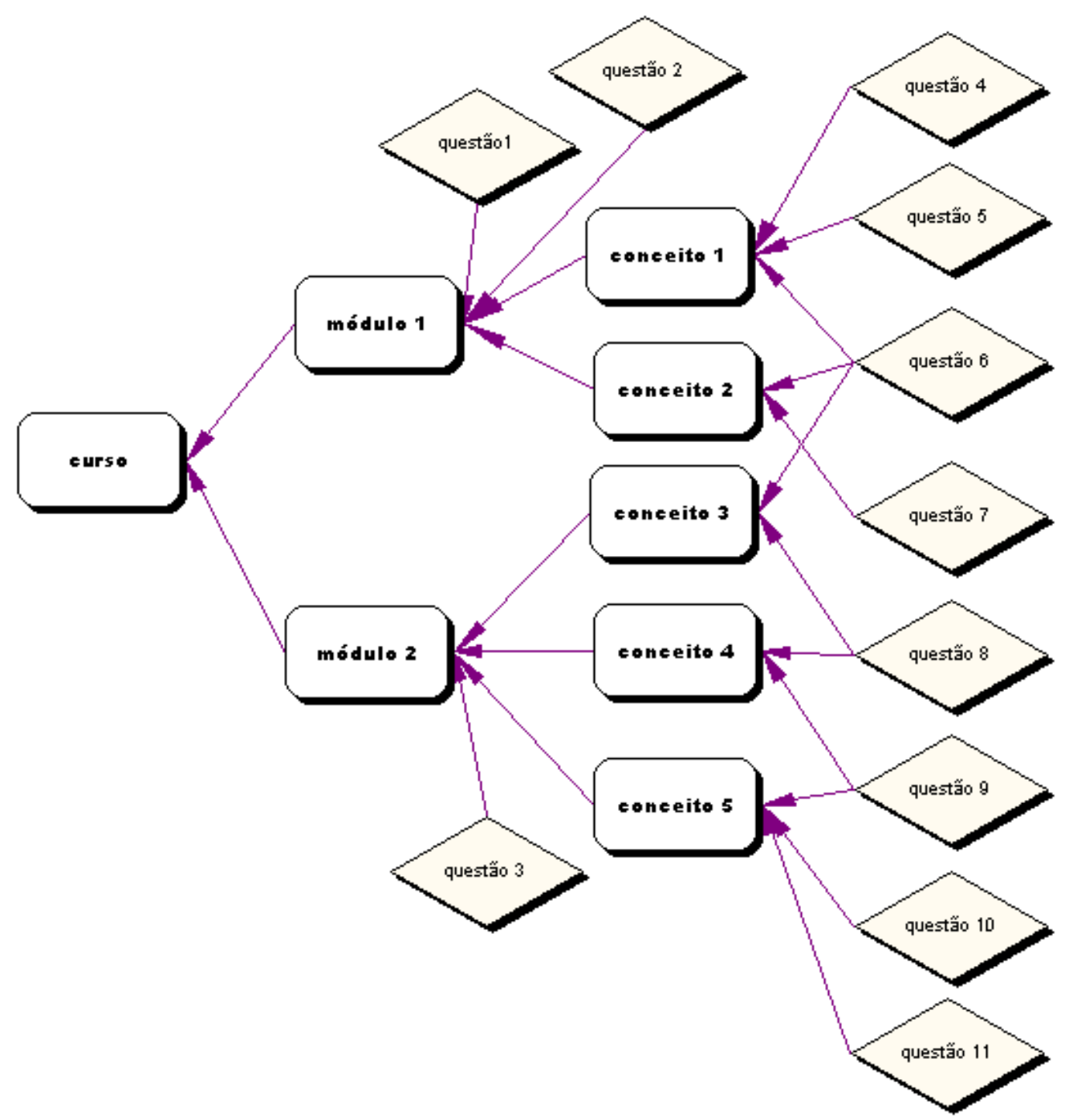

Figura 4.3: Áreas do conteúdo e questões em uma Hierarquia de Currículo (adaptada de Huang (1996b)).

Cada área delimitada na Figura 4.3 é chamada de Componente, que representa o conteúdo em um certo nível. Segundo a Figura 4.3, as questões podem estar inseridas no Conceito (por exemplo, Conceito 1 a 5) quando o conteúdo tratado no item é especifico do domínio, como em um Módulo (por exemplo, a questão 1 e 2 estão associadas ao Módulo 1) quando o conteúdo 
tratado no item é mais genérico. Essas classificações dependem dos pesos numéricos estabelecidos para o Conceito e o Módulo. Para fins de padronização, pode-se considerar um mesmo peso para todos os Componentes. Considera-se somente no CBAT-2 dois níveis de informação - Módulos e Conceitos -, pois caso contrário, o teste pode tornar-se muito longo.

O algoritmo CBAT-2 consiste em três procedimentos: Seleção das Questões, Estimativa da Habilidade e Pontuação e Decisão mestra (Huang, 1996b). Seguem nas próximas seções os detalhes de cada procedimento.

\subsubsection{Seleção das Questões}

As questões no CBAT-2 são catalogadas por dois parâmetros da TRI: nível de dificuldade e fator adivinhação - respectivamente os parâmetros $b$ e $c$. O parâmetro $a$ apresenta algumas dificuldades na calibração e sua interpretação não é ainda compreendida corretamente (Huang, 1996b). Na definição dos parâmetros das questões, Huang (1996b) afirma que a seleção das questões pode ser dividida em duas etapas:

1. Decisão do Componente. Esse primeiro passo consiste na decisão de qual componente a questão virá. Esse componente de trabalho é selecionado aleatoriamente dentre um conjunto de componentes candidatos, que em sua escolha não tem uma probabilidade igualitária dentre os outros componentes. Então entra em cena o peso do componente, que é dado pela seguinte fórmula:

$$
\Upsilon_{i}=\frac{W_{i}}{\sum\left(\frac{W_{i}}{C_{i}}\right)}
$$

onde $\Upsilon_{i}$ é a probabilidade da seleção do $i$-ésimo componente $C_{i}$, e cada $W_{i}$ é o peso de cada $C_{i}$, com $i=1,2,3, \ldots$

2. Seleção dos Componentes. Consiste na seleção da questão dentre aquelas associadas aos componentes eleitos na etapa anterior. A questão é selecionada segundo critérios de informação sobre o item obtido pela FII apresentado na Seção 4.7. A FII da questão $Q_{i}$ é baseada no ML3P, com a habilidade temporária $\theta^{\prime}$. Porém, como no CBAT-2 tem-se somente dois parâmetros e utiliza-se uma FII de três parâmetros, como ajuste, adota-se o parâmetro $a=1.2$ que, segundo Kingsbury and Weiss (1979) apud Huang (1996b), está próximo do valor médio da seleção das questões. Ressalta-se que o parâmetro $a$ é aplicado somente no cálculo da FII. Assim, tem-se as seguintes fórmulas incorporadas ao CBAT-2:

$$
\mu_{i}=\frac{20 \omega_{0}+\Phi_{i}}{20+R_{i}+W_{i}}
$$




$$
\begin{array}{r}
\Phi_{i}=\sum_{j=1}^{n} k_{j} f\left(\theta_{j}^{\prime}\right) \\
f\left(\theta_{j}^{\prime}\right)=\frac{\theta_{j}^{\prime}+4}{8} \\
b_{i}=g\left(\mu_{j}\right)=8 \mu_{j}-4 \\
c=\frac{1}{z}
\end{array}
$$

onde

- $\mu_{i}$ é o nível de dificuldade da questão $Q_{i}$, o qual incorpora uma combinação da dificuldade inicial e histórico do aluno ;

- $\omega_{0}$ é a dificuldade inicial da questão $Q_{i}$;

- $\Phi_{i}$ é a dificuldade acumulada por cada questão $Q_{i}$;

- $R_{i}$ é o número de vezes que a questão $Q_{i}$ foi respondida corretamente até o momento (de todos os testes anteriores);

- $W_{i}$ é o número de vezes que a questão $Q_{i}$ foi respondida incorretamente até o momento (de todos os testes anteriores);

- $n$ é o número de respostas acumuladas da questão $Q_{i}$ (de todos os testes anteriores) até o momento, com $n=R_{i}+W_{i}$;

- $\theta_{j}^{\prime}$ é a habilidade temporária do aluno que concedeu a $j$-ésima resposta para a questão $Q_{i}$;

- $k_{j}$ é um valor que assume $k_{j}=0$ se a $j$-ésima resposta a $Q_{i}$ for correta, e $k_{j}=2$ se a $j$-ésima resposta de $Q_{i}$ for incorreta;

- $f\left(\theta_{j}^{\prime}\right)$ é uma função de normalização que converte o valor $\theta_{j}^{\prime}$ do intervalo $[-4,4]$ para o intervalo $[0,1]$;

- $g\left(\mu_{i}\right)$ é uma função de normalização, que converte o valor $\mu_{i}^{\prime}$ do intervalo $[0,1]$ para o intervalo $[-4,4]$. $g$ é dita função reversa de $f$;

- O valor 20 é o fator de normalização de $\mu_{i}$;

- $b_{i}$ é o parâmetro dificuldade da questão $Q_{i}$;

- $c$ é o parâmetro adivinhação; 
- $z$ é a quantidade de opções de resposta para as questões. Por exemplo: se for resposta do tipo verdadeiro ou falso então $z=2$, se for resposta de múltipla escolha com quarto escolhas mutuamente exclusivas então $z=4$. Se a resposta à questão for dissertativa, então $c=0$, isto é, não há adivinhação.

\subsubsection{Estimativa da Habilidade no CBAT-2}

A estimativa da habilidade $\theta$ fornece subsídios para a possibilidade de medir o conhecimento do aluno. Com o $\theta$ estimado, faz-se a seleção da próxima questão para o aluno. Um estimador de habilidade temporário $\theta^{\prime}$ faz-se necessário até o término do teste, o qual é recalculado a cada questão respondida pelo aluno. Ao final do teste, tem-se como resultado um valor $\theta$ final. Cada novo valor $\theta$ obtido é recalculado mediante o Método Bayesiano (Huang, 1996b).

Huang (1996b) afirma que pode-se ter estimadores de habilidade para cada conceito e para cada módulo, de forma que se tenha $\theta_{i}^{\prime}$ para cada Componente $C_{i}$ em um sub-currículo do teste $(i=1,2,3, \ldots)$.

\subsubsection{Pontuação e a Decisão Mestra}

As habilidades estimadas em cada componente no CBAT-2 podem ser convertidas em valores comparáveis com pontuações mais comuns obtidas com testes via lápis e papel (Huang, 1996b), como por exemplo a escala de 0 a 10. O TAI baseado no CBAT-2 terminará quando o aluno atingir um certo nível de habilidade pré-estabelecido pelo administrador do teste, ou quando o aluno realizar o número máximo de questões em cada componente do sub-currículo (Huang, 1996a).

\subsection{Potencialidades dos Testes Adaptativos Informati- zados}

Segundo Oliveira (2002), os TAI's têm as seguintes potencialidades:

- A individualização de um teste. O aluno terá um teste personalizado, segundo seu desempenho durante o processo de teste;

- O tempo de teste em relação ao aluno é reduzido, mantendo o mesmo nível de confiança de um TI convencional. Isso é vantagem, pois reduz a fadiga que os longos testes causam nos alunos;

- Se o sistema foi desenvolvido para a WWW, pode-se utilizar o TAI nas ferramentas de Educação à Distância; 
- Rapidez e robustez do teste para o aluno e o professor.

Oliveira (2002) também destaca algumas limitações dos TAI's:

- O BI de um TAI que necessite de calibração requer um banco cuidadosamente calibrado, verificando a confiabilidade desse banco frente aos dados fornecidos pela calibração;

- Por envolver métodos estatísticos, a implementação de um sistema baseado na TRI pode ser custosa e trabalhosa.

\subsection{Considerações Finais}

Nesse capítulo foram abordados os principais tópicos relacionados com os Testes Adaptativos Informatizados (TAI's): a Teoria de Resposta ao Item (TRI), o Modelo Logístico de Um Parâmetro (ML1P), o Modelo Logístico de Dois Parâmetros (ML2P), o Modelo Logístico de Três Parâmetros (ML3P), o Modelo Logístico de Quatro Parâmetros (ML4P), o Banco de Itens (BI), o algoritmo Content-Balanced Adaptive Testing (CBAT-2) e a Função de Informação de um Item (FII).

No Capítulo 5 serão apresentados sistemas que utilizam alguns modelos de TAI's baseados na TRI e no CBAT-2, e também o processo de integração entre Ambientes Computacionais de Tarefas (ACT's) - ambientes que propiciam cenários de aprendizagem para aprendizes - e TAI's em sistemas para uso na internet. 


\section{Capítulo 5}

\section{Integração de Testes Adaptativos Infor- matizados e Ambientes Computacionais de Tarefas}

Uma forma para validar as hipótese dessa pesquisa foi o desenvolvimento de um ACA para o EPI do ICMC-USP. Tal ambiente propicia cenários de aprendizagem para estudantes e aprendizes. Uma forma de conceber um ACA é por meio da integração entre dois ou mais sistemas. Dessa maneira, a Seção 5.1 descreve o processo de integração, exemplificado por dois ACA's da literatura, frutos da integração entre ambientes computacionais.

\subsection{Processo de Integração}

Uma forma de conceber um ACA é integrando componentes, módulos ou partes de outros sistemas. Tais ambientes de integração podem ser formados a partir de dois Módulos:

- O Módulo do Teste é composto por um TI que tem o papel de avaliar conhecimento do aluno, o qual pode fornecer um Modelo de Aluno;

- O Módulo de Aprendizagem é onde o aluno pode realizar um conjunto de ações e reflexões para sua aprendizagem, segundo o Modelo de Aluno obtido no Módulo do Teste. Como exemplo tem-se um STI (ver Seção 2.3.4).

Pode-se selecionar diferentes maneiras de compor esses módulos, sendo uma delas:

1. Um TAI que tem o papel de avaliar o aluno no Módulo do Teste - diagnóstico do aluno; 
2. Um ACT que apresenta ao aluno um conjunto de tarefas pré-determinadas pelo sistema no Módulo de Aprendizagem - tarefas ao aluno. A escolha das tarefas pode dar-se por intermédio de lições (leitura e interpretação) ou tarefas para a aprendizagem.

Um ACT apresenta ao aluno um conjunto de tarefas que propiciam o desenvolvimento de habilidades intelectuais, como por exemplo, a leitura e interpretação de artigos científicos em inglês. Ou seja, tarefas que fornecem subsídios para o aprendizado do aluno em um domínio de conhecimento. A Figura 5.1 ilustra de uma forma genérica o processo de integração entre o Módulo do Teste e Módulo de Aprendizagem. Os dados dos alunos, questões e tarefas podem estar armazenado em um banco de dados.

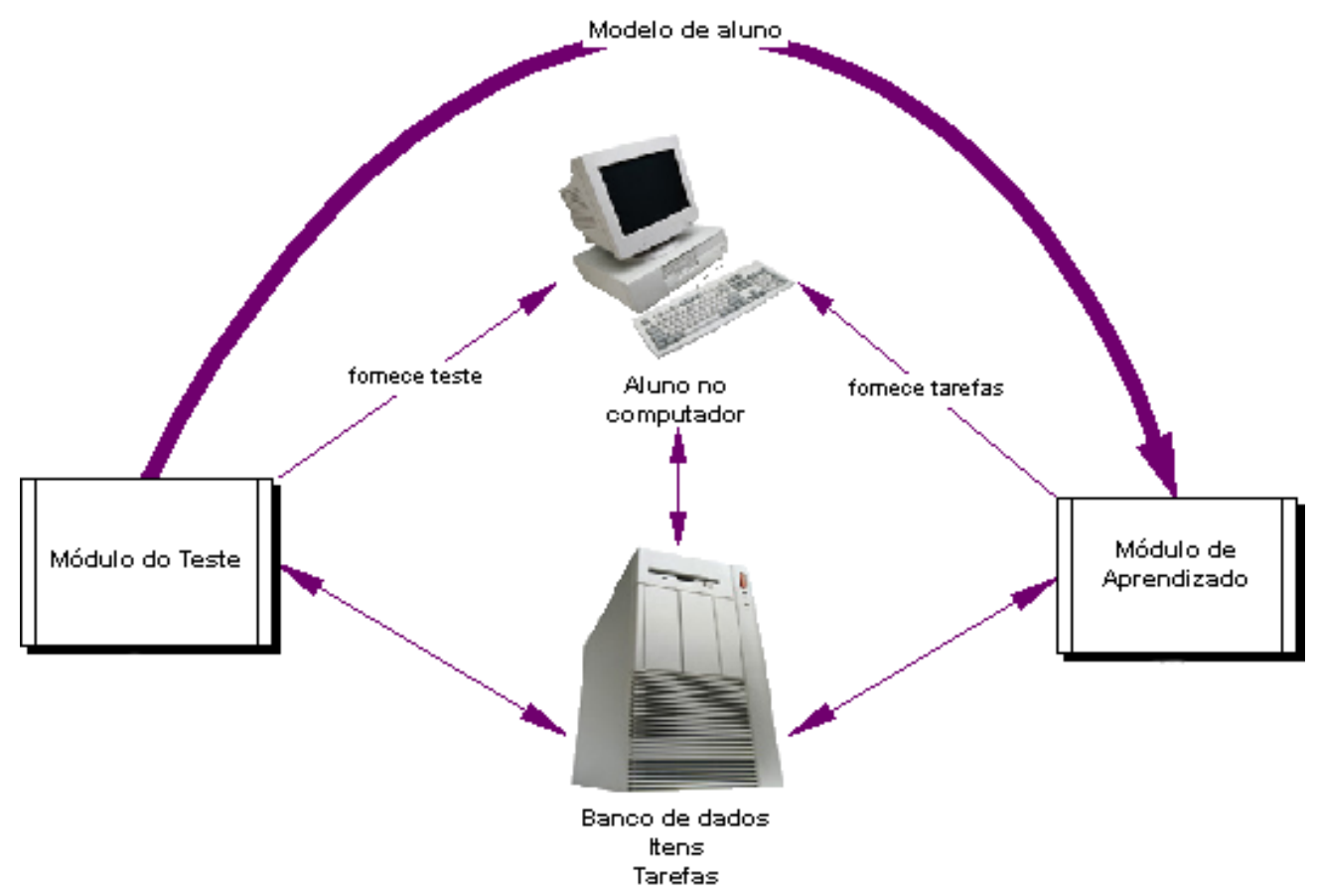

Figura 5.1: Integração entre Módulos de Teste e de Aprendizado.

Na seção seguinte apresenta-se dois exemplos de ambientes de integração.

\subsection{Exemplos de Ambientes de Integração}

Em termos de ACA que são frutos da integração entre Módulo do Teste e Módulo de Tarefas, destacam-se dois ambientes: O TREE (Conejo et al., 1999, 2000, 2001) e o INSPIRE (Papanikolaou et al., 2001; Gouli et al., 2001). 


\subsubsection{Projeto TREE}

O projeto TREE (Training of European Environmental trainers and technicians in order to disseminate multinational skills between European countries) tem como principal objetivo o desenvolvimento de um STI final para a classificação e identificação das diferentes vegetações européias, que é composto por três partes principais.

1. O Sistema Especialista (Expert System) é caracterizado por simular o raciocínio de um especialista de domínio do conhecimento;

2. O Sistema Tutor (Tutorial System) é composto por quatro módulos: Modelo de Aluno, o Modelo Tutor, o Módulo de Diagnóstico e a Base de Conhecimento (ver detalhes na Seção 2.3.4;

3. O Sistema de Geração de Teste (Tests Generation System) faz o diagnóstico do aluno, sendo que no caso do TREE, escolheu-se o sistema SIETTE (Intelligent Evaluation System using Tests for Teleducation) ${ }_{1}^{1}$ para avaliar os alunos. Ele é um sistema de TAI para a WWW, que pode ser utilizado para qualquer domínio do conhecimento. O SIETTE pode ser utilizado de duas formas (Conejo et al., 1999, 2001):

(a) Professores e especialistas de domínio podem elaborar e definir testes aos alunos, organizando as perguntas e respostas de acordo com o tema, o critério de parada do teste, o número máximo e mínimo de questões, etc;

(b) Alunos podem usar o SIETTE para realizar um TAI que fornecerá um modelo de aluno para o STI. O professor pode mudar manualmente as porcentagens de perguntas de cada assunto que irão compor o teste, e o número mínimo de perguntas de cada um deles (Conejo et al., 2001). O modelo de TAI utilizado no SIETTE é o CBAT-2 (Ver Seção 4.8), que possibilita trabalhar simultaneamente com diversos Componentes (ver Figura 4.3 da Seção 4.8.1), cobrindo uma quantidade maior de subáreas de um domínio do conhecimento. A Figura 5.2 mostra a arquitetura geral do SIETTE sendo acessado por dois tipos de usuários: professor e aluno, onde o professor por meio de uma interface WWW edita as questões do teste, que consiste em: especificar o teste (número de questões, tempo, etc) e validar o teste (verificar se as questões são consistentes). A partir disso o Gerador de Teste Adaptativo gerenciando o teste e as questões ao aluno - que acessa o teste por meio da WWW -, usando as informações das questões e do modelo temporário de aluno.

\footnotetext{
${ }^{1}$ http://sirius.lcc.uma.es/siette/index.jsp
} 


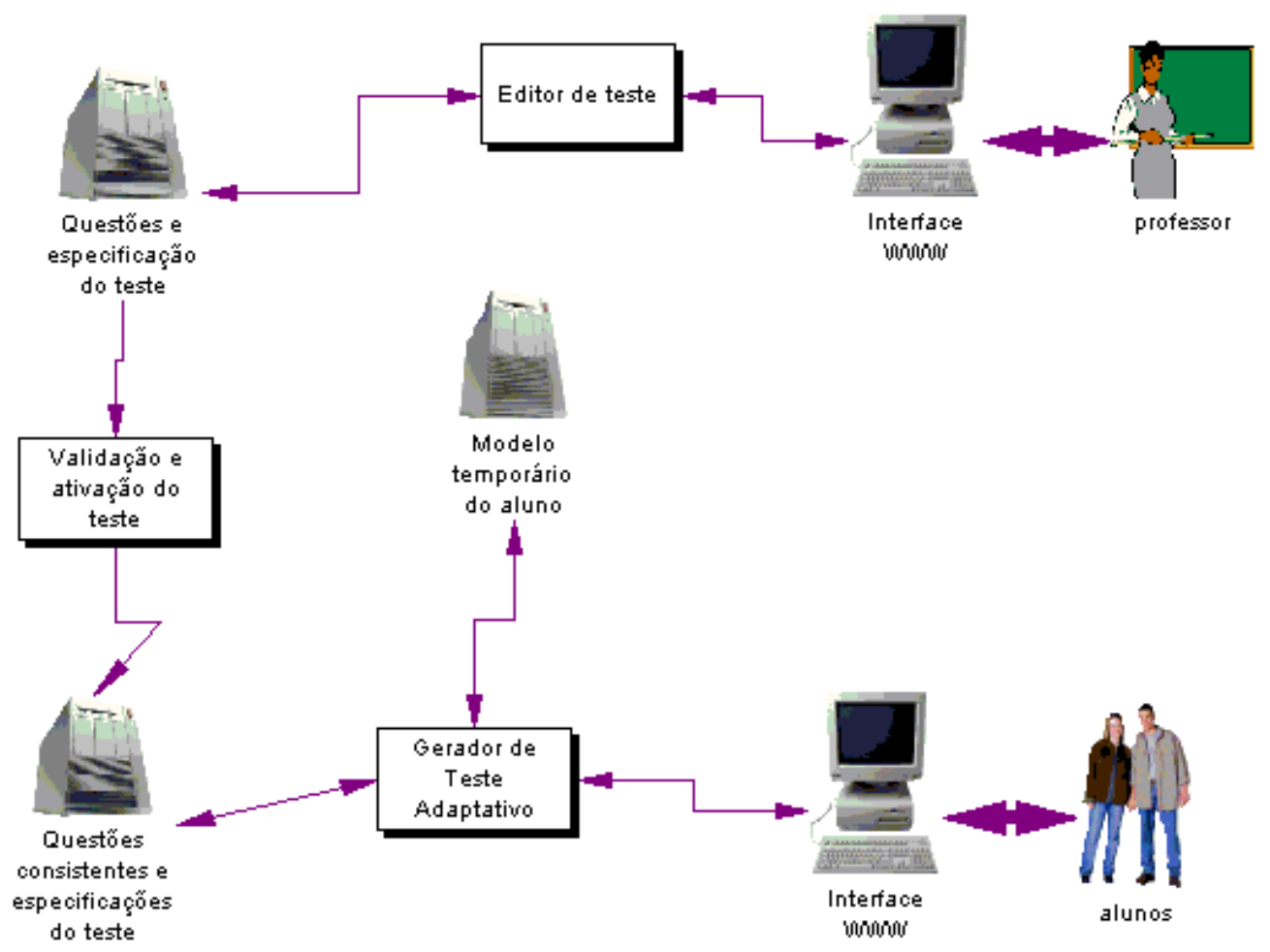

Figura 5.2: Arquitetura geral do SIETTE (adaptada de Conejo et al. (2001)).

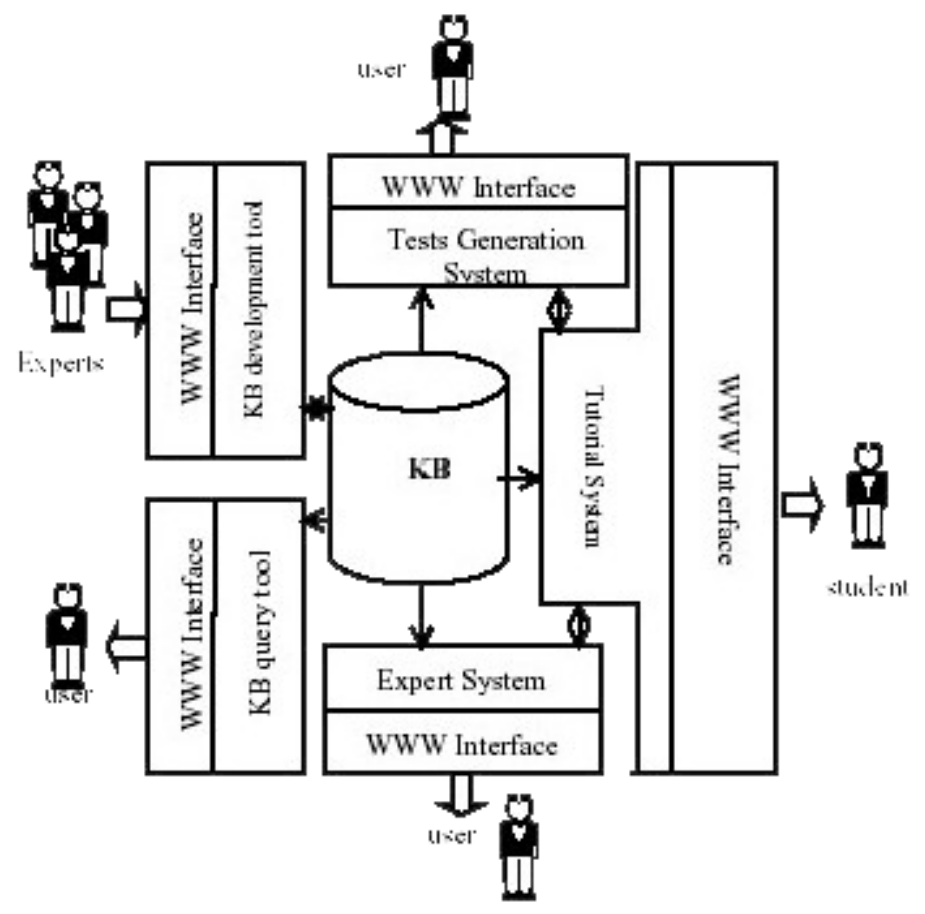

Figura 5.3: A estrutura do TREE (extraída de Conejo et al.(1999)). 
Na estrutura do TREE observa-se que o Módulo de Teste é o TAI e o Módulo de Tarefas é o STI, o qual integrados, compõem o ACA final. A Figura 5.3 mostra que além das três partes, existem mais duas que são relativas ao gerenciamento da base de conhecimento (knowledge Base, KB). A base de conhecimento está interligada com todas as partes do TREE, observandose a presença de uma interface WWW para alunos, usuários em geral e especialistas.

O SIETTE mostra-se como um TAI muito útil e versátil no desenvolvimento de ACA's, como é o caso do projeto TREE. O SIETTE também pode ser utilizado em outros cenários de aprendizado, basta que a base seja abastecida com um outro domínio. Detalhes do SIETTE e do TREE podem ser encontrados em (Conejo et al., 1999, 2000, 2001).

\subsubsection{Sistema INSPIRE}

O INSPIRE (Intelligent System for Personalized Instruction in a Remote Environment) monitora as atividades do aluno, adaptando-se dinamicamente para selecionar lições que ajustamse ao conhecimento e forma de aprendizado do aluno. Isto é, as lições são selecionadas de acordo com o nível de conhecimento do aluno. A Figura 5.4 mostra a arquitetura do INSPIRE, que foi desenvolvida para facilitar a comunicação do conhecimento entre sistema e aluno por meio de cinco módulos (Papanikolaou et al., 2001):

1. O Módulo de Monitoração da Interação (Interaction Monitoring Module) monitora as respostas dos alunos durante a interação com o sistema e atualiza o modelo de aluno;

2. O Módulo de Diagnóstico do Aluno (Diagnostic Module) processa os dados armazenados sobre o aluno e decide como classificar o conhecimento do aluno;

3. O Módulo Gerador de Lições (Lesson Generation Module) seleciona as questões de acordo com o objetivo e nível de conhecimento do aluno;

4. O Módulo de Apresentação (Presentation Module) gera páginas de material educacional para serem enviadas ao aluno, isto é, apresenta as lições ao aluno;

5. O Armazenamento de Dados (Data Storage) armazena o domínio do conhecimento e o modelo do aluno.

No Módulo de Diagnóstico do Aluno existe uma Avaliação Adaptativa (Gouli et al., 2001), que é caracterizada por um teste que estima a habilidade $\theta$ do aluno (ver Seção 4.3). O teste é realizado segundo critérios do ML3P e do CBAT-2. Porém, percebe-se uma modificação sutil quanto ao cálculo da estimativa de habilidade $\theta$, que dá-se no INSPIRE, a partir do método de Newton-Raphson iterativo modificado (NR), abordado na Seção 4.6. O término do teste é 


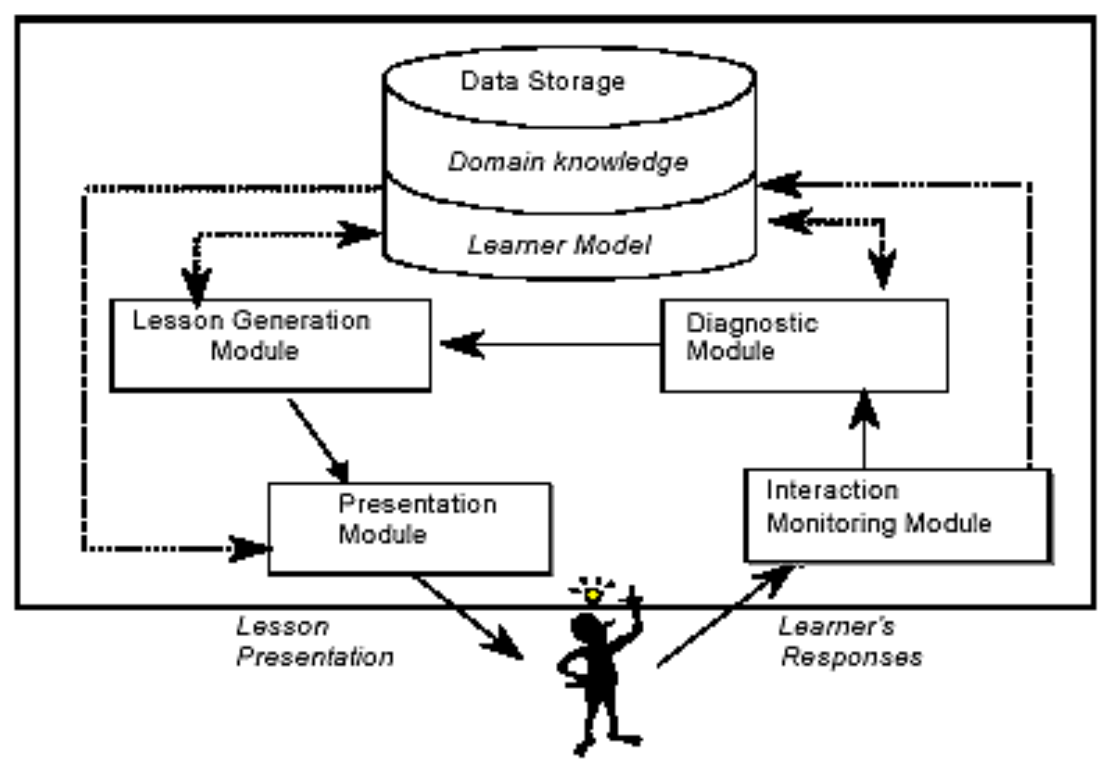

Figura 5.4: Componentes e interações com o aluno (extraída de Papanikolaou et al. (2001)).

estabelecido pelo professor por meio de uma ferramenta de editor de testes do próprio INSPIRE, permitindo uma configuração flexível do teste.

O INSPIRE é uma integração entre um módulo de tarefas e um TAI, o qual oferece uma retroalimentação ao aluno para o seu processo de aprendizado (Gouli et al., 2001). Detalhes do INSPIRE podem ser vistos em Papanikolaou et al. (2001).

\subsection{Considerações Finais}

Foram abordados nesse capítulo o projeto TREE e o sistema INSPIRE, resultado da integração de TAI's e ACT's. Em ambos existe o mesmo objetivo, que é fornecer elementos para o aprendizado de alunos em um determinado domínio. O TAI fornece um Modelo de Usuário para o ACT que verifica tal modelo e seleciona tarefas ao aluno.

Neste capítulo foram destacados dois ACA's de integração, que embasam o desenvolvimento do ACA proposto por esta pesquisa. O Capítulo6 trata do desenvolvimento de um TAI com o propósito de integrá-lo a um ACA desenvolvido, descrito no Capítulo 7. 


\section{Capítulo 6}

\section{Implementação de um Teste Adaptativo Informatizado para o Inglês Instrumen- tal}

Um Teste Adaptativo Informatizado (TAI) adapta-se ao nível estimado de habilidade do aluno, conforme abordado no Capítulo 4. Dado um BI calibrado ou com uma estimativa inicial para os parâmetros dos itens, com um número menor de questões do que testes tradicionais é possível estimar a habilidade do aluno e mapeá-la para uma nota final. Considerando suas potencialidades, desenvolveu-se um TAI baseado no CBAT-2 denominado ADEPT, que proporciona um teste individualizado e que com poucas questões, avalie o aluno, diferentemente de testes objetivos tradicionais que têm um número fixo de questões para todos os alunos, não considerando o conhecimento individual de cada aluno.

O ADEPT foi desenvolvido com o objetivo de formar o Módulo do Teste (ver Seção 5.1 do Capítulo 57, segundo os quatro Módulos do EPI para alunos de mestrado do ICMC-USP, no ACA desenvolvido descrito no Capítulo 7. Ressalta-se que o EPI do ICMC-USP trabalha em uma perspectiva de avaliar o conhecimento parcial do aluno (Aluísio et al., 2003) e o ADEPT trabalha segundo a teoria dos Testes Adaptativos.

O teste foi implementado na linguagem $P H P{ }^{1}$ (interface WWW) e o BI em $M y S Q L 2$. Além disso, houve a implementação em linguagem $C$ do código do CBAT-2 com adaptações.

Na Seção 6.1, apresenta-se a arquitetura do ADEPT e a funcionalidade de seus módulos. A Seção 6.2 descreve as alterações realizadas no CBAT-2 e na Seção 6.3 descreve-se e analisa-se dois experimentos realizados com alunos do mestrado do ICMC-USP.

\footnotetext{
${ }^{1}$ http://br.php.net

${ }^{2} \mathrm{http}: / /$ www.mysql.com
} 


\subsection{Arquitetura do ADEPT}

O sistema é dividido em dois módulos principais (Figura 6.1): o módulo que contém o TAI e o módulo de comunicação com o usuário.

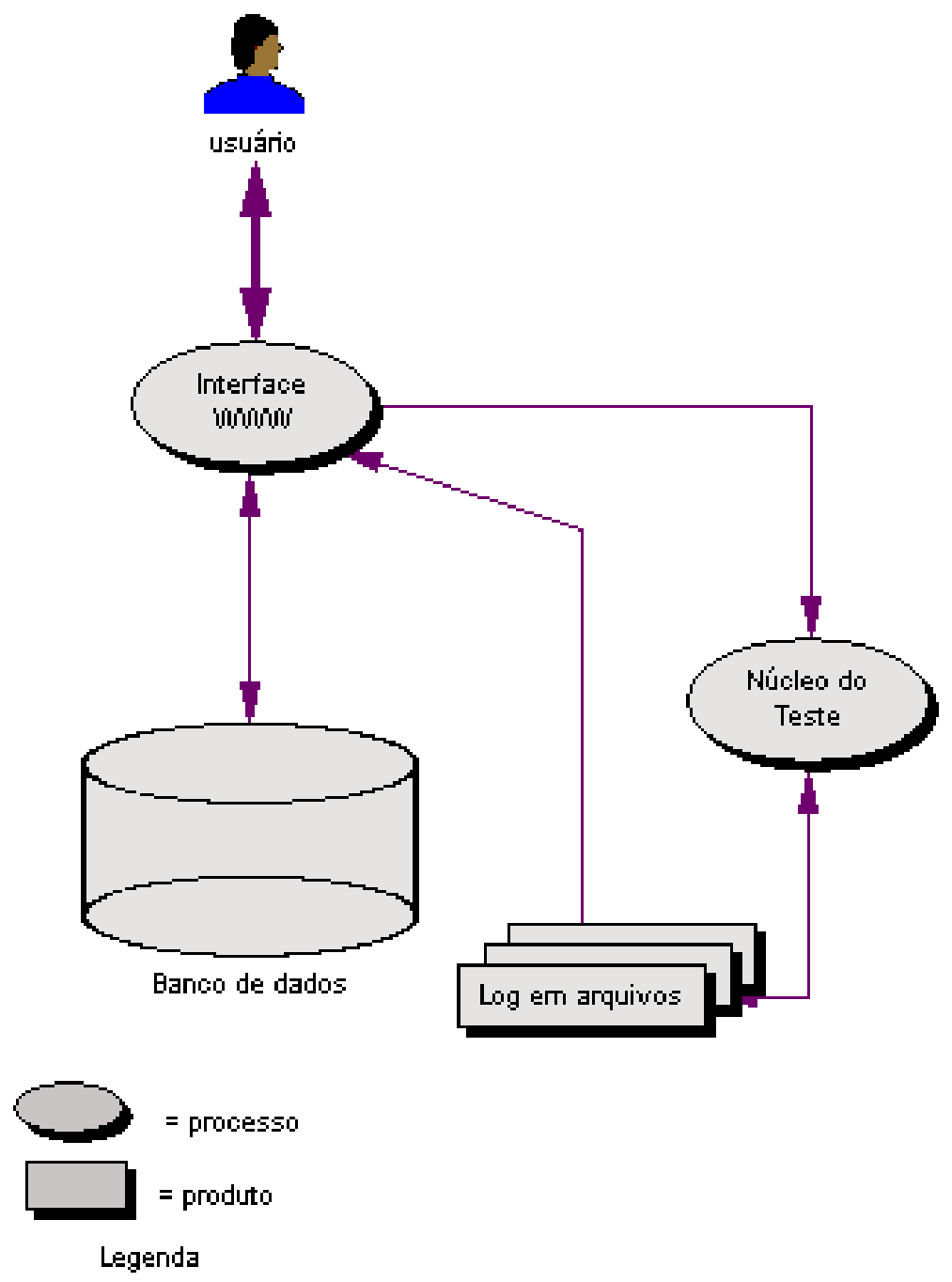

Figura 6.1: Arquitetura do ADEPT.

No Núcleo do Teste (módulo 1) encontra-se a implementação do CBAT-2, desenvolvido na linguagem $C$. A escolha da linguagem deve-se essencialmente à potencialidade da mesma frente à manipulação de fórmulas, aritmética de ponto flutuante e rapidez na execução de um código que envolve muitos laços e fórmulas com muitas variáveis. Aqui ocorre a seleção do próximo item, a calibração do BI e a estimativa da habilidade do aluno. Todos os dados referentes ao percurso (parâmetros) de cada aluno que realizou o TAI são gravados no log em arquivos. 
Na Interface WWW (módulo 2) a interação do usuário com o sistema dá-se pelo navegador, por meio da linguagem PHP. Esse é o módulo que realiza o papel da comunicação entre o banco de dados (BI e informações como: dados dos alunos e informações adicionais para o sistema) e o Núcleo do Teste.

Os módulos interagem para que o sistema possa calibrar os itens da base e selecionar as questões ao aluno em tempo de execução. O sistema propicia para o professor a depuração da trajetória do aluno no teste, por meio do log em arquivo. O aluno pode utilizar o TAI somente mediante uma autenticação por meio de login e senha, cadastrados pelo administrador do sistema. Seguem os passos de um aluno que realiza um teste no ADEPT, enumerados na Figura 6.2 .

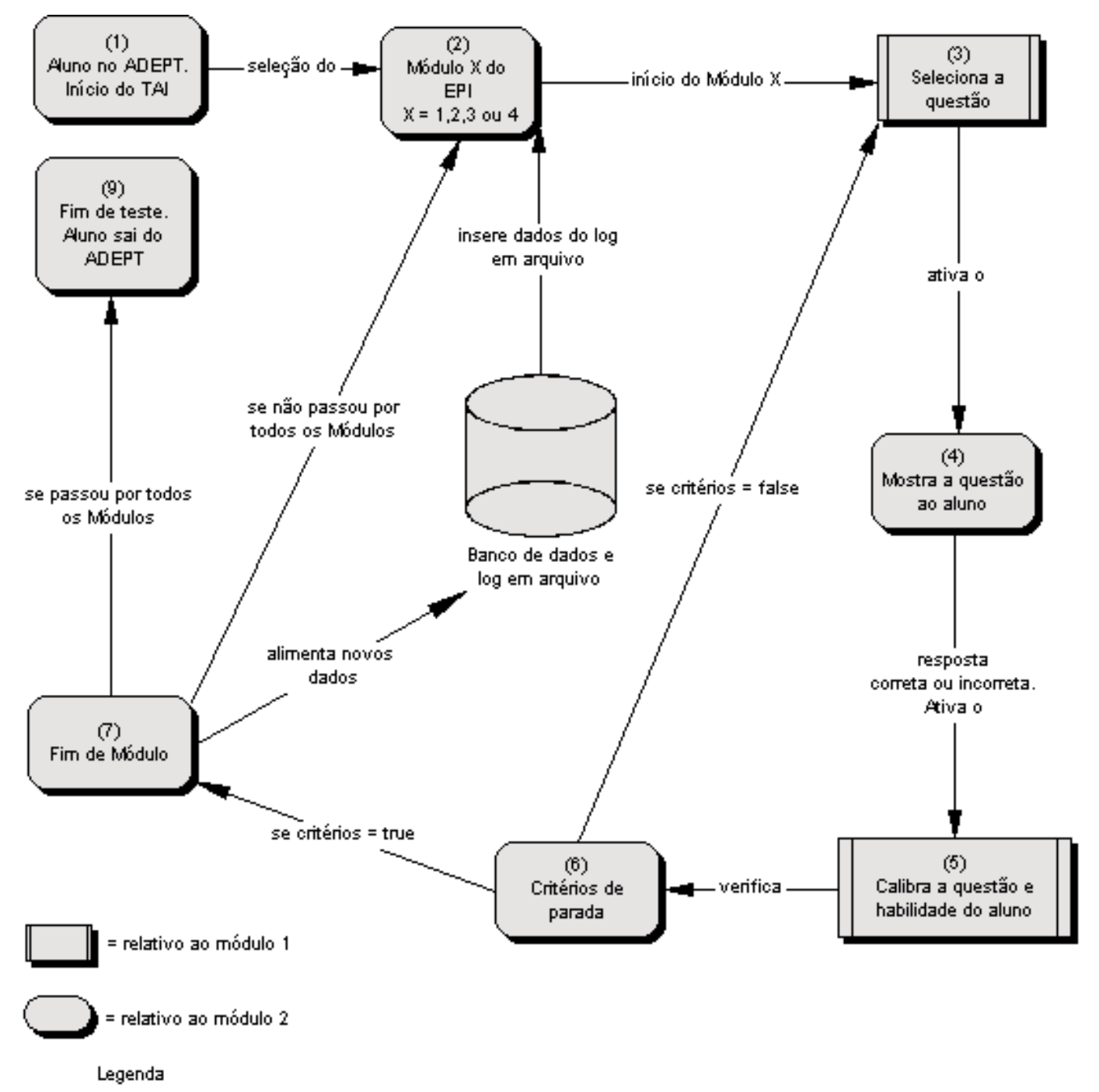

Figura 6.2: A estrutura e funcionamento do ADEPT.

- O aluno, após a autenticação, inicia o teste em (1); 
- Em (2) seleciona-se o Módulo X do EPI (1, 2, 3 ou 4);

- Em (3) seleciona-se uma questão, a partir do $\theta$ do aluno e do parâmetro $b$ do BI;

- Ocorre a exibição da questão selecionada em (4);

- O aluno responde a questão e em (5) calibra-se os parâmetros relativos à questão selecionada e à habilidade do aluno. Após o término do Módulo, esses dados são gravados no $\log$ em arquivo;

- Verifica-se em (6) se os critérios de parada são satisfeitos. Caso não sejam, o sistema é direcionado para (3), repetindo o processo até que os critérios de parada sejam satisfeitos;

- No caso dos critérios de parada satisfeitos em (6), termina-se o Módulo X do EPI, desencadeando a atualização do banco de dados, e caso ainda restem outros Módulos para o aluno realizar, o processo inicia-se em (2);

- Se o aluno passou por todos os Módulos do EPI, então o sistema interpretará como fim de teste (9), realizando o cálculo do $\theta$ final do aluno assim como sua nota final de teste.

Essa configuração do sistema garante que o teste seja robusto e faça o menor número de acessos a base de dados, já que o carregamento dos dados ocorre somente ao fim de cada Módulo. Os cálculos das fórmulas são realizados pelo Núcleo do Teste, o que garante rapidez devido ao código fonte na linguagem $C$. O sistema também possui informações adicionais do conteúdo ministrado pelo teste e alguns tópicos de ajuda sobre a utilização do sistema.

\subsubsection{Banco de Itens do ADEPT}

Em termos de dados da base, os itens do BI são as questões das provas do EPI do ICMCUSP referentes aos anos de 2001, 2002 e 2003, em um total de 5 exames distribuídos entre a Computação, Matemática Computacional e Estatística. Eles totalizaram 30 provas com aproximadamente 20 questões cada. A inserção, contabilização e filtragem de todas as questões da base foram realizadas pelo autor dessa pesquisa, totalizando 140 questões sem reuso, ou seja, não existem questões ou textos com repetição no BI.

O conhecimento tratado nas questões do ADEPT é o mesmo que do EPI para o mestrado do ICMC-USP. O site CAPTEAP ${ }^{3}$ é um dos resultados do trabalho de mestrado desenvolvido no ICMC-USP por Aquino (2001), onde são realizados os Exames de Proficiência para o mestrado do ICMC-USP que procuram avaliar os alunos ingressantes quanto a compreensão do texto, a habilidade de reconhecer tipos de textos científicos em inglês, com a estrutura e convenções da língua que lhes são características. O EPI possui quatro Módulos:

\footnotetext{
${ }^{3}$ http://www.nilc.icmc.usp.br/capteap
} 
- Módulo 1 - Convenções da Língua Inglesa. Aborda a morfologia, o vocabulário, a sintaxe, os tempos verbais e os marcadores de discurso utilizados nas partes de cada seção de um artigo científico em inglês. Atualmente, esse Módulo é dividido em duas Partes: Gap e Purpose;

- Módulo 2 - Estrutura do Texto. Trata de algumas funções de cada seção de um artigo. Atualmente, esse Módulo é dividido em duas Partes: Introduction e Abstract;

- Módulo 3- Compreensão do Texto. Trata da compreensão e do reconhecimento das relações entre as idéias contidas em uma seção de um artigo. Esse Módulo é composto somente pela Parte Comprehension;

- Módulo 4 - Estratégias de Escrita. Aborda estratégias de escrita como, por exemplo, definições, descrições, classificações e argumentações. Atualmente, esse Módulo é dividido em duas Partes: Setting e Review of Literature.

As questões do Módulo 1 e 4 são simples, ou seja, são independentes. Veja exemplos delas na Figura 6.3 e Figura 6.4. Já os Módulos 2 e 3 são compostos por questões dependentes, relacionadas com um texto em inglês (Figura 6.5. Figura 6.6 e Figura 6.7). Esse tipo de questão é denominada testlet (detalhes em Oliveira (2002)).

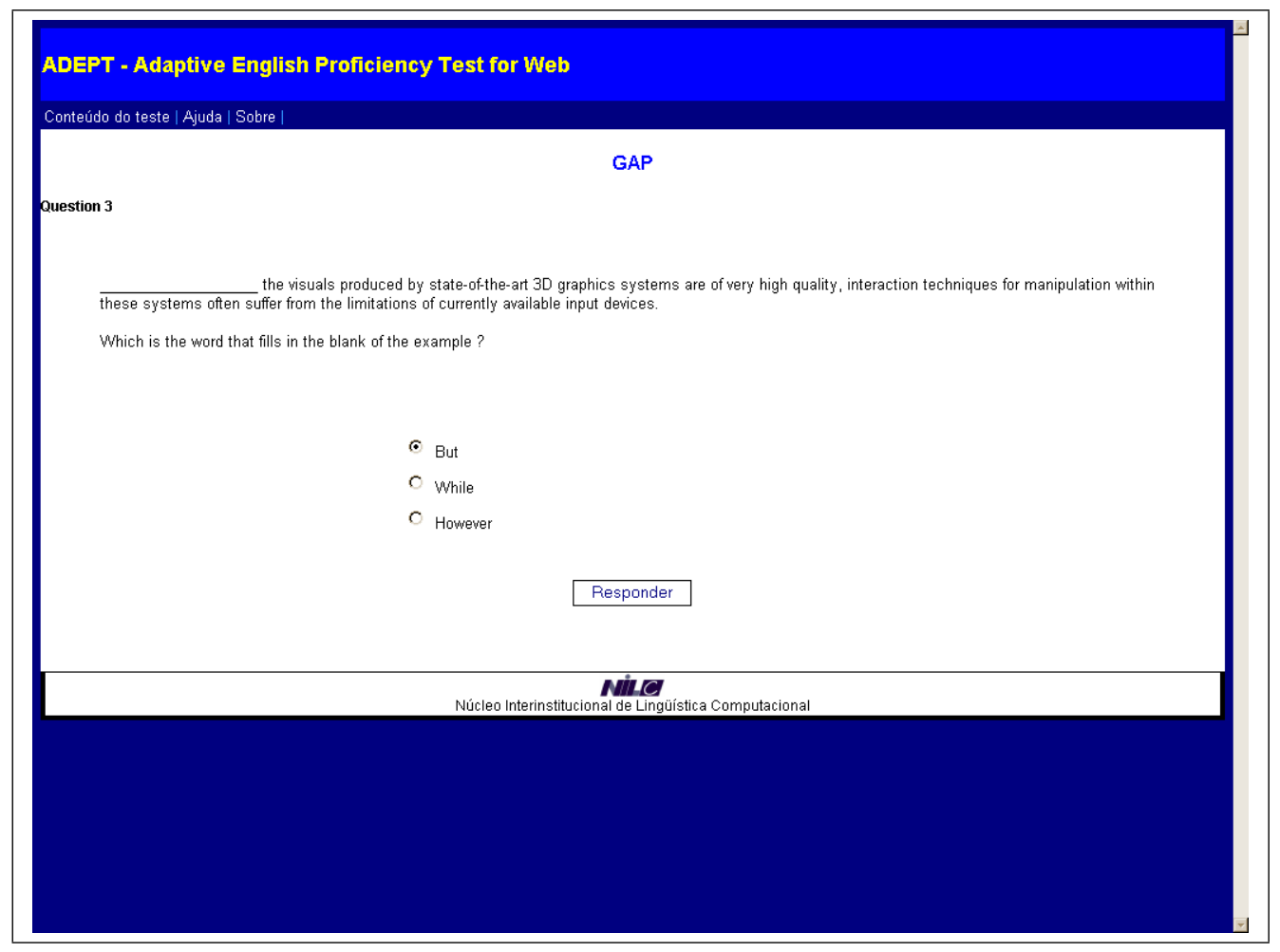

Figura 6.3: Tela de uma questão do ADEPT da Parte Gap. 


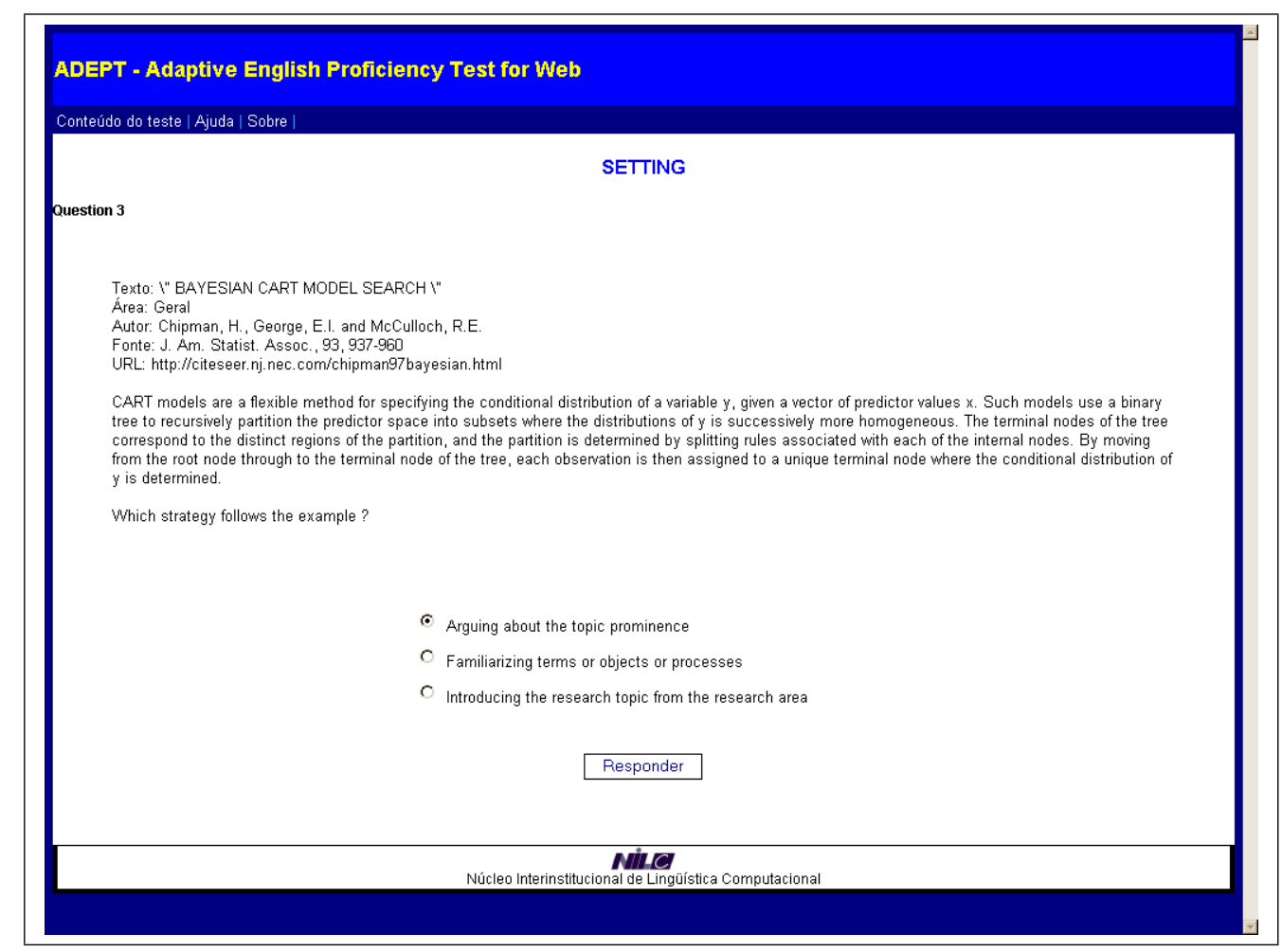

Figura 6.4: Tela de uma questão do ADEPT da Parte Setting.

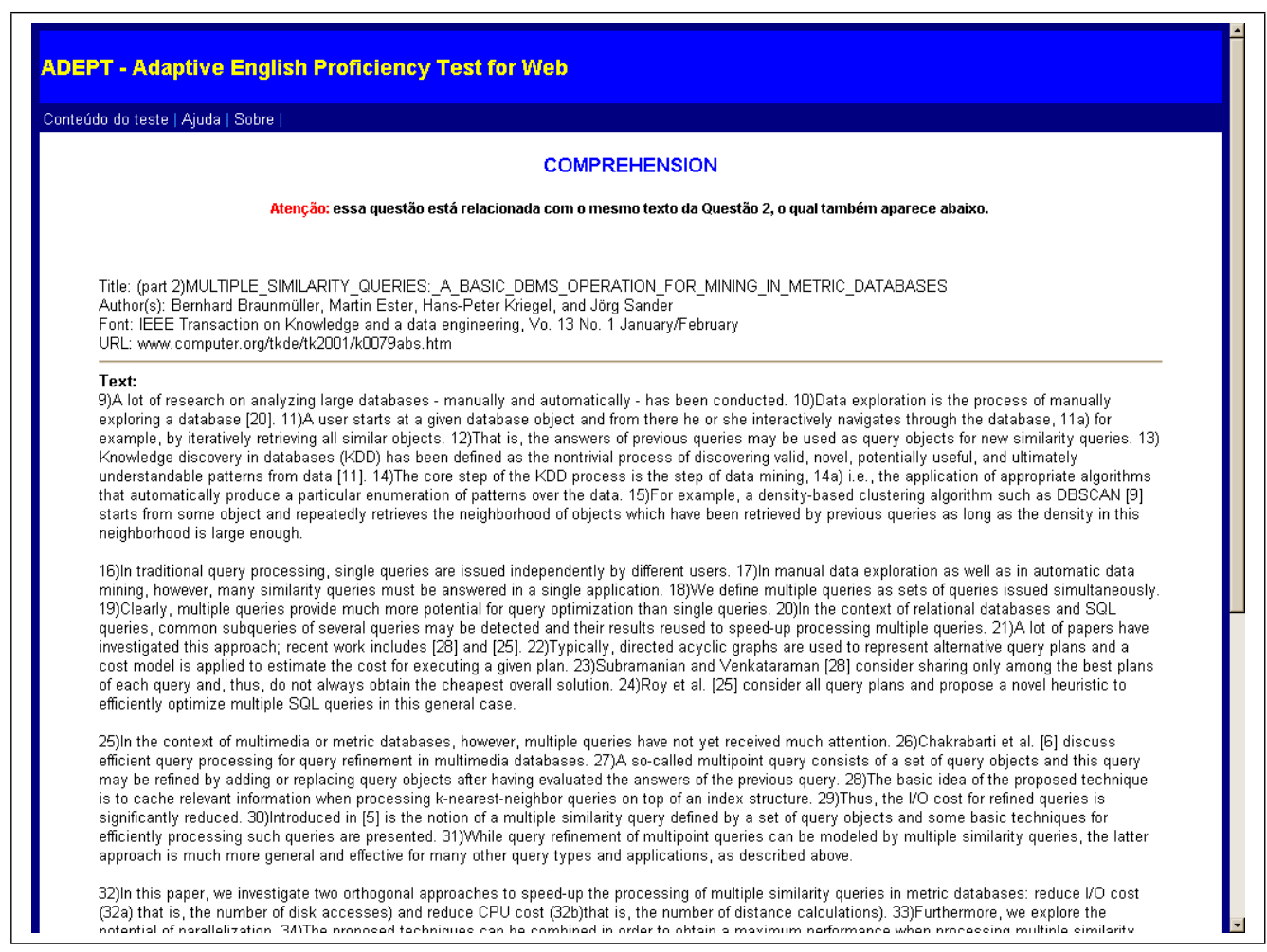

Figura 6.5: Tela de uma questão do ADEPT da Parte Comprehension. 


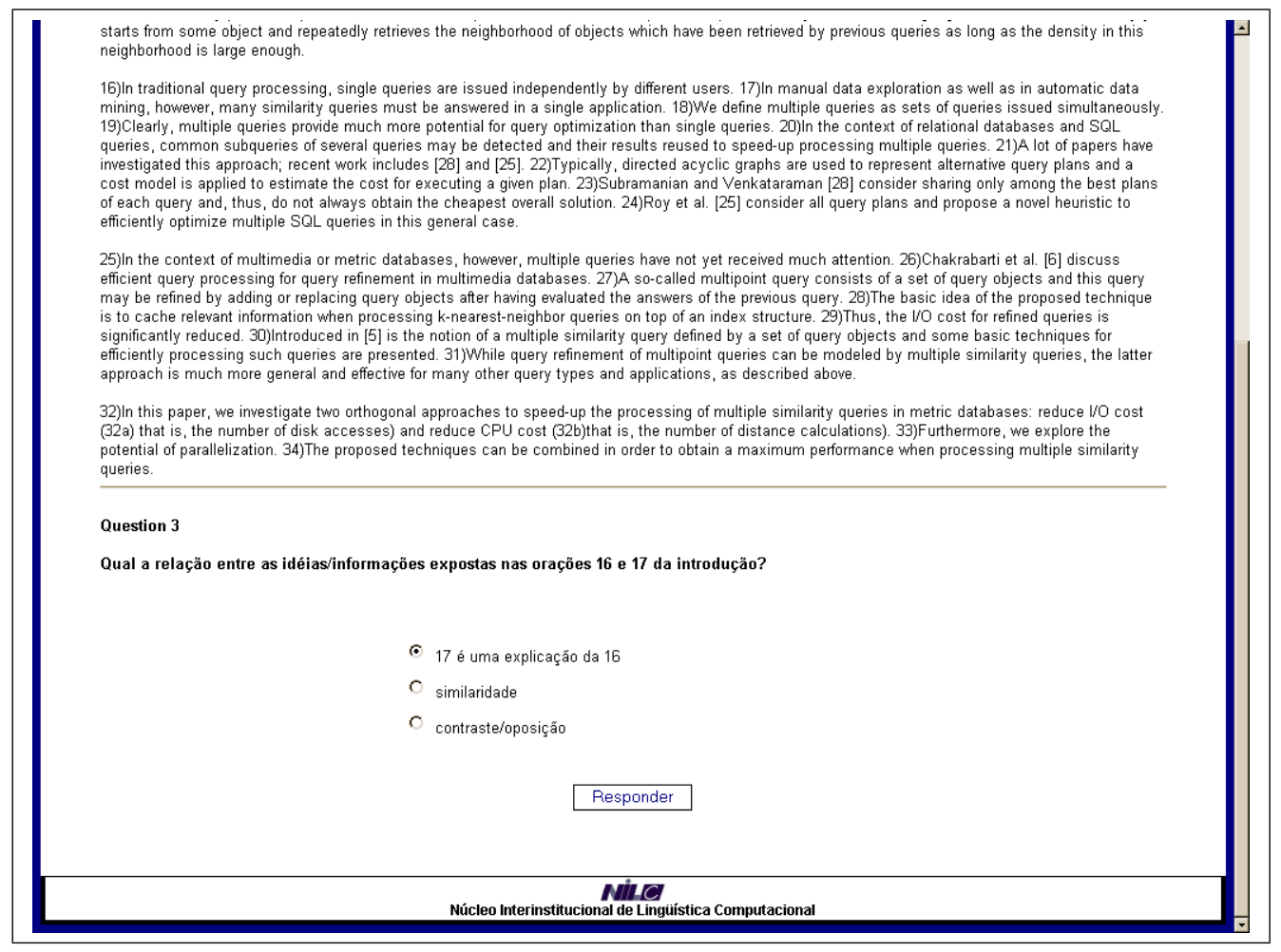

Figura 6.6: Continuação da tela de uma questão do ADEPT da Parte Comprehension.

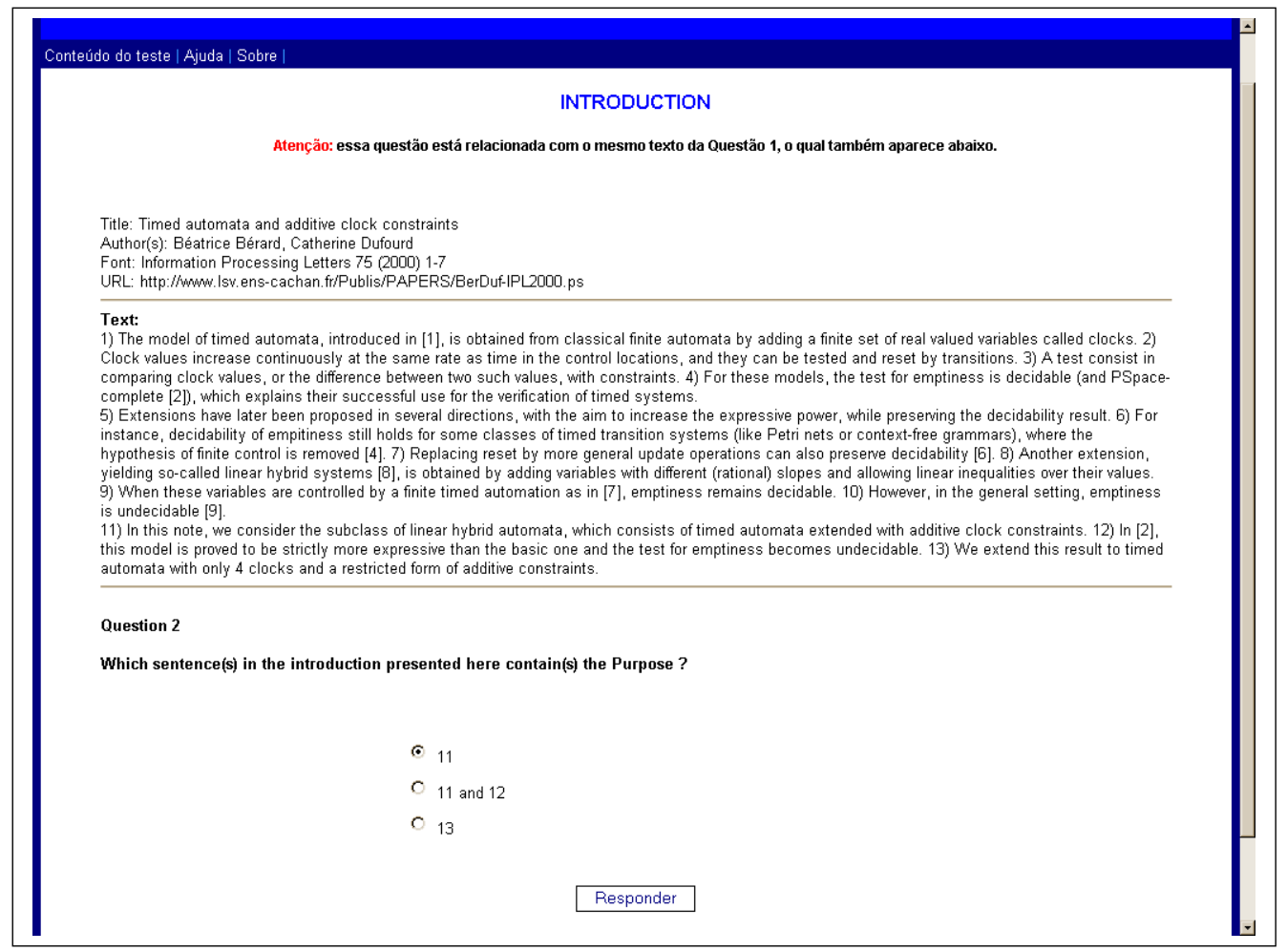

Figura 6.7: Tela de uma questão do ADEPT da Parte Introduction. 
Todas as questões inseridas no BI foram extraídas de exames já realizados nos anos anteriores. O EPI do mestrado em Ciências da Computação e Matemática Computacional do ICMC-USP consiste em vários padrões de provas. Tais padrões indicam qual Parte entra em uma prova. Por exemplo, a Parte Review of Literature não tem sido muito usado nas provas, em contraste com Introduction e Gap que sempre estão presentes nas provas. A Tabela 6.1 mostra o número de itens na distribuição das Partes de cada Módulo no BI.

Tabela 6.1: Número de questões armazenadas na base de dados do ADEPT.

\begin{tabular}{|c|c|c|}
\hline Módulo & Parte & Número de itens \\
\hline 1 & Gap & 38 \\
\hline 1 & Purpose & 10 \\
\hline 2 & Introduction & 24 \\
\hline 2 & Abstract & 36 \\
\hline 3 & Comprehension & 18 \\
\hline 4 & Setting & 12 \\
\hline 4 & Review of Literature & 2 \\
\hline
\end{tabular}

Para a realização de cada Módulo do EPI adotou-se o parâmetro $\theta=0,0$, ou seja, ao término de cada Módulo o $\theta$ é reiniciado com tal valor, e conseqüentemente inicia-se um novo Módulo.

\subsubsection{Critérios de Parada do Teste}

Uma importante etapa na elaboração e execução de um TAI é o critério de parada (ver Seção 4.1). Foram adotados dois critérios de parada para o ADEPT:

1. Número mínimo de 3 questões e máximo de 6 questões respondidas em cada Módulo do teste;

2. Número mínimo e máximo para o parâmetro $\theta$, estabelecido segundo Baker (2001) respectivamente $-3,0$ e 3,0 .

Foi estabelecido para o teste uma hierarquia nos critérios de parada, sendo priorizado o número mínimo de questões realizadas pelo aluno por Módulo. Ou seja, quando um aluno obtiver um valor $\theta \leq-3,0$ ou $\theta \geq 3,0$, porém ainda não atingiu um número mínimo de questões respondidas no Módulo, este não encerrará até que seja atingido o mínimo de questões respondidas. 


\subsubsection{Cálculo da Nota Final do Aluno}

O parâmetro $\theta$ é calculado segundo os resultados parciais $\theta_{1}, \theta_{2}, \theta_{3}$ e $\theta_{4}$, que pertencem respectivamente ao Módulo 1, Módulo 2, Módulo 3 e Módulo 4. A partir dos valores parciais obtidos em cada Módulo do teste, obtém-se o $\theta$ segundo a seguinte equação:

$$
\theta=\theta_{1} * 0,15+\theta_{2} * 0,30+\theta_{3} * 0,30+\theta_{4} * 0,25
$$

regida por pesos de cada Módulo do EPI, mostrados na Tabela 6.2.

Tabela 6.2: Peso de cada módulo para o TAI.

\begin{tabular}{|l|l|}
\hline Módulo 1 & $15 \%$ \\
\hline Módulo 2 & $30 \%$ \\
\hline Módulo 3 & $30 \%$ \\
\hline Módulo 4 & $25 \%$ \\
\hline
\end{tabular}

Os Módulos 2 e 3 do EPI possuem um peso maior, pois envolvem a leitura de uma seção de um artigo científico. O Módulo 2 é também o que possui maior peso no cálculo da pontuação formal do EPI do ICMC-USP, pelo sistema CAPTEAP.

\subsection{Alterações Realizadas no CBAT-2}

O algoritmo CBAT-2 é parte de um TAI em que há uma autocalibração dos itens da base. O artigo de Huang (1996a) descreve o CBAT-2 muito sucintamente, ou seja, há somente algumas fórmulas e citações de fórmulas de outros autores. Por isso, fez-se necessária uma imersão e plena compreensão de cada fórmula envolvida com o CBAT-2. Para isso, fez-se leituras dos estudos de Lord (1980) e Baker (2001). A seções seguintes mostram as escolhas e alterações realizadas para o CBAT-2 apresentado em Huang (1996a) e Huang (1996b). O projeto do algoritmo do CBAT-2 encontra-se no ApêndiceA.

\subsubsection{Seleção dos Itens no ADEPT}

Para a seleção de um item, primeiramente calcula-se a FII (Seção 4.7) do ML3P com $D=$ 1,7 (Seção 4.4.3). Após calculado o valor de $I_{i}(\theta)$ para cada $i$-ésima questão, busca-se o maior valor calculado $\left(I_{i}(\theta)=\max \right)$ e seleciona-se a $i$-ésima questão associada. Considerouse $\Upsilon_{i}=1$ (Seção 4.8.1), pois as questões do BI têm o mesmo peso. Além da busca pelo $I_{i}(\theta)=\max$, pode-se selecionar um item a partir de uma seleção aleatória em um intervalo de valores. 


\subsubsection{Estimativa da Habilidade do Aluno}

Huang (1996b) sugere a estimativa do parâmetro $\theta$ (habilidade do aluno) segundo o Método Bayesiano (Owen (1975) apud Huang (1996b)), que é um método analítico de calibração. Porém, sabe-se que implementar métodos analíticos pode ser uma tarefa difícil e cara, por isso utilizou-se o método numérico método de Newton-Raphson iterativo modificado (ver Seção Seção 4.6 do Capítulo 4).

\subsubsection{Expansão do ADEPT}

No projeto do ADEPT foi considerado o fator expansão do sistema, ou seja, futuramente poderá haver a necessidade de inserir novas Partes do EPI ou mesmo mais questões para o BI. Para isso, basta acrescentar no BI as instruções sobre as novas Partes e as questões associadas. O ADEPT permite o máximo de 9999 questões, de 9 Módulos e de 9 Partes por cada Módulo, pois existe uma função no código que compõe, a partir de outros números, um único número que poderá ser até 9999.

\subsection{Experimentos Realizados com o ADEPT}

Foram realizados dois experimentos com dois grupos específicos de alunos de mestrado do programa de Ciências da Computação e Matemática Computacional do ICMC-USP, que ingressam na instituição nos anos de 2002 e 2003. Os principais objetivos da realização dos experimentos no TAI são: obter uma calibração inicial dos parâmetros dos itens do BI, levantar algumas conjeturas acerca da realização de TI's e seus pontos positivos e negativos, obter dados numéricos para uma análise do comportamento de funções e equações inerentes ao CBAT-2 e ao ML3P. Os dados foram obtido e analisados com a precisão de 6 casas decimais.

O Experimento 1 (EXP1) foi realizado com alunos de mestrado reprovados no EPI do ICMC-USP no primeiro semestre de 2003. Já o Experimento 2 (EXP2) foi realizado em um momento posterior ao EXP1 com alunos de mestrado aprovados no EPI. Ressalta-se aqui que os alunos que realizaram o EXP1 não realizaram o EXP2, e vice-versa.

O teste ficou disponível por um período de cinco dias, nos quais foi possível a sua realização em qualquer horário do dia, flexibilizando o horário do teste para o aluno. Os detalhes sobre os dados analisados e resultados de ambos experimentos estão em Gonçalves \& Aluísio (2004). Para a convocação dos alunos, foram remetidas cartas de solicitação (onde $X$ e $Y$ são respectivamente as datas inicial e final, que variam conforme as datas estipuladas para cada experimento) para a realização do TAI. 


\section{Carta de solicitação de colaboração voluntária para um experimento científico}

$\mathrm{Eu}$, Jean Piton Gonçalves, aluno de mestrado dessa instituição, venho por meio dessa solicitar uma colaboração voluntária para um experimento científico referente a minha pesquisa.

Parte de minha pesquisa é o desenvolvimento de um Teste Adaptativo Informatizado (TAI) para o aprendizado do inglês instrumental. O TAI é um tipo de teste em que as questões são selecionadas conforme o nível de habilidade estimado do aluno, ou seja, a próxima questão a ser selecionada depende da resposta dada a anterior, com isso, temos um teste individualizado.

O teste adaptativo poderá ser acessado no endereço http://www.nilc.icmc.usp.br/capteap/ clicando o botão "Teste Adaptativo Informatizado", podendo ser realizado a partir das 12:00h do dia $X$ até as 12:00h do $Y$. O tempo de teste é variável; o número de questões do teste depende do seu desempenho durante a realização do teste (em um intervalo de 12 a 24 questões). O assunto englobado no teste é o mesmo da prova de proficiência em inglês do ICMC, podendo ser considerado como preparatório para esse exame.

Ressalto que para a análise dos dados, será mantido o anonimato.

Para participar desse experimento, envie um e-mail para jpiton@icmc.usp.br com as seguintes características:

Cabeçalho da mensagem: quero participar do Teste Adaptativo

Corpo da mensagem: coloque seu numero USP

Atenção: uma vez acessado o teste nas datas estipuladas, o mesmo não poderá ser acessado novamente, ou seja, tem-se apenas uma única oportunidade para realizar o teste.

Agradeço a colaboração

Atenciosamente

Jean Piton Gonçalves

Cada questão do BI é composto por por seis parâmetros, sendo eles:

- $a, b, c$ são respectivamente os parâmetros discriminação, dificuldade e adivinhação da TRI, que foram descritos na Seção 4.3.1.

- $W, R$ são respectivamente o número de respostas incorretas e corretas de todos os alunos que realizaram a questão (ver Seção 4.8.2);

- $\Phi$ é a dificuldade acumulada na questão (ver Seção 4.8.2).

Para efeitos de análise, foi calculada a nota média ( $\overline{n t}$ ), que representa a média aritmética das notas do grupo de alunos que realizaram um teste, dada pela fórmula: 


$$
\overline{n t}=\sum_{i=1}^{n} \frac{n t_{i}}{n}
$$

onde $n t_{i}$ é a nota do $i$-ésimo aluno e $n$ é o número de alunos do grupo.

\subsubsection{Experimento Número 1}

O EXP1 foi realizado no período de 15 a 19 de setembro de 2003, com 12 alunos de mestrado do programa de Ciências da Computação e Matemática Computacional do ICMC-USP que foram reprovados no EPI do primeiro semestre de 2003. A sequiência da apresentação dos Módulos do EPI, com suas respectivas partes, ao aluno foram: Módulo 2, Módulo 3, Módulo 4 e Módulo 1. A Figura 6.8 mostra tal seqüência.

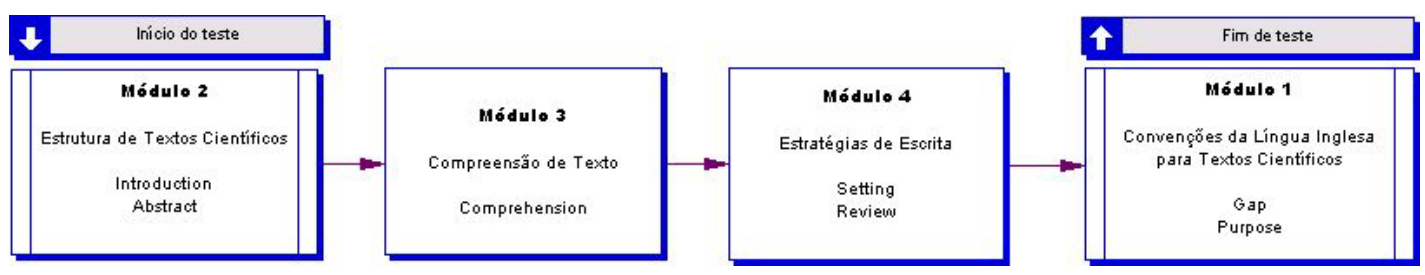

Figura 6.8: Seqüência de apresentação dos Módulos do EPI ao usuário no experimento 1.

Anterior à realização do experimento, a orientadora da pesquisa de mestrado e idealizadora do EPI automatizado do ICMC-USP Prof ${ }^{a}$ Dr $^{a}$ Sandra Maria Aluísio, estimou o parâmetro $b$ inicial das 140 questões a serem inseridas no BI. Para classificar o parâmetro $b$, o especialista (orientadora) dividiu as questões em quatro classes hierárquicas: difícil, médio, fácil e muito fácil, conforme Tabela 6.3 .

Tabela 6.3: Tabela das classes do parâmetro $b$.

\begin{tabular}{|c|c|}
\hline Classe & Parâmetro $b$ \\
\hline Difícil & 2,5 \\
\hline Médio & 1,0 \\
\hline Fácil & $-1,0$ \\
\hline Muito Fácil & $-2,5$ \\
\hline
\end{tabular}

Para a referida classificação, considera-se a experiência do especialista, com $-3,0 \leq b \leq$ 3,0 . 


\section{Análise dos Itens da Base do Experimento 1}

No EXP1, foram calibradas 51 questões, sendo atualizados apenas os parâmetros $b, W, R$ e $\Phi$. Os parâmetros $a$ e $c$ são fixados respectivamente em 1,200000 e 0,333333 (ver Seção 4.8), portanto não sofreram calibração. A Tabela 6.4 mostra o número de questões calibradas por Módulo.

Tabela 6.4: Quantidade de questões calibradas por Módulo e Parte no experimento 1.

\begin{tabular}{|c|c|c|}
\hline Módulo & Parte & Calibradas \\
\hline 1 & Gap & 17 \\
\hline 1 & Purpose & 0 \\
\hline 2 & Introduction & 10 \\
\hline 2 & Abstract & 2 \\
\hline 3 & Comprehension & 12 \\
\hline 4 & Setting & 10 \\
\hline 4 & Review of Literature & 0 \\
\hline
\end{tabular}

Para as partes Purpose e Review of Literature não houve nenhuma questão calibrada, porque as questões foram classificadas com dificuldade média (Classe Médio), e como os alunos iniciavam o teste com questões da Classe Fácil, então não puderam nesse experimento receber tais questões. Houve 12 questões em que a calibração acarretou o acréscimo do parâmetro $b$ e 39 questões sofreram decréscimo. As questões número de 147 e 148 tiveram 9 acessos, sendo esse valor o máximo de acessos em uma questão; por outro lado houve 16 questões com apenas 1 acesso cada. Houve 89 questões que não sofreram nenhum acesso, portanto, não houve calibração de nenhum parâmetro. As questões número 62, 63, 64, 126, 127 inicialmente estimadas na Classe Difícil foram calibradas, apresentando decréscimo em $b$.

Para efeitos de análise, as questões número 2, 30, 54 e 62 (ver Tabela 6.5) apresentam uma calibração numericamente considerável. Considerando a diferença absoluta entre o parâmetro $b$ das questões iniciais e calibradas, todas as questões sofreram mudanças quanto à sua classe de dificuldade, ou seja, as questões número 2 e 30 tiveram seu parâmetro $b$ acrescidos em relação a $\omega_{0}$ ( $b$ da base inicial) e as questões de número 54 e 62 sofreram decréscimo em $b$. Certamente que os parâmetros $W, R$ e $\Phi$ influenciaram nessas mudanças, porém não pode-se dizer ou mesmo estabelecer uma relação "linear", isto é, dizer que o valor $\Phi$ da questão 30 é maior, e por isso houve acréscimo. Se assim fosse, a questão 62 sofreria acréscimo e não decréscimo. Observando-se os valores obtidos para o parâmetro $\Phi$, vemos que, embora a questão esteja calibrada, o valor de $\Phi=0$.

Isso é decorrente da forma como é calculado o valor $\Phi$, que incrementa valores caso o aluno forneça uma resposta incorreta à questão, ou permanece inalterado caso o aluno forneça uma resposta correta. Nas questões do BI que apresentam tal fato, temos $W=0$ e $R \geq 1$. 
Por isso é importante destacar que o comportamento da calibração dos itens não pode ser focado ou atribuído à um parâmetro especificamente, mas sim à um grupo de parâmetros que conjuntamente contribuem para re-estimar $b$ a cada vez que a questão é respondida. Além disso, o parâmetro $\theta$ e a resposta do aluno à questão (correta ou incorreta) também estão contidos na calibração do $b$.

Tabela 6.5: Diferença absoluta entre o parâmetro $b$ das questões iniciais e calibradas no experimento 1 .

\begin{tabular}{|c|c|c|c|}
\hline ID da questão & $\omega_{0}$ & $b$ & Diferença absoluta \\
\hline 2 & $-2,5$ & $-2,300260$ & 0,199740 \\
\hline 54 & -1 & $-2,246780$ & 1,246780 \\
\hline 30 & 1 & 1,730950 & 0,730950 \\
\hline 62 & 2,5 & 2,005210 & 0,494790 \\
\hline
\end{tabular}

Um fato importante do TAI baseado no CBAT-2 é que para a seleção da próxima questão ao aluno, leva-se apenas em consideração os parâmetros $\omega_{0}$ e $\theta$. Portanto, os parâmetros $W, R$ e $\Phi$ contribuem somente para a estimativa do novo parâmetro dificuldade $b$.

\section{Análise dos Alunos do Experimento 1}

Foram extraídos alguns dados sobre cada aluno: tempo de teste (em horas), o parâmetro $\theta$, nota final normalizada na escala de 0,00 a 10,00 , número de questões respondidas $(n q)$ pelo aluno no teste. A Tabela 6.6 mostra os resultados obtidos de cada aluno, aqui denotado por $A X$ (aluno $X$ ). Por exemplo, o $A 1$ foi o primeiro aluno que realizou o teste e o $A 5$ foi o quinto aluno que realizou o teste. 
Tabela 6.6: Dados de cada aluno no experimento 1 .

\begin{tabular}{|c|c|c|c|c|}
\hline aluno & $\theta$ & nota final & tempo de teste & nq \\
\hline A1 & $-2,179950$ & 1,37 & $0: 56$ & 23 \\
\hline A2 & 0,113540 & 5,19 & $0: 34$ & 19 \\
\hline A3 & $-2,063260$ & 1,56 & $0: 33$ & 19 \\
\hline A4 & $\mathbf{- 2 , 6 5 7 8 5 0}$ & $\mathbf{0 , 5 7}$ & $\mathbf{0 : 1 7}$ & $\mathbf{1 7}$ \\
\hline A5 & $\mathbf{0 , 8 9 0 1 2 4}$ & $\mathbf{6 , 4 8}$ & $\mathbf{2 : 0 4}$ & $\mathbf{2 3}$ \\
\hline A6 & $-2,145110$ & 1,42 & $0: 34$ & 18 \\
\hline A7 & $-0,345111$ & 4,42 & $0: 38$ & 19 \\
\hline A8 & $-1,222150$ & 2,96 & $0: 33$ & 15 \\
\hline A9 & $-0,479210$ & 4,20 & $0: 29$ & 22 \\
\hline A10 & 0,449445 & 5,75 & $0: 55$ & 18 \\
\hline A11 & 0,559544 & 5,93 & $0: 58$ & 22 \\
\hline A12 & $\mathbf{- 0 , 5 4 1 6 8 7}$ & $\mathbf{4 , 1 0}$ & $\mathbf{1 : 0 3}$ & $\mathbf{2 4}$ \\
\hline
\end{tabular}

Da Tabela 6.6 selecionou-se três alunos ( $A 4, A 5$ e $A 12)$ para uma análise de seus resultados. Esses alunos são classificados segundo seus níveis de conhecimento obtidos pela nota no teste, que são maior nota, nota média (calculada em 3,66, ver fórmula 6.2) e menor nota - respectivamente os alunos $A 5, A 12$ e $A 4$. A Tabela 6.7 mostra os parâmetros $\theta$ parciais, ou seja, o parâmetro habilidade ao final de cada Módulo. Observa-se que o $A 5$ teve dificuldades na realização do teste no Módulo 3, e que o $A 4$ teve dificuldades nos Módulos 2, 3, e 4. O $A 12$ teve dificuldades ao realizar o Módulo 4. O melhor resultado foi o $A 5$ no Módulo $2 \operatorname{com} \theta$ máximo.

Tabela 6.7: Dados dos alunos 5, 12 e 4 no experimento 1 .

\begin{tabular}{|l|c|c|c|}
\hline & $A 5$ & $A 12$ & $A 4$ \\
\hline Módulo 1 - $\theta_{1}$ & 1,793640 & 0,161365 & $-0,718999$ \\
\hline Módulo 2 $-\theta_{2}$ & 3,000000 & 0,812209 & $-3,000000$ \\
\hline Módulo 3 - $\theta_{3}$ & $-2,257890$ & -0.893115 & $-3,000000$ \\
\hline Módulo 4 - $\theta_{4}$ & 1,713780 & $-2,166480$ & $-3,000000$ \\
\hline Final - $\theta$ & 0,890124 & $-0,541687$ & $-2,657850$ \\
\hline Nota final [0-10] & 6,48 & 4,10 & 0,57 \\
\hline Questões respondidas & 23 & 24 & 17 \\
\hline
\end{tabular}

Os valores máximos e mínimos do teste são apresentados na Tabela 6.8. Por exemplo, a maior nota $(6,48)$ foi do aluno $A 5$ que teve o maior tempo de teste $(2: 04 \mathrm{~h})$ e o menor tempo de teste foi do $A 4(0: 17 \mathrm{~h})$ que teve a menor nota $(0,57)$. 
Tabela 6.8: Valores máximos e mínimos do teste referentes aos alunos envolvidos no experimento 1 .

\begin{tabular}{|l|c|}
\hline Maior nota & 6,48 \\
\hline Menor nota & 0,57 \\
\hline Maior tempo de teste & $2: 04 \mathrm{~h}$ \\
\hline Menor tempo de teste & $0: 17 \mathrm{~h}$ \\
\hline Maior número de questões respondidas & 24 \\
\hline Menor número de questões respondidas & 15 \\
\hline
\end{tabular}

\subsubsection{Experimento Número 2}

O EXP2 foi realizado no período de 25 a 30 de setembro de 2003 em diferentes horários, por 9 alunos aprovados no EPI para o mestrado de Ciências Matemáticas e Matemática Computacional do ICMC-USP. A seqüencia da apresentação dos Módulos ao aluno foram: Módulo 1, Módulo 2, Módulo 4 e Módulo 3. A Figura 6.9 mostra tal sequiencia, que sofreu uma mudança em relação ao EXP1, justificada na Seção 6.3.3. A base de itens selecionada para a realização do EXP2 é a base anteriormente calibrada no EXP1.

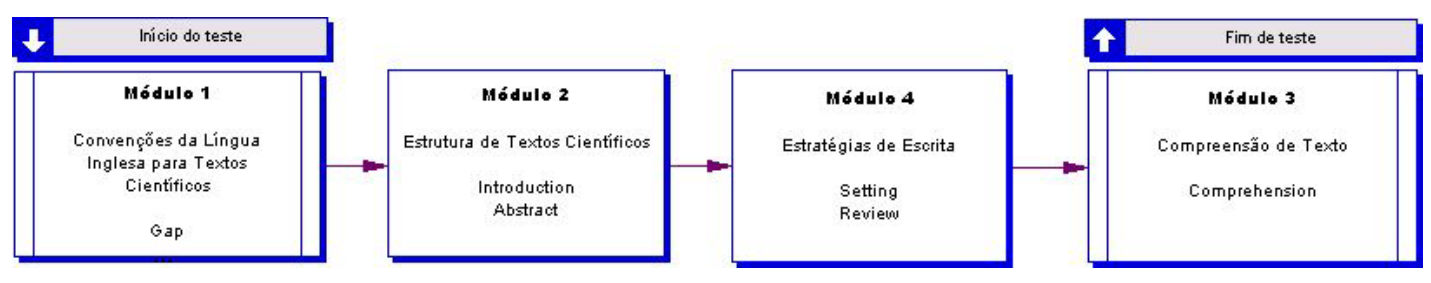

Figura 6.9: Seqüência de apresentação dos Módulos do EPI ao usuário no experimento 2.

\section{Análise dos Itens da Base do Experimento 2}

O EXP2 apresentou 57 questões calibradas estritamente nesse experimento, e três situações de calibração:

1. 33 questões foram calibradas primeiramente no EXP1 e a seguir no EXP2;

2. 15 questões foram calibradas no EXP2 mas não estavam calibradas no EXP1;

3. 9 questões foram calibradas apenas no EXP1.

De fato, esperou-se que algumas questões fossem recalibradas, outras calibradas pela primeira vez e algumas apenas calibradas no EXP1. Em termos da calibração dos itens, foram modificados apenas os parâmetros $b, W, R$ e $\Phi$, pois $a$ e $c$ são fixos. Houve 19 itens da base de questões que sofreram um acréscimo no parâmetro $b$, e outros 38 um decréscimo. 
Tabela 6.9: Quantidade de questões calibradas por Módulo e Parte no experimento 2.

\begin{tabular}{|c|c|c|}
\hline Módulo & Parte & Calibradas \\
\hline 1 & Gap & 16 \\
\hline 1 & Purpose & 4 \\
\hline 2 & Introduction & 10 \\
\hline 2 & Abstract & 4 \\
\hline 3 & Comprehension & 10 \\
\hline 4 & Setting & 12 \\
\hline 4 & Review of Literature & 1 \\
\hline
\end{tabular}

As questões que foram mais acessadas foram 138, 139 e 51 contabilizadas em 9 acessos cada. Por outro lado, 16 questões contabilizaram 1 acesso durante o decorrer do experimento EXP2. Em 83 questões não foi contabilizado nenhum acesso. As questões número 62, 63, 64 estimadas próximo da Classe Difícil foram calibradas. Com isso, nota-se um decréscimo em $b$ que ocasionou na mudança das questões número 62 e 64 para valores próximos da Classe Médio (tabelas com detalhes dos valores de $b$ estão em Gonçalves \& Aluísio (2004)).

Verificando o parâmetro $b$ de alguns itens, as questões número 51 e 63 apresentam uma diferença absoluta considerável, que acarretou uma mudança na classe do parâmetro $b$ (ver Tabela 6.10), obtendo um decréscimo no valor de $b$ em relação à base inicial.

Tabela 6.10: Diferença absoluta entre o parâmetro $b$ do experimento $1\left(\omega_{0}\right)$ e experimento $2(b)$.

\begin{tabular}{|c|c|c|c|}
\hline ID da questão & $\omega_{0}$ & $b$ & Diferença absoluta \\
\hline 51 & $-1,201540$ & 0,125059 & 1,326599 \\
\hline 62 & 2,005210 & 0,557256 & 1,447954 \\
\hline 63 & 2,123130 & 2,146500 & 0,023370 \\
\hline
\end{tabular}

\section{Análise dos Alunos no Experimento 2}

A Tabela 6.11 mostra os dados de cada aluno no EXP2 de onde selecionou-se três alunos para análise de seus resultados. Os alunos são classificados segundo seus níveis de conhecimento obtidos pela nota no teste, que são maior nota, nota média (calculada em 4,08 , ver fórmula 6.2) e menor nota - respectivamente os alunos $A 2, A 4$ e $A 6$.

A Tabela 6.12 mostra os parâmetros $\theta$ parciais, ou seja, o parâmetro habilidade ao final de cada Módulo. O $A 2$ obteve um $\theta$ máximo nos Módulos 1, 2 e 3 do EPI, e o $A 4$ nos Módulos 1 e 2. Um outro fato é que o todos os três tiveram dificuldades na realização do Módulo 4 EPI.

Os valores máximos e mínimos do teste são apresentados na Tabela 6.13. Por exemplo, a maior nota foi do aluno $A 2(8,94)$ e o maior tempo de teste foi do $A 3(0: 56 \mathrm{~h})$. 
Tabela 6.11: Dados de cada aluno no experimento 2 .

\begin{tabular}{|c|c|c|c|c|}
\hline aluno & $\theta$ & nota final & tempo de teste & nq \\
\hline A1 & $-0,770247$ & 3,72 & $0: 19$ & 18 \\
\hline A2 & $\mathbf{2 , 3 6 1 5 5 0}$ & $\mathbf{8 , 9 4}$ & $\mathbf{0 : 2 0}$ & $\mathbf{2 0}$ \\
\hline A3 & $-1,658780$ & 2,24 & $0: 56$ & 20 \\
\hline A4 & $\mathbf{0 , 2 6 6 3 9 2}$ & $\mathbf{5 , 4 4}$ & $\mathbf{0 : 1 9}$ & $\mathbf{1 9}$ \\
\hline A5 & $-0,653473$ & 3,91 & $0: 24$ & 22 \\
\hline A6 & $\mathbf{- 2 , 1 5 7 5 6 0}$ & $\mathbf{1 , 4 0}$ & $\mathbf{0 : 1 3}$ & $\mathbf{1 8}$ \\
\hline A7 & 0,973298 & 6,62 & $0: 19$ & 19 \\
\hline A8 & $-1,491180$ & 2,51 & $0: 15$ & 18 \\
\hline A9 & $-1,843630$ & 1,93 & $0: 19$ & 21 \\
\hline
\end{tabular}

Tabela 6.12: Dados dos alunos 2, 4 e 6 no experimento 2 .

\begin{tabular}{|l|c|c|c|}
\hline & $A 2$ & $A 4$ & $A 6$ \\
\hline Módulo $1-\theta_{1}$ & 3,000000 & 3,000000 & 0,368940 \\
\hline Módulo $2-\theta_{2}$ & 3,000000 & 3,000000 & $-3,000000$ \\
\hline Módulo 3 $-\theta_{3}$ & 3,000000 & $-3,000000$ & $-1,876330$ \\
\hline Módulo 4 $-\theta_{4}$ & 0,446207 & $-0,734432$ & $-3,000000$ \\
\hline Global - $\theta$ & 2,361550 & 0,266392 & $-2,157560$ \\
\hline Nota final $[0,10]$ & 8,94 & 5,44 & 1,40 \\
\hline Questões respondidas & 20 & 19 & 18 \\
\hline
\end{tabular}

Tabela 6.13: Valores máximos e mínimos do teste referentes aos alunos envolvidos no experimento 1 .

\begin{tabular}{|l|c|}
\hline Maior nota & 8,94 \\
\hline Menor nota & 1,40 \\
\hline Maior tempo de teste & $0: 56 \mathrm{~h}$ \\
\hline Menor tempo de teste & $0: 13 \mathrm{~h}$ \\
\hline Maior número de questões respondidas & 22 \\
\hline Menor número de questões respondidas & 18 \\
\hline
\end{tabular}

\subsubsection{Resultados Comparativos - Experimentos Número 1 e 2}

Nessa seção, apresenta-se uma análise comparativa entre o EXP1 e EXP2, em termos das questões da base e dos alunos frente ao TAI, considerando as mudanças na seqüencia de exposição dos Módulos do EPI, do EXP1 para o EXP2. Isso deve-se o diagrama de conteúdo do EPI (Figura 6.10). Esse mostra que Introduction engloba todos os outros conteúdos, que Comprehension engloba Gap e Purpose, Setting e Review of Literature. A mudança na seqüencia da 
avaliação buscou avaliar as implicações entre iniciar por um conteúdo mais "complexo" ou por um mais "simples". As Partes Setting e Review of Literature, Gap e Purpose são componentes da estrutura de uma introdução. Dessa forma se um aluno compreende e acerta a questão sobre Introduction implica que compreendeu seus componentes constituintes. Já Comprehension avalia os marcadores discursivos que, estando presentes em uma introdução, estão relacionados com as partes Setting e Review of Literature, Gap e Purpose, embora essas últimas avaliem outro tipo de habilidade.

O Módulo 2 do EPI é considerado complexo, pois exige a leitura de um texto longo (uma introdução) e a tarefa relacionada a ele é da classe de "Análise" que é a quarta em dificuldade das seis categorias da Taxonomia de Bloom (Aquino, 2001). Já o Módulo 1 que inicia o EXP2 é classificado de "Conhecimento" que é aquele que exige o menor grau de habilidade na Taxonomia.

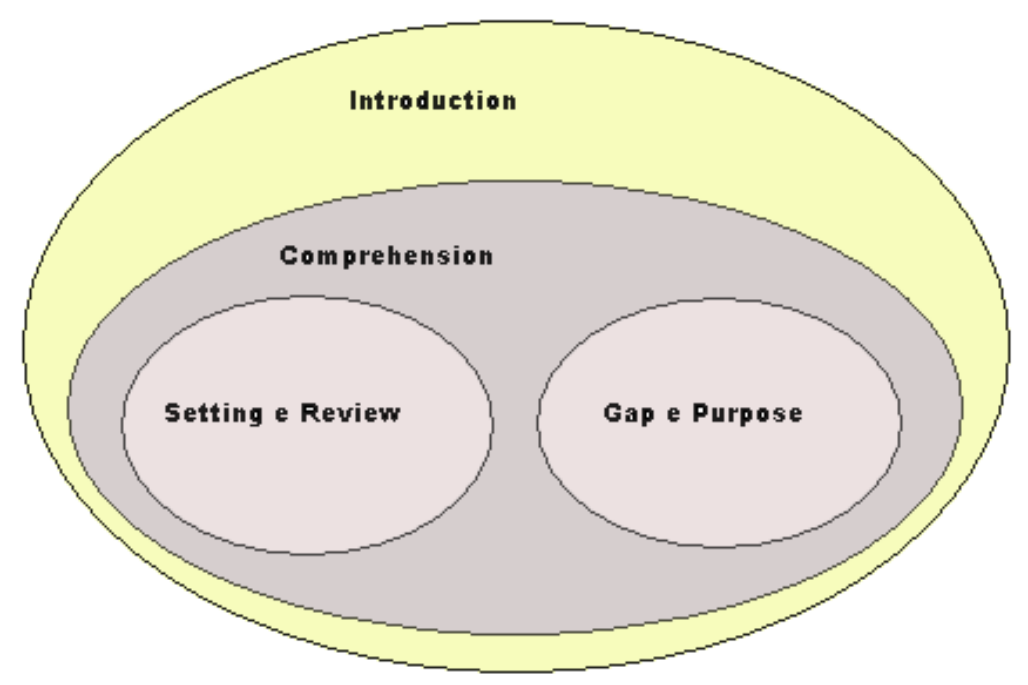

Figura 6.10: Diagrama de conteúdo do EPI.

\section{Análise dos Itens da Base}

Um dado importante a ser considerado é o número de questões calibradas por Módulo do EPI. No EXP2 foram calibradas algumas questões das Partes Purpose e Review of Literature (ver Tabela 6.9), que no EXP1 não haviam sido calibradas (ver Tabela 6.4). No EXP2 completou-se a calibração de todas as Partes.

Na Tabela 6.14 apresenta-se as questões em que as respostas foram unânimes quanto ao número de corretas e incorretas. As questões de número 14, 131 e 149 foram respondidas corretamente, não apresentando nenhuma resposta incorreta; e por outro lado, as questões número 57 e 133 têm todas as questões respondidas incorretamente pelos alunos. 
Tabela 6.14: Questões que os alunos responderam totalmente corretas e totalmente incorretas. $\omega_{0}$ é o $b$ inicial, anterior ao experimento 1 .

\begin{tabular}{|c|c|c|c|c|c|}
\hline ID da questão & $\omega_{0}$ & $b$ & Incorretas & Corretas & $\Phi$ \\
\hline 14 & 1,000000 & $-1,455650$ & 0 & 6 & 0,000000 \\
\hline 131 & $-1,000000$ & $-2,227830$ & 0 & 6 & 0,000000 \\
\hline 149 & $-1,000000$ & $-2,954100$ & 0 & 13 & 0,000000 \\
\hline 57 & 1,000000 & 1,595630 & 2 & 0 & 2,835490 \\
\hline 133 & 1,000000 & 1,200680 & 1 & 0 & 1,369060 \\
\hline
\end{tabular}

Os valores do parâmetro dificuldade obtidos segundo a Tabela 6.14 são procedentes com a proposta de calibração, ou seja, nota-se que as questões número 14, 131 e 149, que foram inicialmente estimadas, respectivamente, como Classes Médio, Fácil e Fácil, somente foram respondidas corretamente pelos alunos, o que propiciou uma queda no parâmetro dificuldade $b$. Já as questões 57 e 133, que respectivamente foram inicialmente estimadas como Classes Fácil e Médio, tiveram o $b$ acrescido devido às respostas incorretas. O valor $\Phi=0$ esta presente nas questões que foram respondidas incorretamente, valor decorrente da função $\Phi$. Desse cenário, extrai-se algumas conjecturas:

- Se a diferença entre o número de vezes que a questão foi respondida corretamente e incorretamente for positiva, então o parâmetro $b$ sofrerá um decréscimo, ou seja, a questão está se tornando cada vez mais "fácil" a medida que os alunos mais acertam que erram a questão;

- Se maior a diferença entre o número de vezes que a questão foi respondida corretamente e incorretamente for negativa, então o parâmetro $b$ sofrerá um acréscimo, ou seja, a questão tende a tornar-se mais "difícil" a medida que os alunos mais erram que acertam a questão.

Um conjunto de dados importante é o número de questões calibradas somando-se o EXP1 com o EXP2, presente na Tabela 6.15. A Tabela 6.16 mostra os resultados globais de ambos experimentos. 
Tabela 6.15: Número de questões calibradas do experimento 1 e experimento 2 por Parte em cada Módulo do EPI.

\begin{tabular}{|c|c|c|}
\hline Módulo & Parte & Calibradas \\
\hline 1 & Gap & 19 \\
\hline 1 & Purpose & 4 \\
\hline 2 & Introduction & 10 \\
\hline 2 & Abstract & 6 \\
\hline 3 & Comprehension & 14 \\
\hline 4 & Setting & 12 \\
\hline 4 & Review of Literature & 1 \\
\hline
\end{tabular}

Tabela 6.16: Resultados globais da base de questões final.

\begin{tabular}{|c|c|}
\hline Total de questões não calibradas & 74 \\
\hline Total de questões calibradas & 66 \\
\hline Total de acessos as questões & 367 \\
\hline Total de acessos às questões no Módulo 1 & 23 \\
\hline Total de acessos às questões no Módulo 2 & 16 \\
\hline Total de acessos às questões no Módulo 3 & 14 \\
\hline Total de acessos às questões no Módulo 4 & 13 \\
\hline
\end{tabular}

\section{Testlets}

O BI do TAI é atualmente composto por 21 testlets, que envolvem 78 questões, sendo 30 calibradas pelo EXP2 e 48 não calibradas. São apresentados na Tabela 6.17 os principais dados sobre os testlets da base, classificados em três grupos de calibração:

Testlet totalmente calibrado: todas as questões envolvidas no testlet foram calibradas;

Testlet parcialmente calibrado: algumas questões envolvidas no testlet foram calibradas;

Testlet não calibrado: nenhuma questão envolvida no testlet foi calibrada.

Tabela 6.17: Dados dos grupos dos testlets no experimento 2 .

\begin{tabular}{|c|c|}
\hline Testlet & Quantidade \\
\hline Totalmente calibrado & 7 \\
\hline Parcialmente calibrado & 3 \\
\hline Não calibrado & 11 \\
\hline Total de testlets & 21 \\
\hline
\end{tabular}

As duplas de questões número 65 e 66, 126 e 127, 140 e 141 pertencem a mesma Classe entre si. Isso confirma a integridade do TAI desenvolvido nessa pesquisa, porque a partir de 
dados iniciais $\omega_{0}, R=0, W=0$ e $\Phi=0$, resultou em um mesmo valor $b$ somente após a primeira calibração. Isto é, nas mesmas condições iniciais os valores para a calibração são os mesmos.

Já as questões número 134 e 135 apresentaram o mesmo cenário, porém na segunda calibração. Isso decorre que o $R=2, W=0$ e $\Phi=0$ para ambas questões, o que garante também o mesmo valor $b$. Conclui-se que, enquanto não existir nenhuma resposta incorreta à questão, e o parâmetro $\omega_{0}=0$, o comportamento citado anteriormente é factível.

Um outro resultado importante é a inalteração do valor de $b$ quando a questão for calibrada, ou seja, a partir do momento que o aluno responde a uma questão, sempre haverá uma mudança no valor do parâmetro $b$, ou para um valor superior ou um valor inferior.

\section{Análise dos Alunos}

Foram analisados nas Seções 6.3.1 e 6.3.2 os testes dos alunos que realizaram respectivamente o EXP1 e EXP2. Embora sejam duas análises estanques, o que diferencia ambos experimentos em termos de avaliação de alunos é terem ou não sido aprovados no EPI do ICMC-USP, pois os dois grupos são alunos do mesmo programa de pós-graduação, submetidos pelo menos uma vez ao exame. Por isso, nessa seção, trataremos dos 21 alunos em um único contexto. A Tabela 6.18 mostra os dados relativos de todos os alunos participantes dos experimentos.

Tabela 6.18: Valores máximos e mínimos do teste referentes aos alunos envolvidos em ambos experimentos.

\begin{tabular}{|l|c|}
\hline Maior nota & 8,94 \\
\hline Menor nota & 0,57 \\
\hline Maior tempo de teste & $2: 04 \mathrm{~h}$ \\
\hline Menor tempo de teste & $0: 13 \mathrm{~h}$ \\
\hline Maior número de questões respondidas & 24 \\
\hline Menor número de questões respondidas & 15 \\
\hline
\end{tabular}

Ao selecionar o grupo de alunos de ambos experimentos, observa-se que os alunos $A 2$ do EXP2 e $A 4$ do EXP1 obtiveram respectivamente o melhor e o pior desempenho. $A 2$ respondeu corretamente todas as questões dos Módulos 1, 2 e 3 do EPI, obtendo o valor máximo $\theta=3$, e no Módulo 4 o aluno respondeu incorretamente a questão número 52, o que resultou em uma queda brusca de seu parâmetro $\theta$, que passou de 0,0 (inicial) para -2,880547. O $A 4$ do EXP1 mostrou um alto índice de respostas corretas somente no Módulo 1, que tem o peso de $15 \%$ (ver Tabela 6.2). No restante dos Módulos, o $A 4$ teve um grande número de respostas incorretas.

O cenário do decréscimo brusco do valor $\theta$, caso o aluno responda incorretamente a primeira questão em um Módulo, é comum a todos os alunos que realizaram o teste. 


\section{Análise entre Alunos e Questões da Base de Dados}

Para o $A 2$ do EXP2, antes de responder a questão número 52, os parâmetros dessa questão tinham os seguintes valores: $b=-0,438870, R=5, W=2$ e $\Phi=1,829450$; e após respondêla, o sistema calibrou para novos valores: $b=-0,564331, R=5, W=3$ e $\Phi=2,829450$. Para essa questão $P(\theta=0)=0,699108$, e isso significa que o aluno tinha uma probabilidade de $69 \%$ de acertar a questão, porém errou e por isso na sua nova estimativa do $\theta$ foi penalizado. Isso causou também decréscimo em $b$ e acréscimo em $\Phi$. Esse mesmo fato pode ser observado na questão número 16 , onde $A 5$ do EXP1 ao errar a questão é penalizado com um $\theta=-3,0$. Esse fato é decorrente de $P(\theta=0)=0,681492$, ou seja, o aluno tinha uma probabilidade de $68 \%$ de acertar a questão, mas errou-a.

Nesse cenário da primeira questão da base ao aluno, percebe-se que se o aluno responder incorretamente a questão, ele será fortemente penalizado, já que a FII para $\theta=0$ escolhe sempre uma questão de nível fácil para início do teste. Isso também mostra porque respondendo corretamente a questão, o $\theta$ do aluno tem um sutil acréscimo.

$\mathrm{Na}$ perspectiva do acerto de todas as questões de um Módulo, foi possível levantar as seguintes conjecturas:

- Os Módulos 1 e 4 obtiveram um número maior de questões calibradas do que os outros Módulos. Isso decorre por não conterem questões do tipo testlet, o que permite uma maior variabilidade na escolha de um item;

- Os Módulos 2 e 3 (questões tipo testlet) fazem com que o aluno siga com as respostas das questões no mesmo testlet, diminuindo a variabilidade na escolha da próxima questão;

- No EXP1 a sequiência de apresentação dos Módulos ao aluno é diferente do EXP2 (ver Seção 6.3.3). Pelos resultados dos alunos, a segunda configuração pode ter permitido uma maior motivação para a realização do teste, já que os Módulos 1 e 4 (considerados mais fáceis) foram intercalados entre Módulos 2 e 3 (considerados mais difíceis). Esse resultado também pôde ser observado por meio da nota média dos alunos, 3, 66 para o EXP1 e 4,08 para o EXP2.

A quantidade média de questões respondidas pelos alunos com melhor e pior desempenho, foram respectivamente 21,5 e 17,5. Então, infere-se que quando o aluno responde às questões erradas seqüencialmente, rapidamente seu $\theta$ decairá para $-3,0$, causando o término do Módulo. Nesse caso, nada pode-se afirmar sobre as questões respondidas corretamente.

No requisito corretude do teste, isto é, que o sistema não penalize indevidamente um aluno, percebe-se pelo $A 4$ do EXP1 e $A 5$ do EXP1 que ambos praticamente iniciaram o teste com parâmetros muito similares da base de itens (já que $A 4$ realizou o teste em primeira instância e 
A5 em segunda), e com isso receberam as mesmas questões iniciais em cada Módulo. Porém, os desempenhos desses dois alunos foram drasticamente diferentes conforme dados observados em Gonçalves \& Aluísio (2004).

\subsection{Discussão dos Resultados}

Os EXP1 e EXP2 mostraram alguns comportamentos do BI assim como a trajetória de alguns alunos. Percebe-se que o uso de um TAI é diretamente proporcional a uma melhor individualização e precisão do teste, na medida que os itens são calibrados conforme o acesso à base. Portanto, o quem determina a dificuldade de um item são os próprios alunos, ou seja, não há inferência do professor na calibração da base (salvo para a estimativa inicial).

O parâmetro $b$ e $\theta$, respectivamente de uma questão e um aluno, são estimados por uma relação entre si, em uma relação funcional estabelecida pelo CBAT-2 e ML3P. Um fato interessante foram os resultados obtidos por $A 4$ e $A 5$, que apresentaram resultados de $\theta$ diferentes, embora iniciem com uma situação inicial similar. Com isso, mesmo com condições iniciais muito próximas, o aluno é quem determina o seu próprio caminhar no teste, respondendo corretamente ou incorretamente as questões, em outras palavras, o conhecimento do aluno é o fator determinante para seu próprio sucesso ou fracasso em um TAI. Assim, em um TAI baseado no CBAT-2, o aluno é o agente da calibração em tempo de execução de um BI, gerindo por meio de suas respostas corretas ou incorretas todo o contexto do teste. Pode ser necessário, após um certo tempo de uso do teste, verificar se existem questões que não foram acessadas e talvez re-estimar seu parâmetro $b$ inicial.

\subsection{Considerações Finais}

O desenvolvimento de um TAI baseado no CBAT-2 (com modificações) permite seu uso individual, como um teste diagnóstico e também como módulo de avaliação para o ACA proposto nessa pesquisa. O Capítulo 7 descreve o desenvolvimento e resultados obtidos a partir da implementação de um Ambiente Computacional de Tarefas (ACT) integrado ao ADEPT. 


\section{Capítulo 7}

\section{Implementação de um Ambiente Com- putacional de Aprendizagem para o In- glês Instrumental}

Foi desenvolvido um Ambiente Computacional de Aprendizagem (ACA) que propicia um contexto favorável para o aprendizado do inglês instrumental tratado no EPI para o mestrado do ICMC-USP, sendo útil tanto para um aluno se preparar para o EPI do instituto quanto para um pesquisador novato conhecer o gênero de textos científicos em inglês. O Computer-Aided Learning of English for Academic Purposes (CALEAP-Web) é resultado da integração entre um TAI e um ACT e foi implementado em PHP, C e MySQL.

Na Seção 7.1 apresenta-se a arquitetura do CALEAP-Web e a funcionalidade de seus módulos. A Seção 7.2 traz três projetos que deram suporte ao desenvolvimento de um dos módulos do CALEAP-Web: o ACT chamado CATESE. Na Seção 7.3 uma avaliação da operacionalidade do CALEAP-Web é apresentada seguida de uma discussão dos resultados da avaliação (Seção 7.4).

\subsection{Arquitetura do CALEAP-Web}

O CALEAP-Web é composto por dois módulos:

Módulo 1 (Mod1) - Avaliação do aluno: nesse módulo o aluno é avaliado pelo ADEPT (Capítulo 6. O objetivo aqui é obter o seu nível de conhecimento em inglês instrumental;

Módulo 2 (Mod2) - Sugestão de tarefas sugeridas ao aluno: segundo o nível estimado de conhecimento do aluno, são sugeridas tarefas relacionadas com as possíveis deficiências 
com ele em inglês instrumental. Esse ambiente é denominado Computer-Aided Task Environment for Scientific English (CATESE).

Mod1 e Mod2 estão integrados segundo a Figura 7.1. As informações do modelo de desempenho do usuário $(L 1)$ são:

- A do Módulo do EPI em que houve a deficiência;

- $\theta, P_{\theta}$ e nota normalizada do aluno no Módulo do EPI;

- Número de questões respondidas no Módulo do EPI, separadas em corretas ou incorretas;

- Tempo de teste no Módulo do EPI.

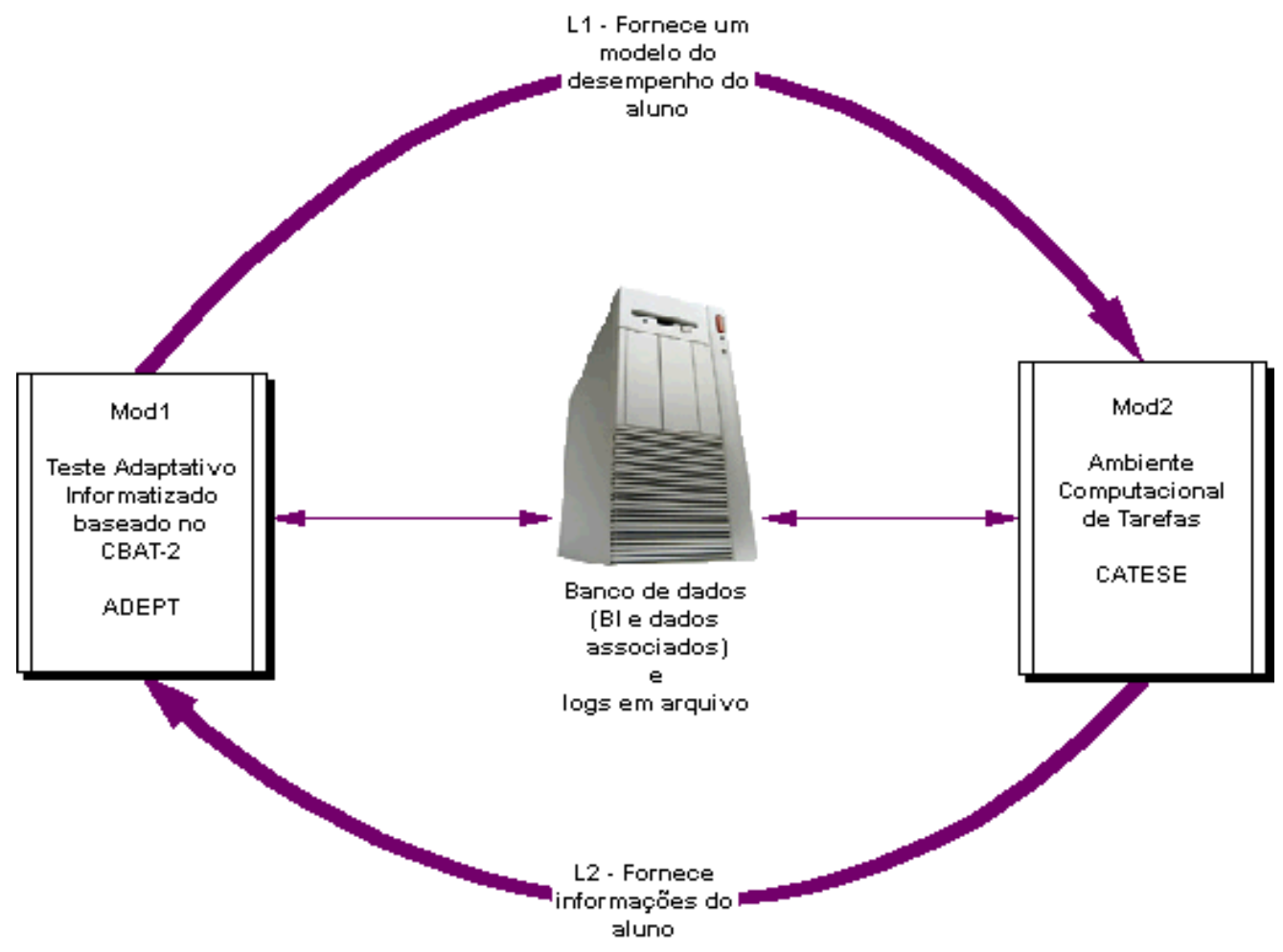

Figura 7.1: Esquema da integração no CALEAP-Web.

As informações em $L 1$ são fornecidas pelo ADEPT ao CATESE ao fim do teste de cada Módulo do EPI se for satisfeito o critério para inicializar uma tarefa, que consiste em um número de erros, caso contrário o aluno não é levado ao CATESE. Há uma tolerância de um erro dentre todas as questões respondidas em um teste. Se o aluno errar pelo menos duas questões, então ao fim do teste (em um determinado Módulo) será sugerida uma tarefa relacionada com o conteúdo específico da Parte do Módulo em que está deficiente. Por exemplo, um aluno está 
no Módulo 1 (com partes Gap e Purpose), e responde incorretamente a duas questões de Gap; este será levado para uma tarefa relacionada com Gap e não Purpose. Um outro exemplo: um aluno está no mesmo Módulo (1) do EPI e responde incorretamente três questões de Purpose; este será levado para uma tarefa relacionada com Purpose e não Gap. Por fim, se esse aluno responder incorretamente duas questões, sendo uma de Gap e outra de Purpose, então será levado a realizar duas tarefas, uma de Gap e outra de Purpose.

As informações do aluno ( $L 2)$ são:

- Tarefas sugeridas ao aluno;

- Indicação que finalizou a execução das tarefas do Módulo do EPI.

As informações em $L 2$ são fornecidas pelo CATESE ao ADEPT para que o aluno refaça o teste sobre o mesmo Módulo do EPI que realizou a tarefa. Se o aluno conseguir um bom desempenho nesse teste, ele será levado ao próximo Módulo do EPI.

\subsubsection{Ambiente Computacional de Tarefas CATESE}

O domínio do conhecimento tratado no CATESE é o mesmo que o do ADEPT, ou seja, o conteúdo do EPI para o mestrado do ICMC-USP (excluindo a Parte Abstract que está presente apenas no ADEPT). Com isso, existe um domínio de conhecimento conhecido e muito estudado (Aluísio et al., 2003), estabelecendo uma relação diretamente proporcional entre avaliação do aluno no TAI e conhecimento adquirido no ACT.

Com a perspectiva de ajudar o aluno na aquisição de conhecimento de inglês instrumental, determinou-se uma seqüencia de aprendizado gerenciada pelo sistema, descrita na Figura 7.2. Para cada Módulo do EPI existe uma tarefa associada que é sugerida a cada aluno, após a realização do teste no Módulo do EPI. Decidiu-se por intercalar avaliação/tarefa de Módulos "fáceis" (Módulos 1 e 4) com as "difíceis" (Módulos 2 e 3) e também por um equilíbrio entre leitura de textos longos com trechos pequenos no EXP2 (ver Capítulo6).

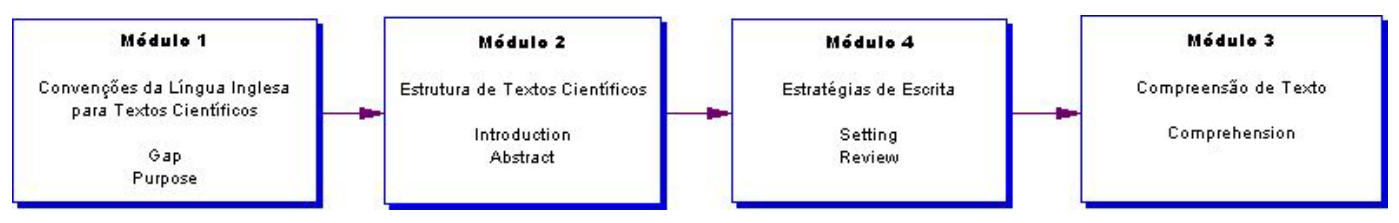

Figura 7.2: Seqüência de aprendizado para o CATESE.

As quatro tarefas foram implementadas com o objetivo de instrumentalizar um aluno ou pesquisador com informações sobre o gênero científico, como por exemplo, a estrutura de um artigo científico e as estratégias de escrita utilizadas, os marcadores discursivos utilizados em cada componente da estrutura de uma seção, tempos verbais adequados, entre outros. Com essas 
informações espera-se que o aluno pesquisador leia principalmente e escreva eventualmente mais rapidamente e com maior precisão um artigo científico de sua área de pesquisa. As tarefas são:

Tarefa 1 (T1): identificação e classificação de marcadores discursivos em sentenças do componente lacuna (Gap) e identificação do tempo verbal de sentenças do componente propósito (Purpose);

Tarefa 2 (T2): seleção dos componentes da estrutura de uma introdução e recuperação de textos de uma base de textos bem escritos para a leitura posterior dos mesmos;

Tarefa 3 (T3): leitura de sentenças relacionadas com um marcador discursivo, para o aluno estabelecer relações entre as funções do discurso e os marcadores apropriados. As funções tratadas são: contraste/oposição, sinalizar mais informação/adição, similaridade, exemplificação, reformulação, consequiência/resultado, conclusão, explicação e dedução/inferência;

Tarefa 4 (T4): identificação e classificação de estratégias de escrita para os componentes contexto e revisão da literatura.

A Tabela 7.1 apresenta as tarefas relacionadas com cada Parte do EPI. T1, T2, T3 e T4 tratam do conteúdo avaliado, respectivamente, pelos Módulos 1, 2, 3, 4 do EPI do ICMC-USP.

Tabela 7.1: Tarefas sugeridas ao aluno e seus conteúdos ministrados.

\begin{tabular}{|c|l|}
\hline Tarefa & \multicolumn{1}{|c|}{ Partes } \\
\hline T1: & Gap e Purpose \\
\hline T2 & Introduction \\
\hline T3 & Setting e Review of Literature \\
\hline T4 & Comprehension \\
\hline
\end{tabular}

\subsubsection{Funcionamento do Sistema}

O aluno inicia o CALEAP-Web (ver Figura 7.3 ) acessando a URL http://www.nilc.icmc.usp.br, mediante um login e senha fornecidos pelo administrador do sistema. O ambiente é acessado de qualquer por meio de um navegador, sem restrições de horário. 


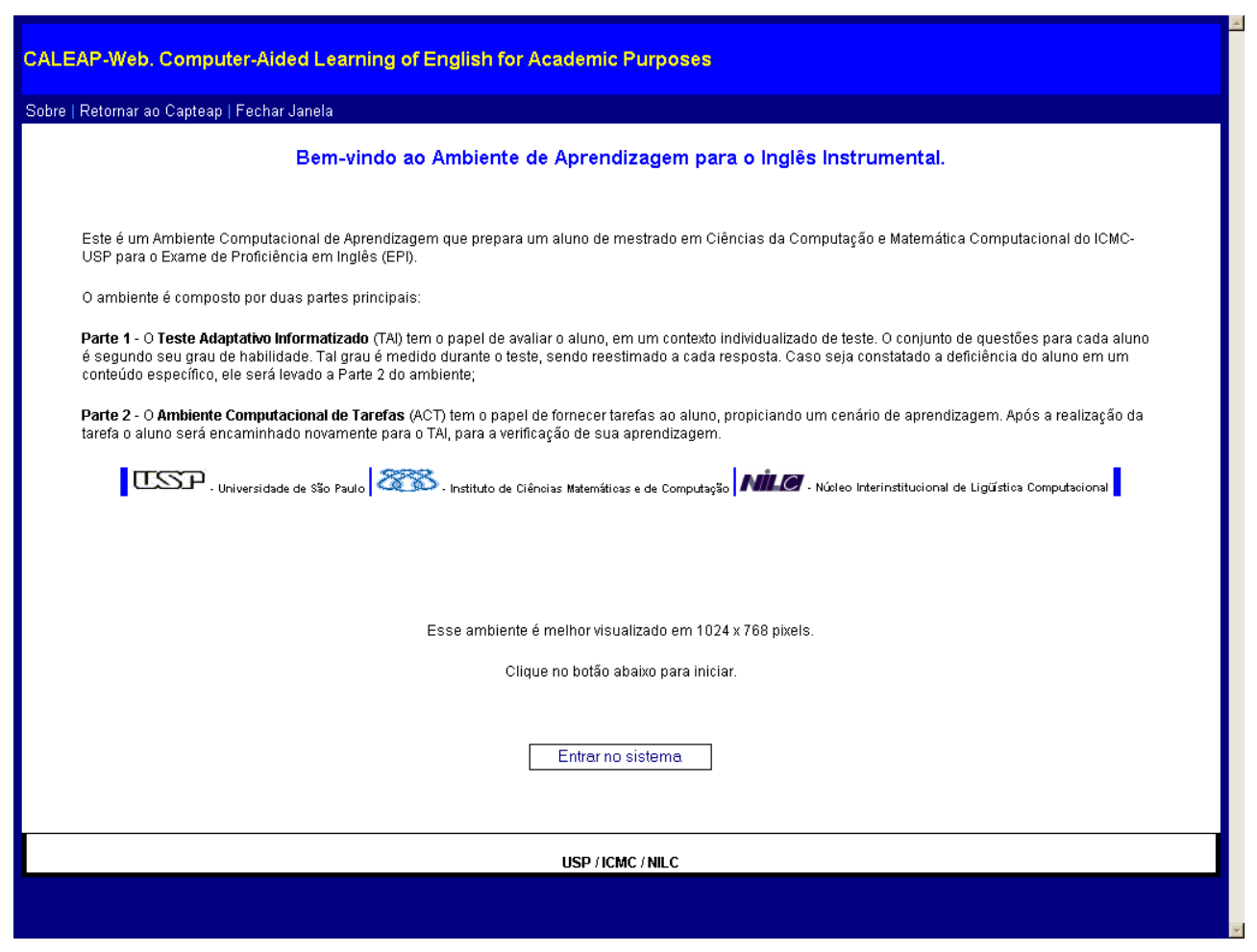

Figura 7.3: Tela inicial do CALEAP-Web.

De forma genérica, o funcionamento do ambiente computacional dá-se segundo a Figura 7.4, onde:

- $A v$ é a avaliação do aluno em um Módulo $M$ do EPI, e $T$ é a tarefa relacionada com esse Módulo;

- $R P$ (reprovado) é quando o aluno não atinge o critério mínimo para a aprovação em um módulo; e $A P$ (aprovado) é quando o aluno atingiu o critério mínimo para aprovação no teste.

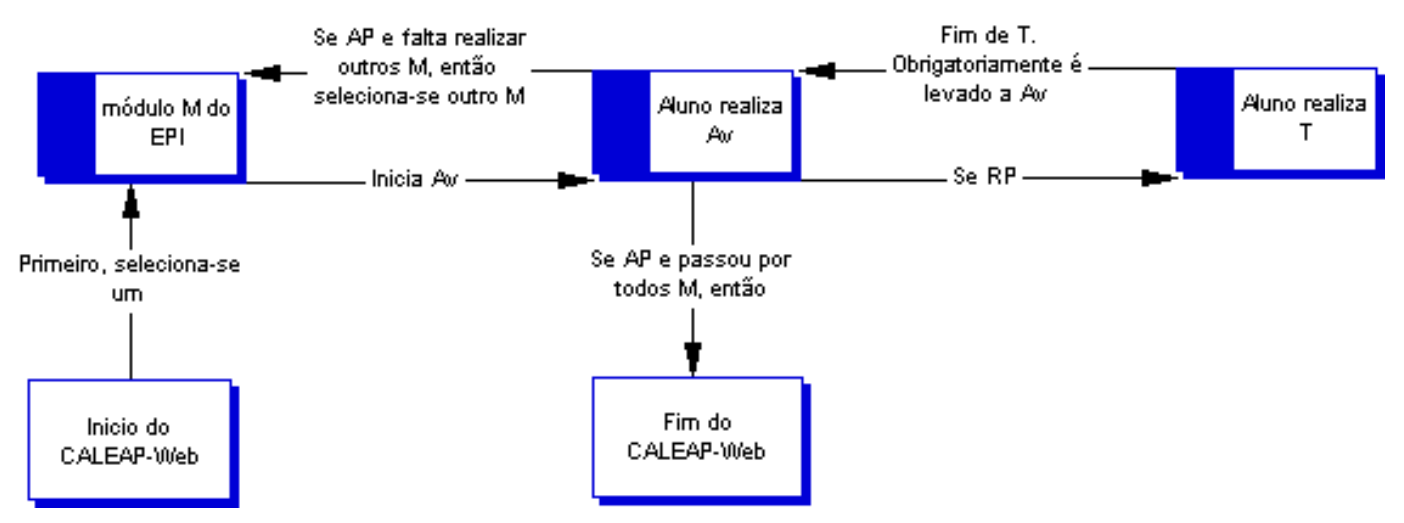

Figura 7.4: Esquema de funcionamento do CALEAP-Web. 
Após a autenticação do aluno, seleciona-se um dos Módulos do EPI para iniciar e realizar a $A v$. Terminada a $A v$ o aluno será $A P$ ou $R P$ no teste. No primeiro caso, passará para o Módulo do EPI seguinte e novamente avaliado pelo ambiente. No segundo caso, o aluno será levado ao ACT para realizar uma tarefa relacionada com suas deficiências detectadas pelo teste. Realizada a tarefa, o aluno será reavaliado pelo teste. O ciclo de aprendizagem avaliaçãotarefa-avaliação é inerente a todos os quatro Módulos gerenciados pelo sistema. O término do ciclo no CALEAP-Web se dará quando o aluno passar pelos quatro Módulos do EPI, porém esse pode interromper o ciclo antes de iniciar nova avaliação. Essa forma de escape possibilita que o aluno planeje seu estudo da maneira que lhe convier. Quando o aluno utilizar o sistema novamente, será inicializado o Módulo no qual ele estava anteriormente.

O CALEAP-Web é baseado na abordagem Aprender-Fazendo (ver Seção 2.1), pois na medida em que o ambiente favorece o aprendizado do inglês instrumental (no escopo de conhecimento dos quatro Módulos do EPI) fazendo com que o aluno realize tarefas relacionadas com sua rotina de pesquisa: leitura de trechos de artigos, identificação de partes importantes de artigos, compreensão da relação entre partes de artigos, entre outros.

\subsection{Projetos que Apoiaram o desenvolvimento do CA- TESE}

Aqui descreve-se alguns projetos realizados no ICMC-USP que deram suporte ao desenvolvimento do ACT para a aprendizagem de inglês instrumental.

\subsubsection{Ferramenta de Suporte à Escrita do AMADEUS}

A Ferramenta de Suporte à escrita do ambiente AMADEUS reutiliza textos bem escritos para auxiliar os escritores não-nativos do inglês a escrever seus artigos científicos em inglês (Aluísio et al., 2003, 2001). O material lingüístico é reutilizado para prover a coesão e a coerência da introdução de um artigo científico, pois atualmente o conhecimento da ferramenta trata da seção Introdução.

A ferramenta utiliza-se do Raciocínio Baseado em Casos (RBC) para modelar as três fases do processo da escrita em inglês: o usuário seleciona as características pretendidas para compor a introdução de um artigo científico, recupera-se os melhores casos, revisa-se o caso selecionado com o objetivo de satisfazer a requisição do usuário. A Figura 7.5 (fase de planejamento) mostra a tela para a seleção dos componentes ( 8 no total) e estratégias (30 no total) composta por:

Componentes: Setting, Review, Gap, Purpose, Methodology, Main Results, Value of the Research e Layout of the Paper; 
Estratégias: introducing research topic from the research area, state of the art, raising questions, entre outros;

Ordem da busca: existem três formas de recuperar os casos: busca idêntica, sublista ou intersecção, selecionadas a partir do grau de certeza do usuário, apresentados no menu Order da Figura 7.5 .

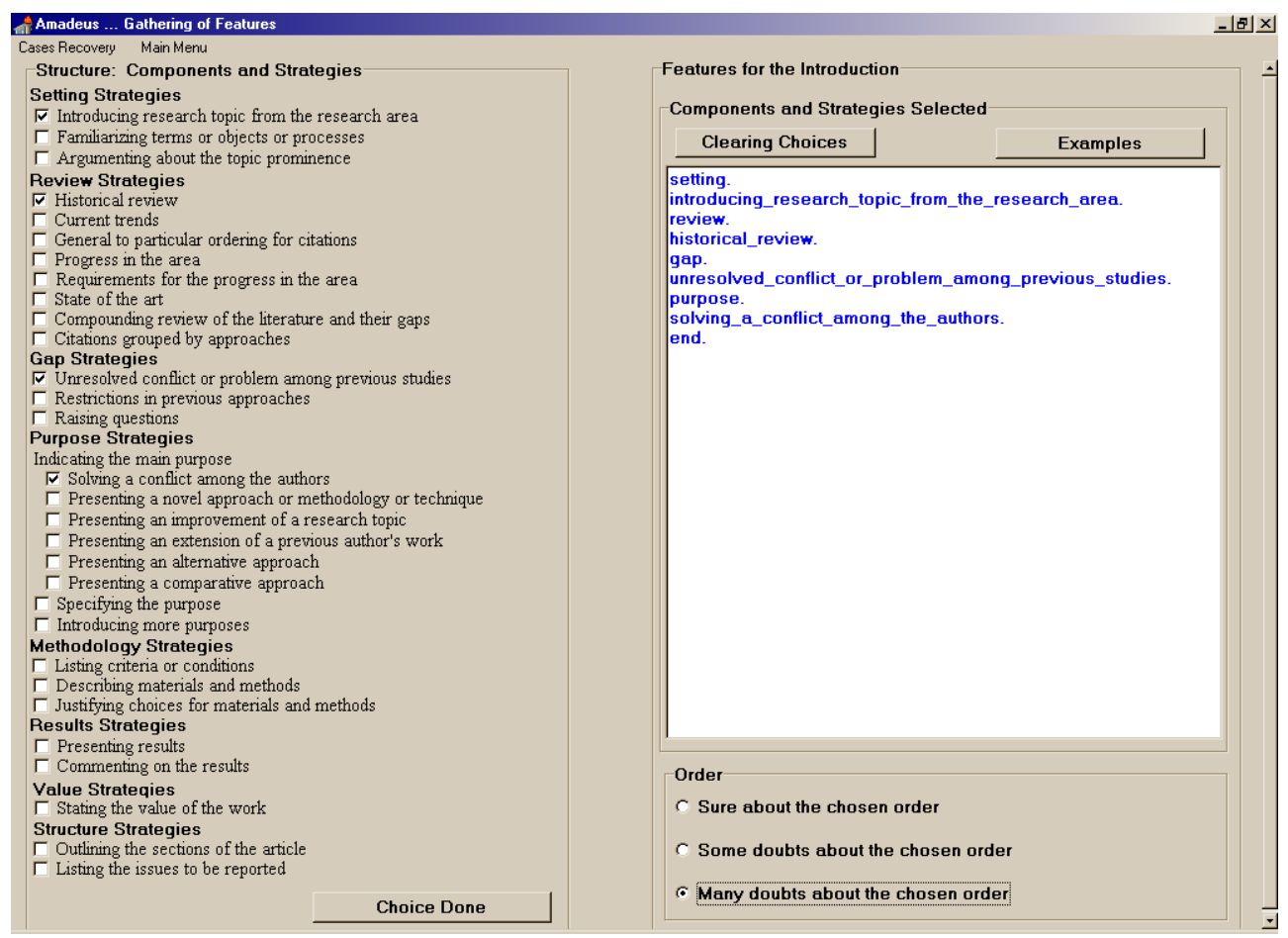

Figura 7.5: Tela de escolha de componentes e estratégias da Ferramenta de Suporte à escrita do AMADEUS.

Após a seleção dos componentes e estratégias, tem-se a recuperação dos casos. A Figura 7.6 mostra a seleção do caso $\operatorname{prl} 21$ dentre todos os recuperados, onde o texto em negrito significa material reusável.

A Ferramenta de Suporte à escrita do AMADEUS trabalha também com a revisão de um caso (Aluísio et al., 2003), fornecendo 10 tipos de revisões para que esse aproxime-se da requisição do usuário, como por exemplo adição de detalhes, ilustrar idéias, adição de marcadores de discurso para melhorar o fluxo de informação, remoção de detalhes para escrever artigos curtos. A Figura 7.7 mostra um exemplo de escolha para revisão do artigo científico prl21, onde o texto em negrito significa o material reusável. 


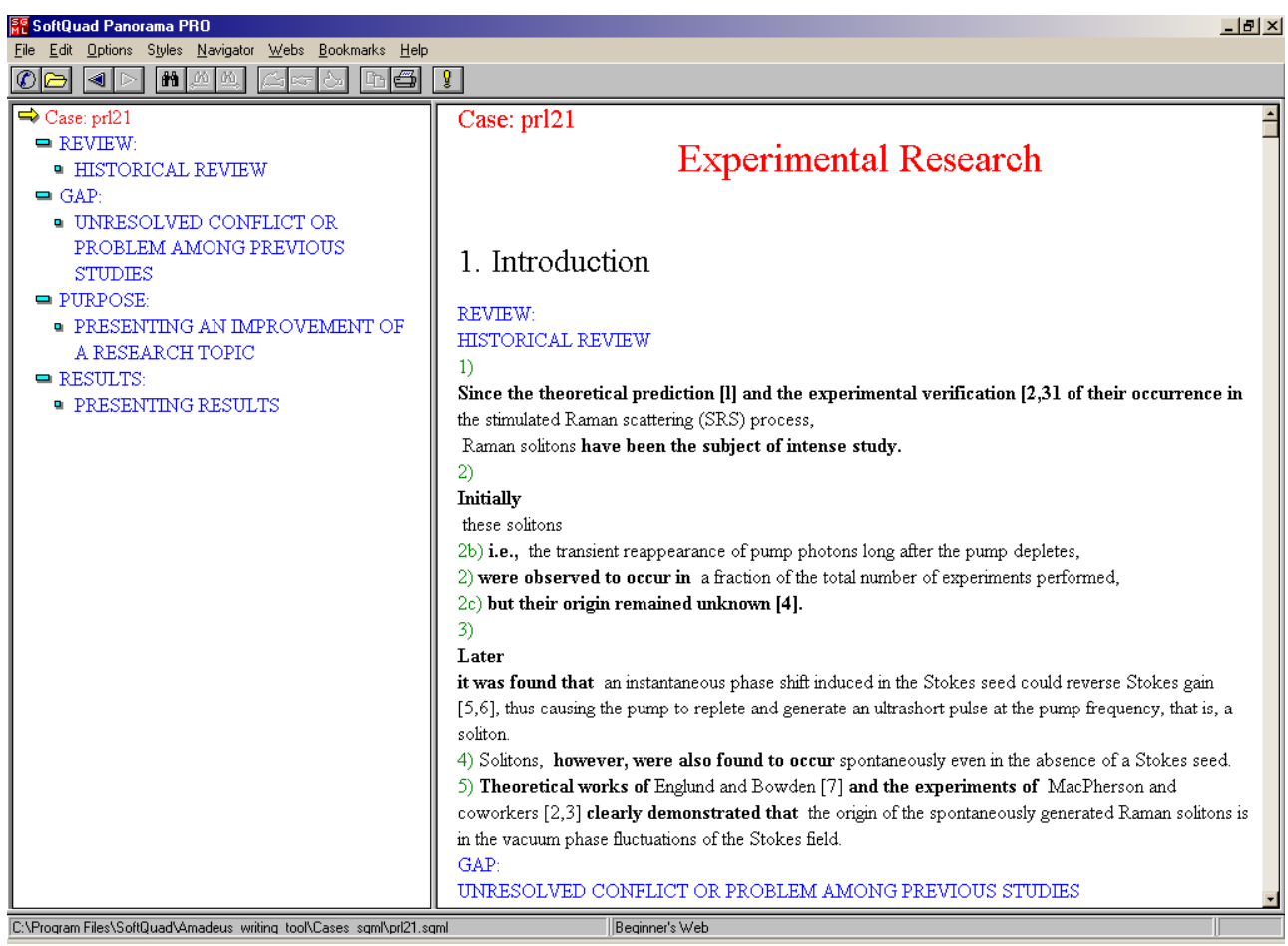

Figura 7.6: Tela da recuperação de casos da Ferramenta de Suporte à escrita do AMADEUS.

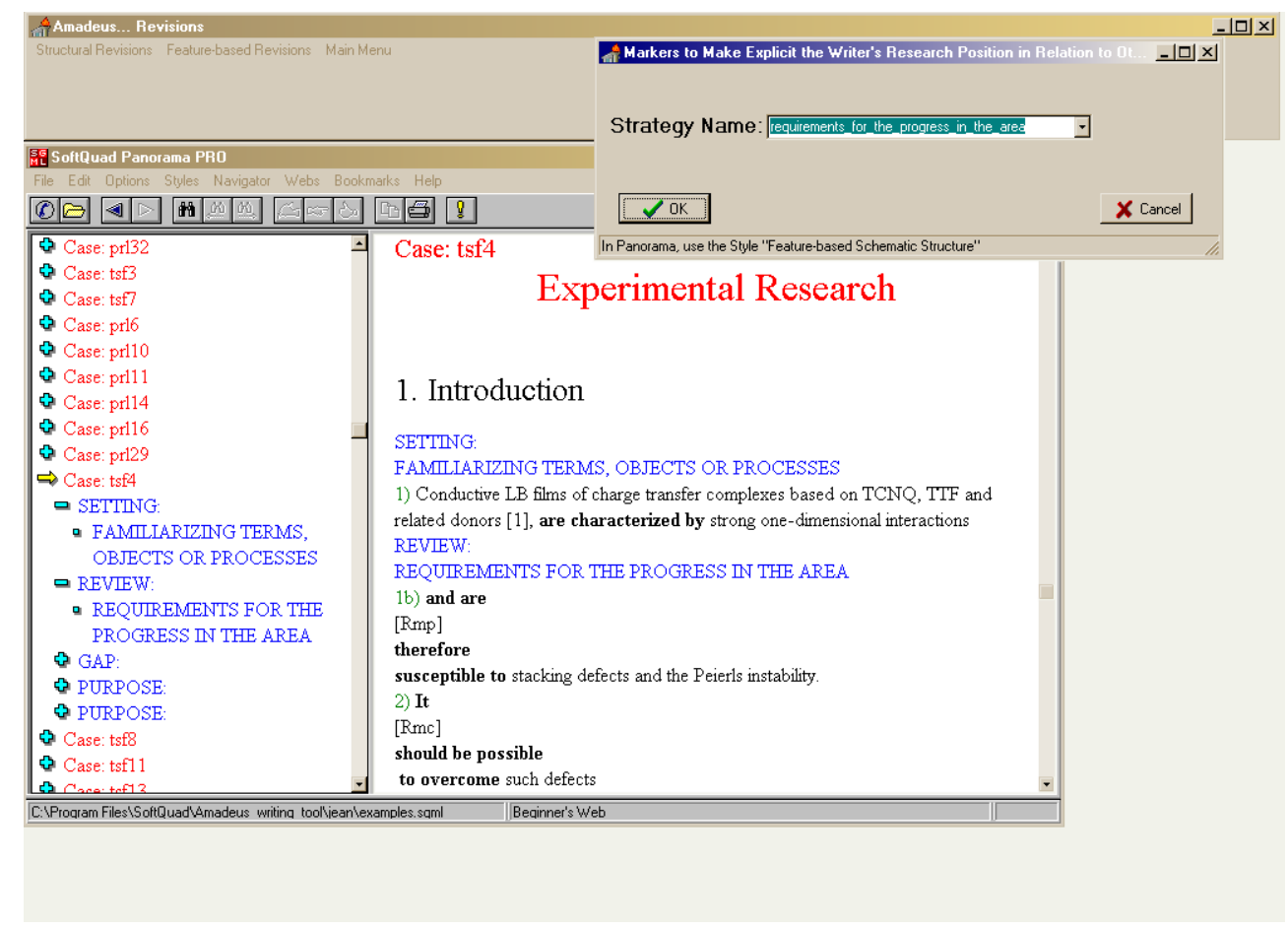

Figura 7.7: Tela de revisão de um artigo científico da Ferramenta de Suporte à escrita do AMADEUS. 


\subsubsection{SciPo: uma Ferramenta de Suporte à Escrita em Português}

O Scientific Writing in Brazilian Portuguese (SciPo) da pesquisa de doutorado de uma aluna do ICMC-USP, baseada no projeto AMADEUS. É uma ferramenta para a WWW, que trabalha com o domínio do português brasileiro, fornecendo suporte à escrita científica de resumos, introduções e conclusões de teses e dissertações, fornecendo também subsídios ao aluno para a leitura e interpretação de artigos científicos. Especificamente, a ferramenta apresenta críticas a uma estrutura de uma dada seção e posteriormente critica também o próprio texto escrito pelo aluno/pesquisador (Feltrim \& Teufel, 2004).

\subsubsection{CALESE: uma Ferramenta de Suporte à Escrita em Inglês}

O Computer-Aided Learning Tool for Scientific Writing in English (CALESE) 2] é uma ferramenta computacional implementada nessa pesquisa, relacionada com a escrita científica em inglês e baseada na Ferramenta de Suporte do AMADEUS e no SciPo. A base de casos foi migrada do AMADEUS e a interface WWW do SciPo. Nas Figuras $7.8 \mathrm{e}$ (7.9 mostra-se a seleção de componentes e estratégias para a escrita de uma introdução de um artigo científico em inglês. O CALESE modela duas das três fases de escrita propriamente dita.

\footnotetext{
${ }^{1}$ http://www.nilc.icmc.usp.br/nilc/projects/scipo.htm

${ }^{2}$ http://www.nilc.icmc.usp.br/calese
} 


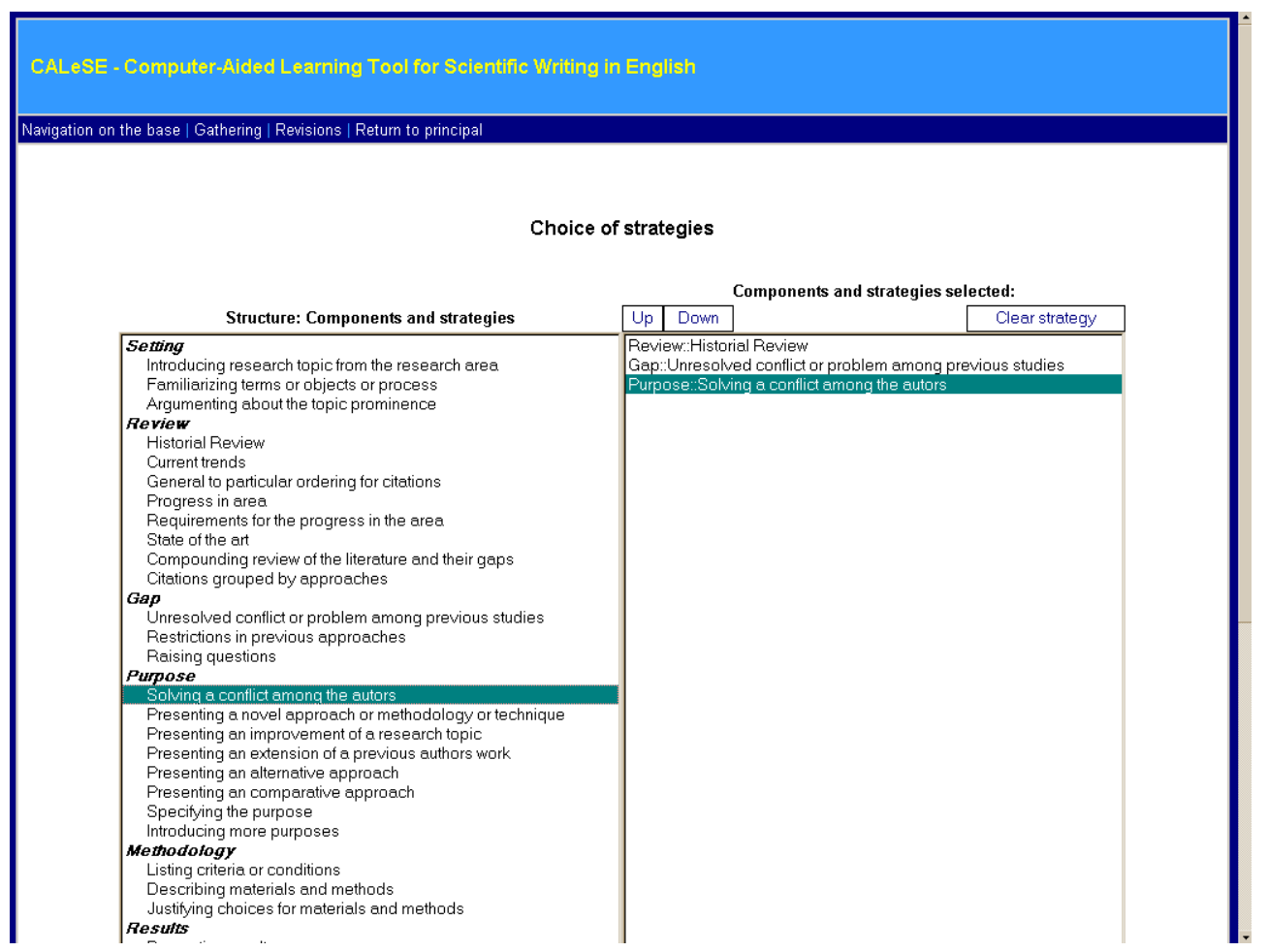

Figura 7.8: Tela da escolha de componentes e estratégias no CALESE.

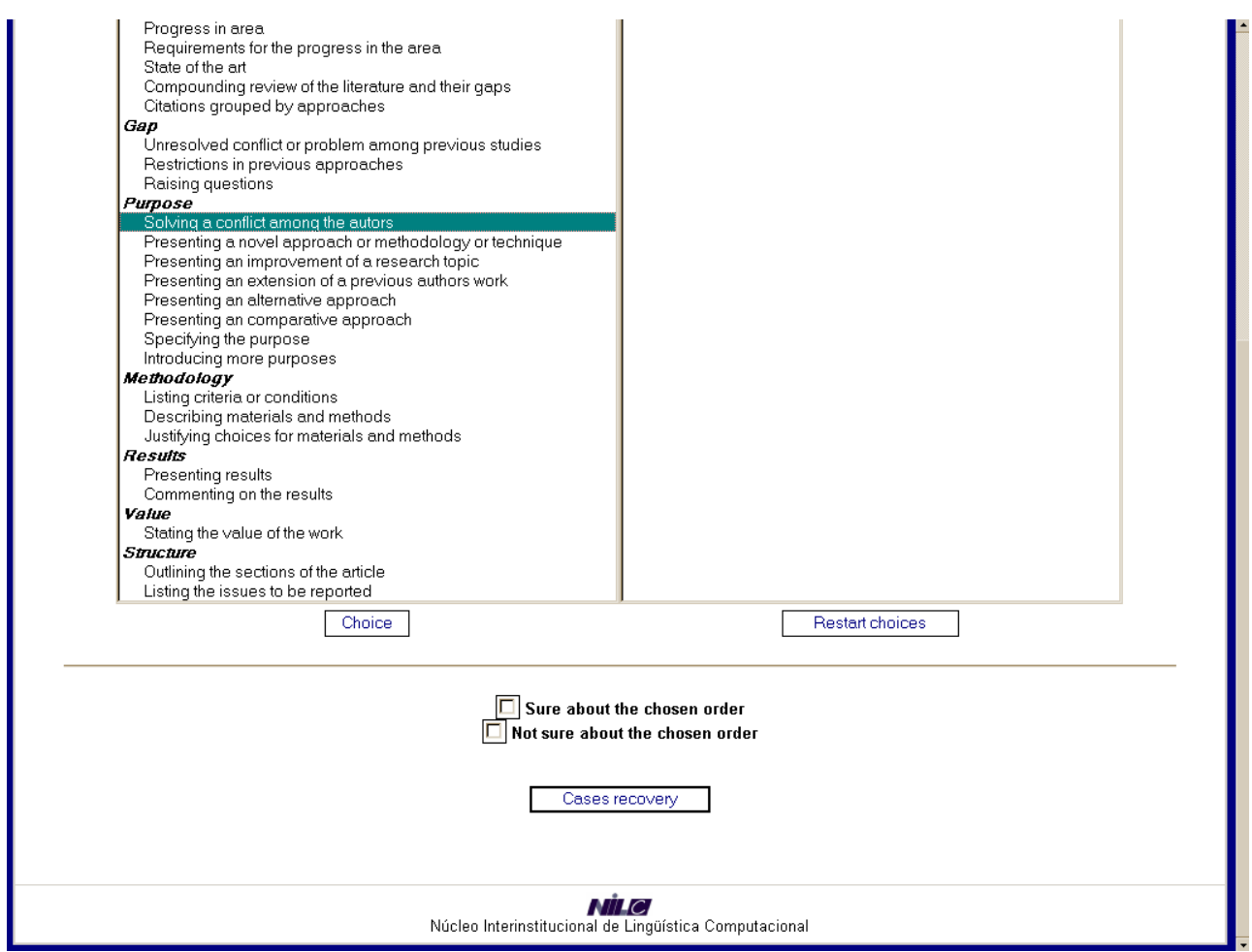

Figura 7.9: Continuação da tela para a escolha de componentes e estratégias no CALESE. 
A base de casos utilizada para as Tarefas 1, 3 e 4 do CATESE foram extraídas do CALESE, criando-se exemplos (trechos de texto) exibidos e formatados em XML. A Tarefa 2 é a adaptação do CALESE com alguns filtros para exibição dos casos. Considerando as quatro tarefas mencionadas na Seção 7.1.1, a T1 tem 13 trechos de artigos de Gap e 40 de Purpose, a T2 tem 51 casos de introduções de artigos, a T3 consiste em 46 trechos (exemplos) de artigos e a T4 tem 34 trechos de artigos de Setting e 38 de Purpose, todos utilizados para o CALEAP-Web.

\subsection{Avaliação da Operacionalidade do CALEAP-Web}

A única avaliação do CALEAP-Web, como um sistema integrado, foi a operacional, visando analisar se o sistema está desempenhando corretamente as suas funções e se é robusto. A avaliação da operacionalidade será demonstrada por algumas simulações de alunos interagindo com as quatro tarefas (ver Seção 7.1.1). Para tal avaliação, selecionou-se quatro alunos que realizaram os experimentos no ADEPT (ver Capítulo 6.3), que foram selecionados a partir do valor $\theta_{M_{i}}$, que é o valor de $\theta$ no $i$-ésimo Módulo do EPI (1, 2, 3 ou 4).

Os alunos selecionados para a interação são considerados de nível médio, porque todos têm $-1,0 \leq \theta_{M_{i}} \leq 1,0$. As simulações terão como hipótese inicial o experimento realizado com os alunos.

\subsubsection{Interação do Aluno com o CALEAP-Web na Tarefa 1}

A $T 1$ trabalha com as Partes Gap e Purpose do Módulo 1 (M1). Para simular T1 escolheuse um certo aluno $(A 1) \operatorname{com} \theta_{M 1}=0,368940$. A Tabela 7.2 mostra seus dados no decorrer do teste para o $M 1$.

Tabela 7.2: Dados do aluno 1 no ADEPT para o Módulo 1 do EPI.

\begin{tabular}{|c|c|c|c|c|}
\hline Questão & ID da Questão & Resposta & theta & $\mathrm{P}($ theta $)$ \\
\hline 1 & 18 & correta & 0,987982 & 0,929454 \\
\hline 2 & 32 & correta & 1,729292 & 0,953165 \\
\hline 3 & 40 & correta & 2,365134 & 0,941802 \\
\hline 4 & 30 & incorreta & 1,727406 & 0,439874 \\
\hline 5 & 37 & correta & 1,905576 & 0,966603 \\
\hline 6 & 38 & incorreta & 0,368940 & 0,499569 \\
\hline
\end{tabular}

$A 1$ é levado à $T 1$, pois respondeu incorretamente à duas questões. A questão número 30 pertence à parte Gap e a questão número 38 à parte Purpose. Devido a isso, o aluno será levado a $T 1$ de Gap e Purpose. O aluno sempre receberá uma tela introdutória padrão (Figura 7.10) 
antes de iniciar o CATESE. Clicando em Iniciar Tarefa 1 o aluno receberá uma tela onde estão as instruções da $T 1$, mostrada na Figura 7.11.

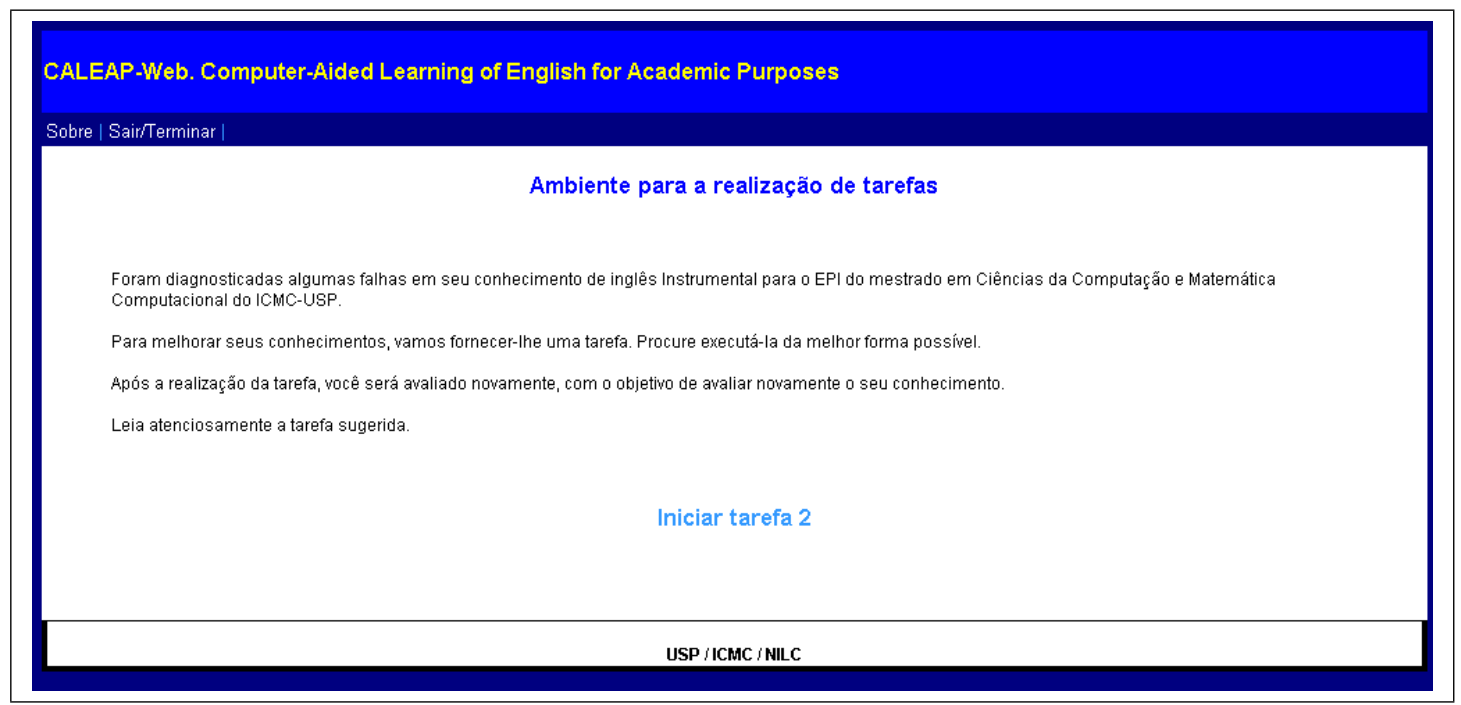

Figura 7.10: Tela introdutória padrão para as tarefas.

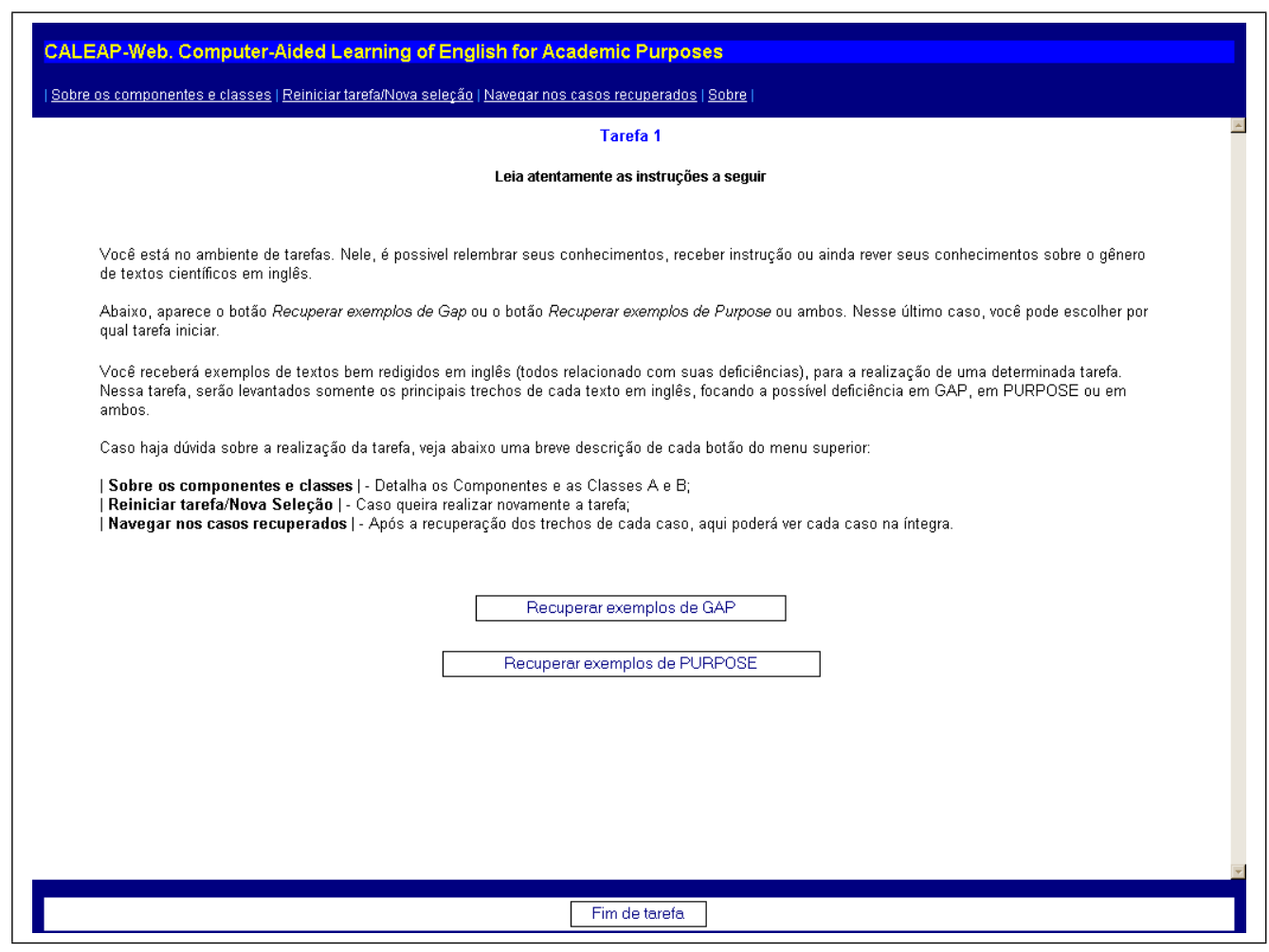

Figura 7.11: Tela com as instruções da Tarefa 1.

Existem dois botões: Recuperar exemplos de Gap e Recuperar exemplos de Purpose. Nesse momento, o aluno poderá optar pelo primeiro ou segundo botão para iniciar a recuperação dos exemplos de textos bem redigidos em inglês. Vamos supor que, inicialmente, $A 1$ escolha 
realizar as tarefas relacionadas com o conteúdo de Gap. Com essa escolha, o aluno é levado à tela de explicações sobre da $T 1$ (Figura 7.12). Os exemplos de Gap foram classificados em duas classes:

Class A: special words are commonly used to indicate the beginning of the Gap. Connectors such as however, but are used for this purpose. The connector is followed immediately by a gap statement in the present or present perfect tense. Which often contains modifiers such as few, little, or no. Signal word + Gap (present or present perfect) + Research topic;

Class B: subordinating conjunctions like while, although, though can also be used to signal the gap. If you use these kinds of signals, you must write a complex sentence typically using modifiers like some, many, or much in the first clause, and modifiers like little, few, or no in the second clause. Signal word + Previous work (present or present perfect) + Gap + topic.

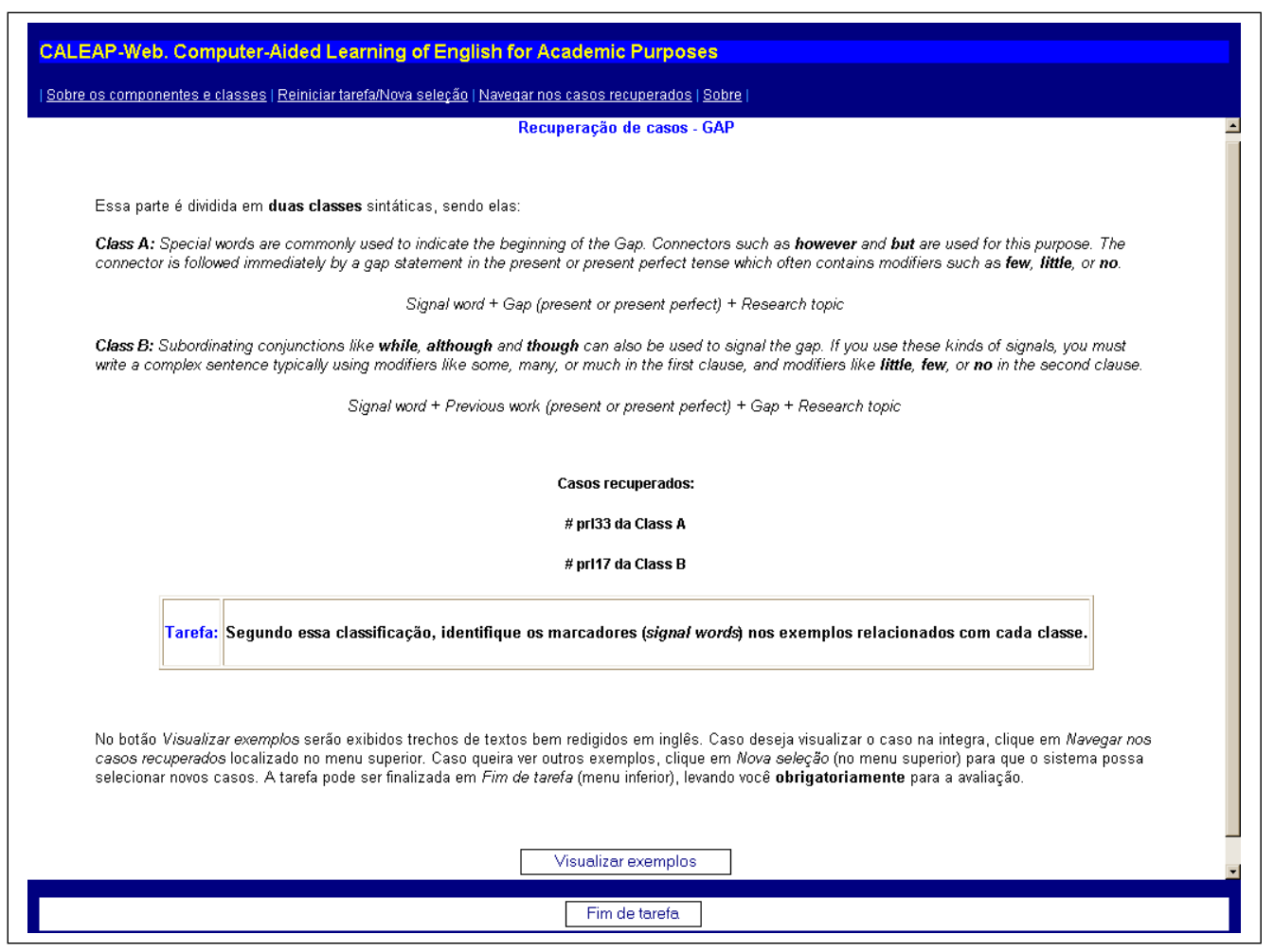

Figura 7.12: Tela com as explicações sobre Gap da Tarefa 1.

O CALEAP-Web recuperará exemplos de textos científicos textos dos casos de ambas as classes. Com isso, a $T 1$ de Gap é identificar e classificar os marcadores nos exemplos que compreendem as características de cada classe. Com um clique em Visualizar exemplos tem-se a tela da Figura 7.13 . Nela são exibidos apenas os trechos de cada caso anteriormente 
selecionados pelo ambiente, possibilitando o aluno realizar a $T 1$. Tem-se também a opção de visualizar o exemplo com o texto completo em Navegar nos casos recuperados (Figura 7.14).

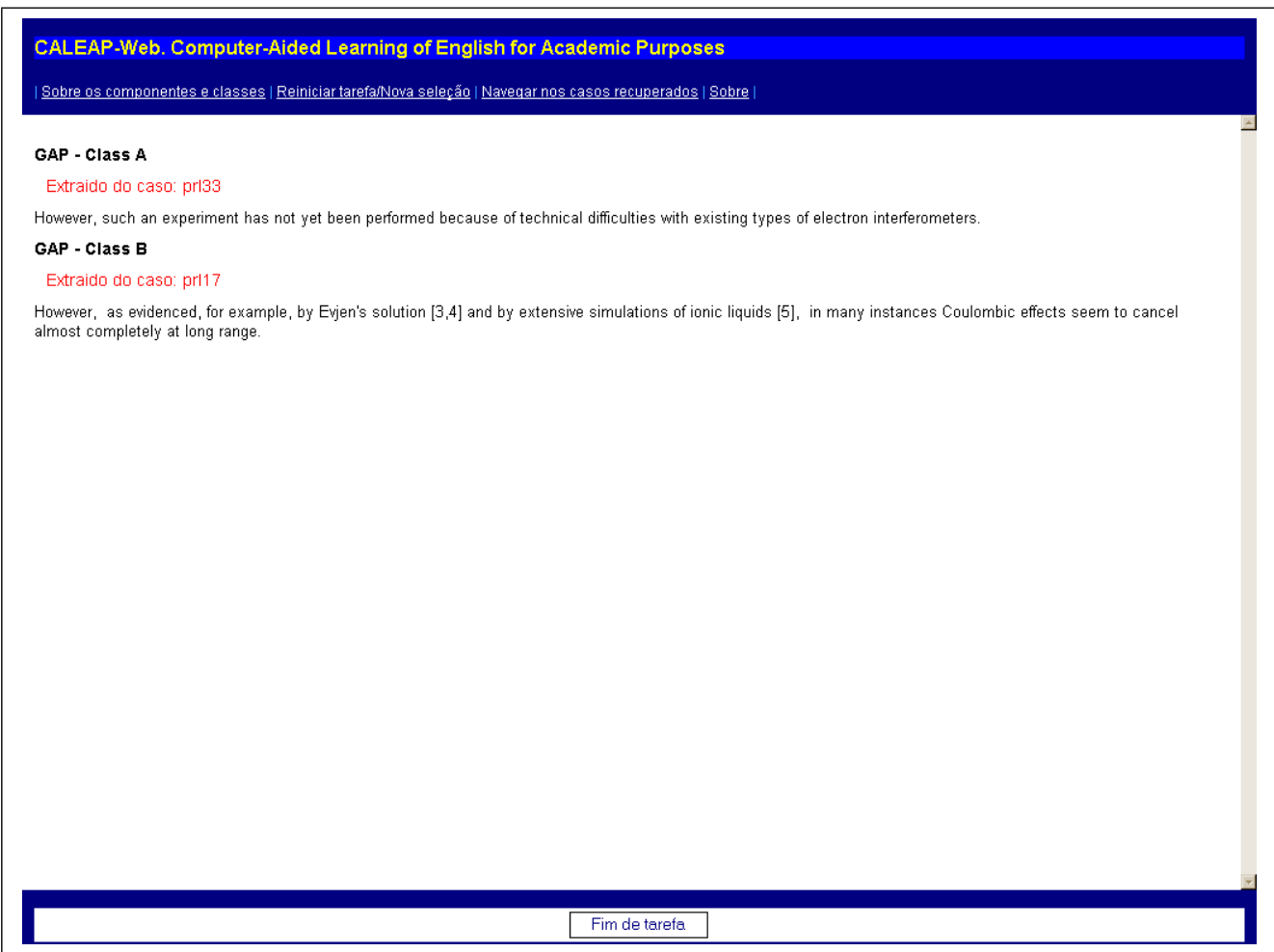

Figura 7.13: Tela da Tarefa 1 com os exemplos de Gap recuperados. 


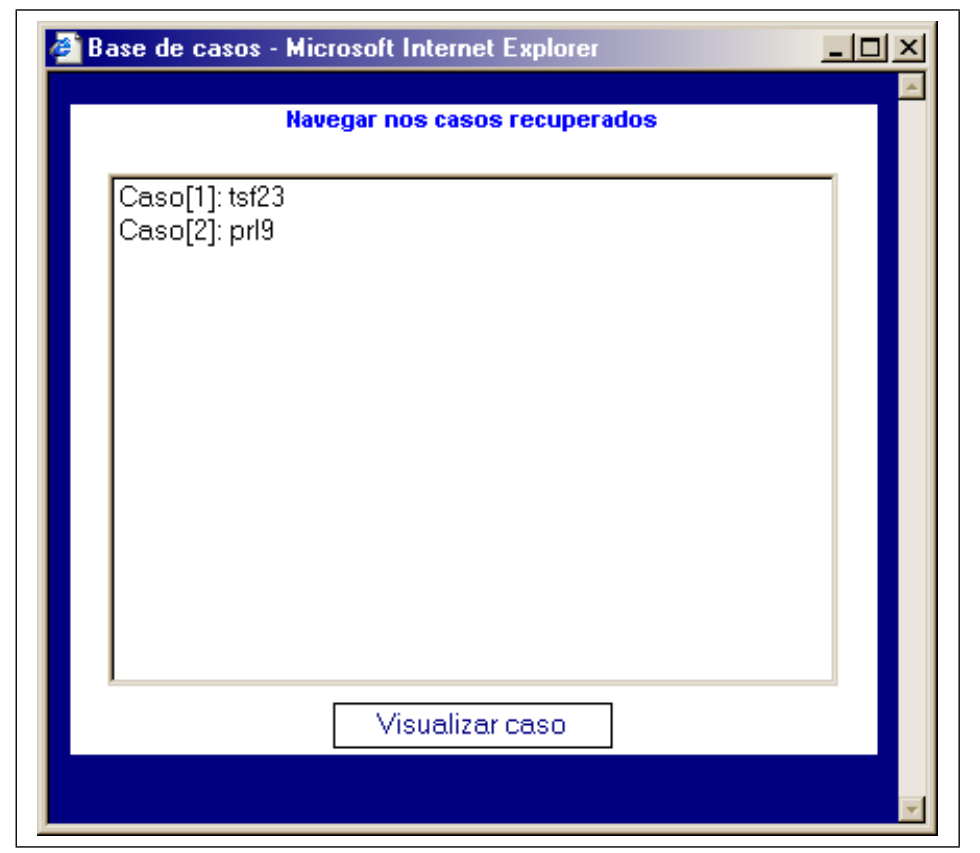

Figura 7.14: Tela de navegação dos exemplos recuperados de Gap da Tarefa 1.

Suponha agora que $A 1$ queira realizar a tarefa novamente, mas com o conteúdo de Purpose. Com essa escolha, o aluno é levado à tela de explicações sobre da T1 (Figura 7.15). Os exemplos de Purpose foram classificados em duas classes:

Class A: the orientation of the statement of purpose may be towards the report itself. If you choose the report orientation you should use the present or future tense. Report orientation + Main Verb (present or future) + Research question;

Class B: the orientation of the statement of purpose may be towards the research activity. If you choose the research orientation you should use the past tense, because the research activity has already been completed. Research orientation + Main Verb (past) + Research question.

Há a recuperação de exemplos de ambas as classes (Figura 7.16. A T1 de Purpose é identificar e classificar os marcadores nos exemplos que compreende as características de cada classe. A opção Navegar nos casos recuperados (Figura 7.14) também está presente.

O aluno poderá realizar novamente a mesma tarefa, mas o ambiente selecionará outros exemplos para a leitura. O botão Fim de tarefa (Figuras 7.15 e 7.16) leva o $A 1$ à avaliação, para que seja reavaliado em seu conhecimento do $M 1$. Se o aluno atingir o critério para a inicialização da tarefa (que consiste em responder incorretamente a 2 ou mais questões), então novamente terá que realizar $T 1$. Caso contrário, isto é, se errar apenas uma ou acertar todas as questões, será levado ao teste do Módulo 2 (M2) do EPI. 


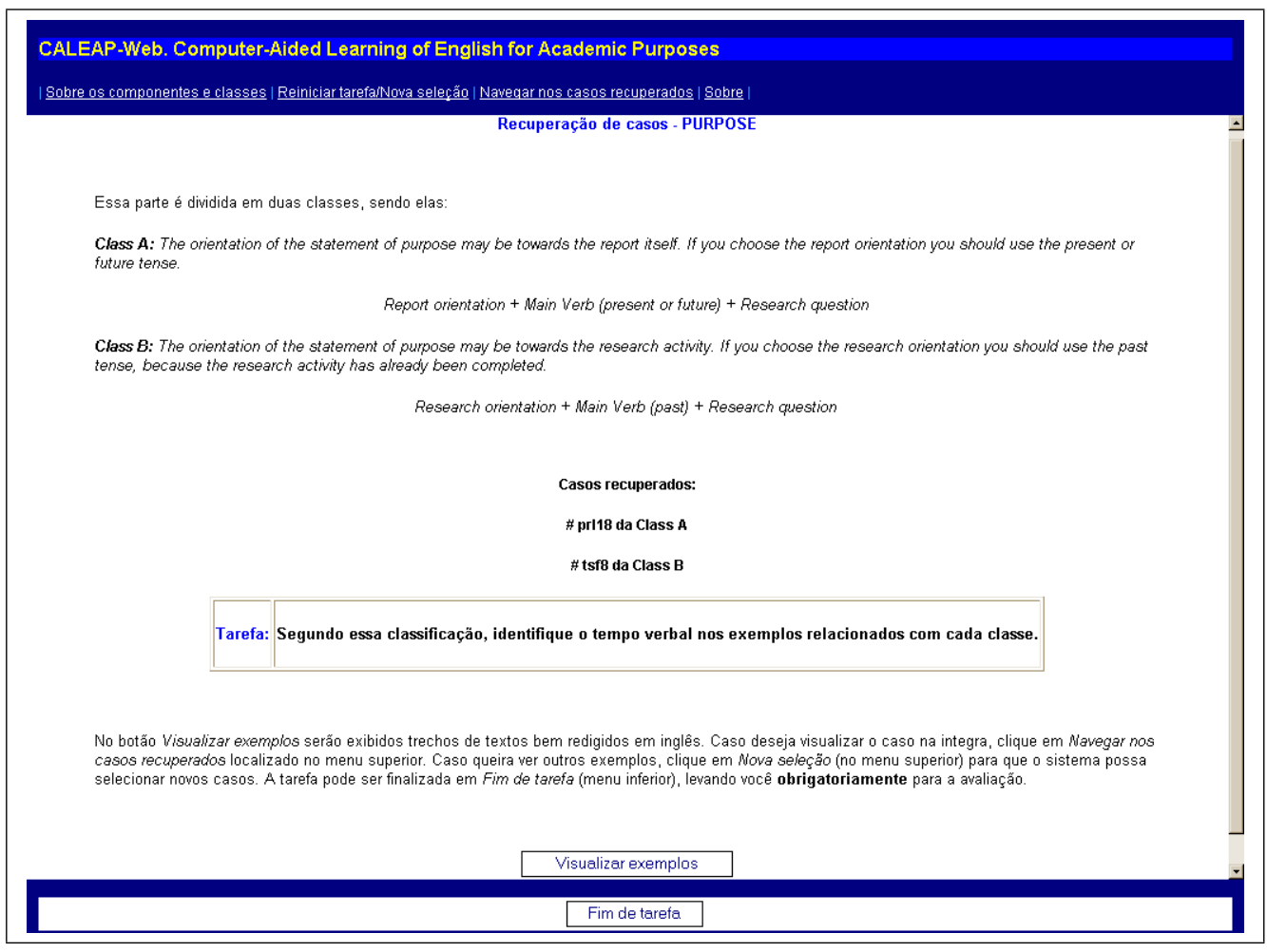

Figura 7.15: Tela com as explicações sobre Purpose da Tarefa 1.

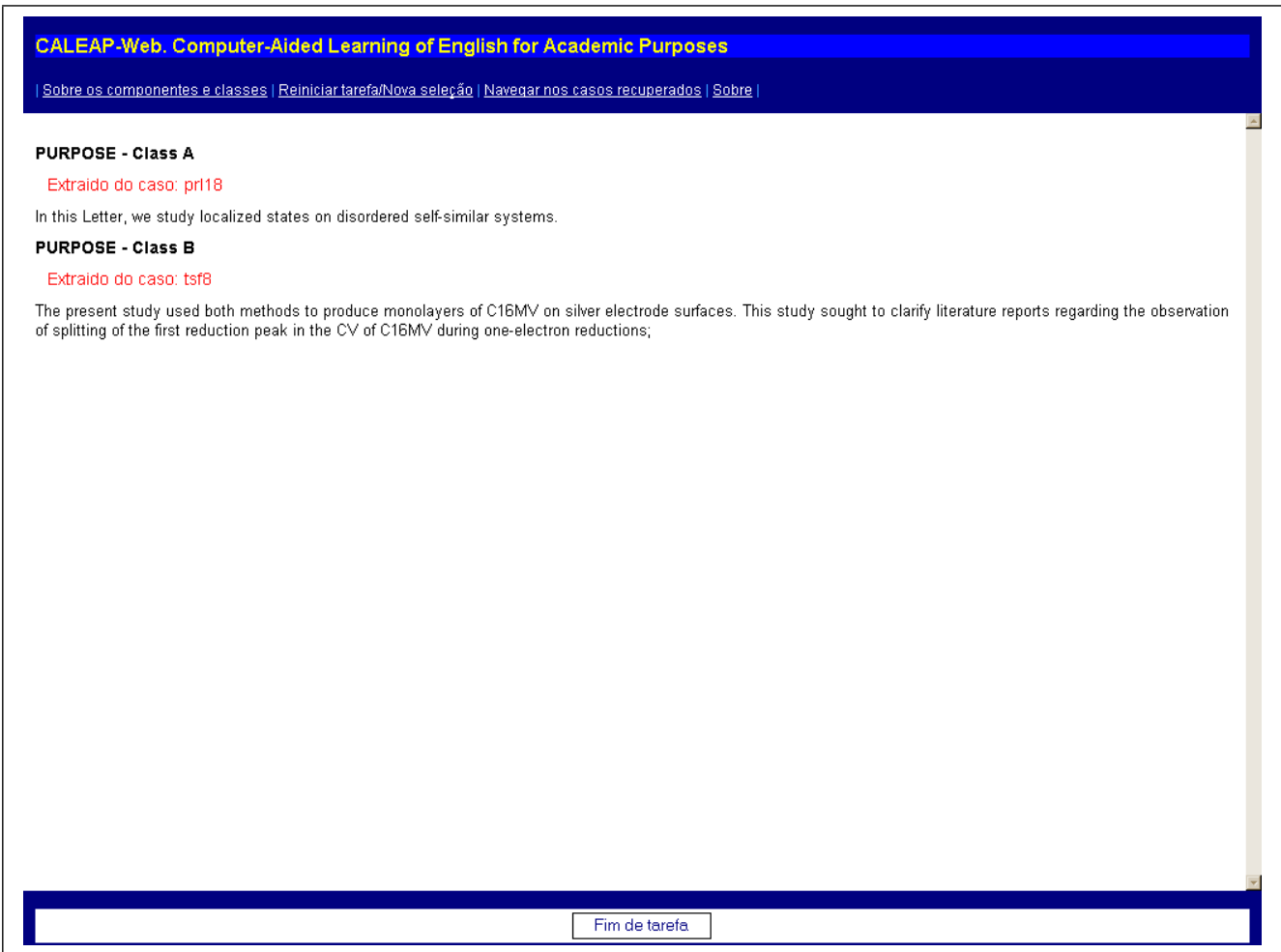

Figura 7.16: Tela da Tarefa 1 com os exemplos recuperados de Purpose. 


\subsubsection{Interação do Aluno com o CALEAP-Web na Tarefa 2}

A T2 trabalha com o conteúdo Introduction do EPI para o mestrado do ICMC-USP. Para a interação, elegeu-se um certo aluno $(A 2) \operatorname{com} \theta_{M 2}=0,037425$. A Tabela 7.3 mostra seus dados no decorrer do teste para o $M 2$.

Tabela 7.3: Dados do aluno 2 no ADEPT para o Módulo 2 do EPI.

\begin{tabular}{|c|c|c|c|c|}
\hline Questão & ID da Questão & Resposta & theta & $\mathrm{P}($ theta $)$ \\
\hline 1 & 148 & correta & 1,004438 & 0,943074 \\
\hline 2 & 149 & correta & 1,539596 & 0,999796 \\
\hline 3 & 147 & correta & 2,075125 & 0,999928 \\
\hline 4 & 62 & incorreta & 0,973475 & 0,364800 \\
\hline 5 & 63 & incorreta & 0,487754 & 0,356234 \\
\hline 6 & 64 & incorreta & 0,037425 & 0,343530 \\
\hline
\end{tabular}

$A 2$ é levado à $T 2$, pois respondeu incorretamente a três questões da parte Introduction do M2. A Figura 7.17 mostra a tela de instruções da T2. Ao clicar o botão Continuar, serão fornecidas informações sobre os componentes que compõem uma introdução de um artigo científico em inglês (Figura 7.18). Com isso a $T 2$ propõe a seleção dos componentes e estratégias e recuperação dos casos para a leitura desses.

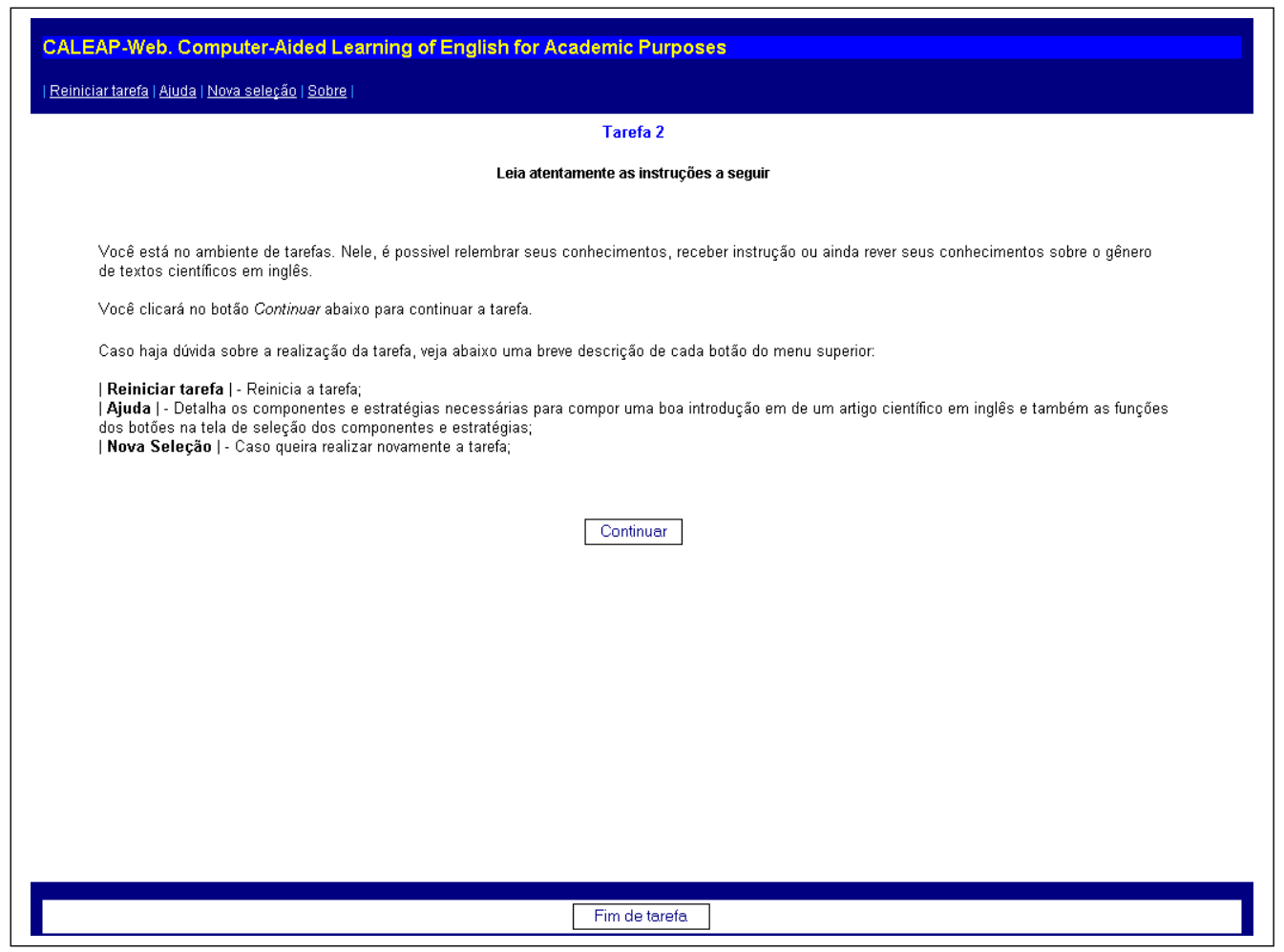

Figura 7.17: Tela com as instruções da Tarefa 2. 


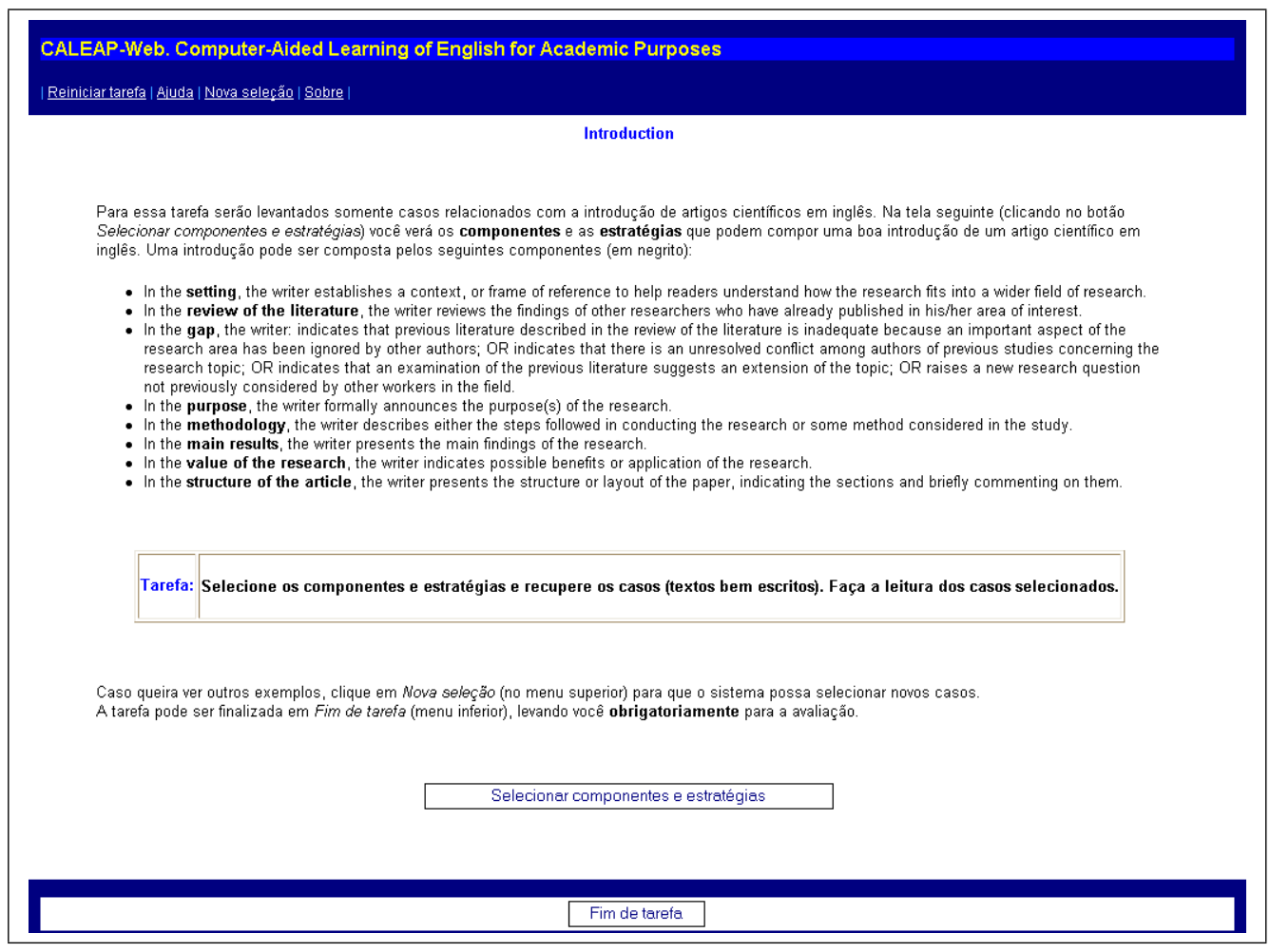

Figura 7.18: Tela com as explicações da Tarefa 2.

Ao clicar no botão Selecionar componentes e estratégias, inicia-se a escolha de estratégias para escrita de introduções de artigos científicos (Figura 7.19]. Essa tarefa foi criada a partir do CALESE, possibilitando recuperar casos segundo as estratégias para a escrita selecionadas. Por exemplo, a Figura 7.19 mostra a escolha de cinco estratégias de escrita e, após clicar em Recuperação de casos, recupera-se os casos tsf4, tsf8, tsf11, tsf14 e prl5 (ver Figura 7.20).

Recuperado os casos, $A 2$ deve realizar a leitura de um ou mais casos a sua escolha, buscando entender a estrutura de Introduções de artigos científicos. Escolhendo-se, por exemplo, o caso $t s f 4$, este é exibido em duas colunas inicialmente iguais (Figura 7.21). Ao clicar no botão Mostrar marcadores, na coluna da direita será exibido os marcadores para os componentes e estratégias do caso (Figura 7.22). Com esse recurso, é possível que o aluno estabeleça um processo reflexivo por exemplificação na aprendizagem de onde e como os componentes e estratégias aparecem em um artigo científico em inglês. 


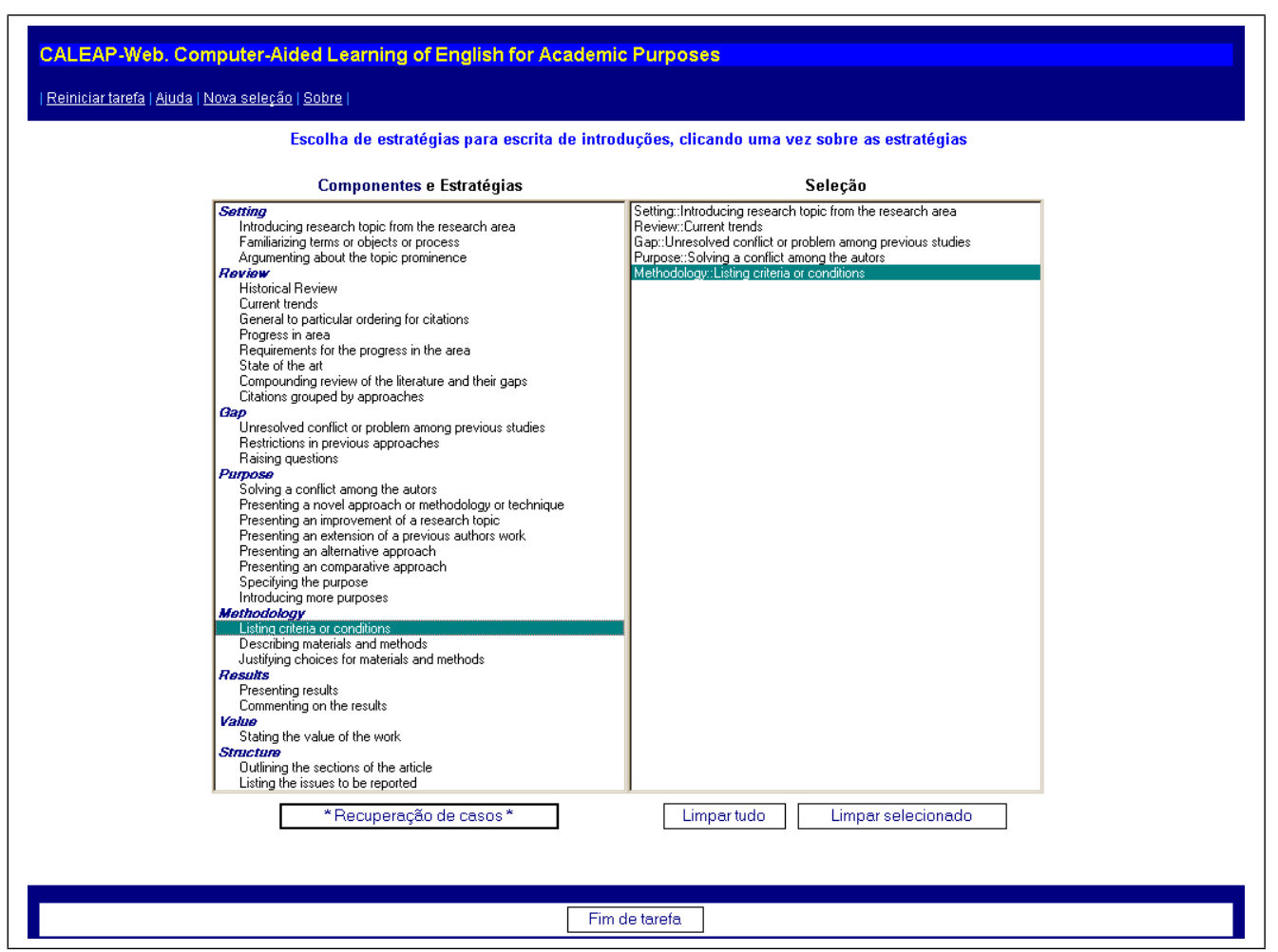

Figura 7.19: Tela da Tarefa 2 para a escolha de estratégias para a escrita de introduções.

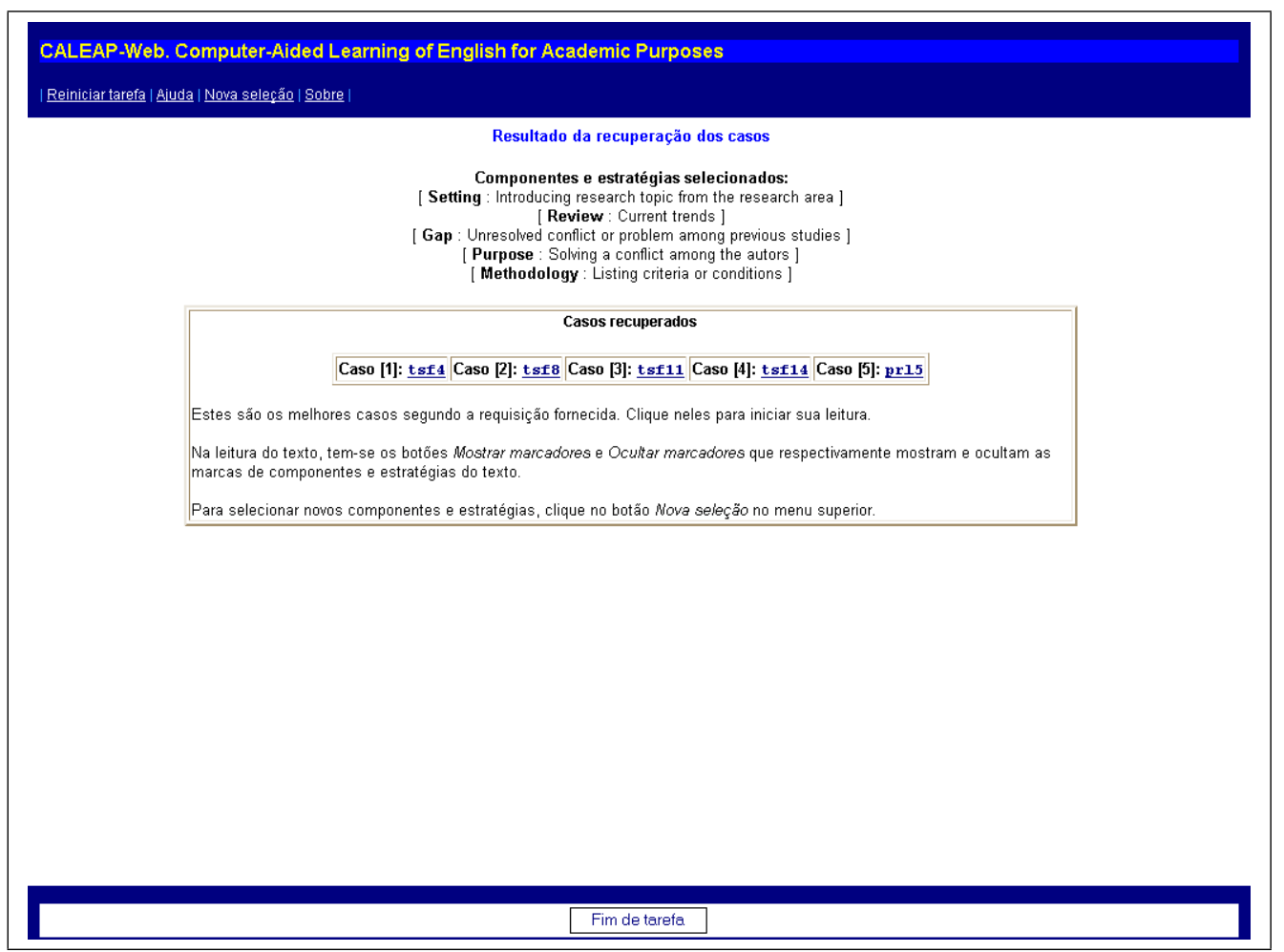

Figura 7.20: Tela com a recuperação de casos da Tarefa 2. 


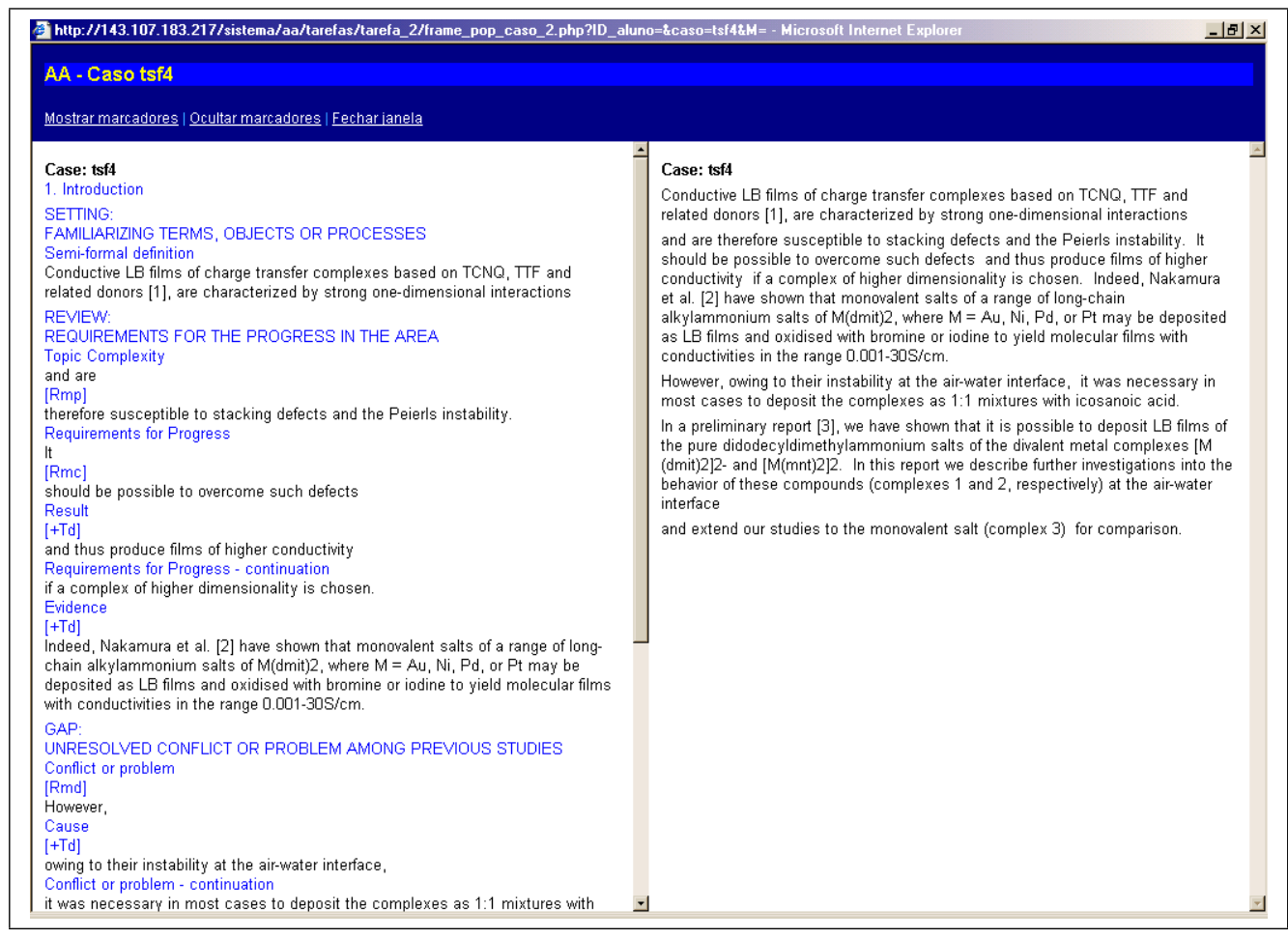

Figura 7.21: Tela 1 com a exibição do caso tsf4 para a Tarefa 2.

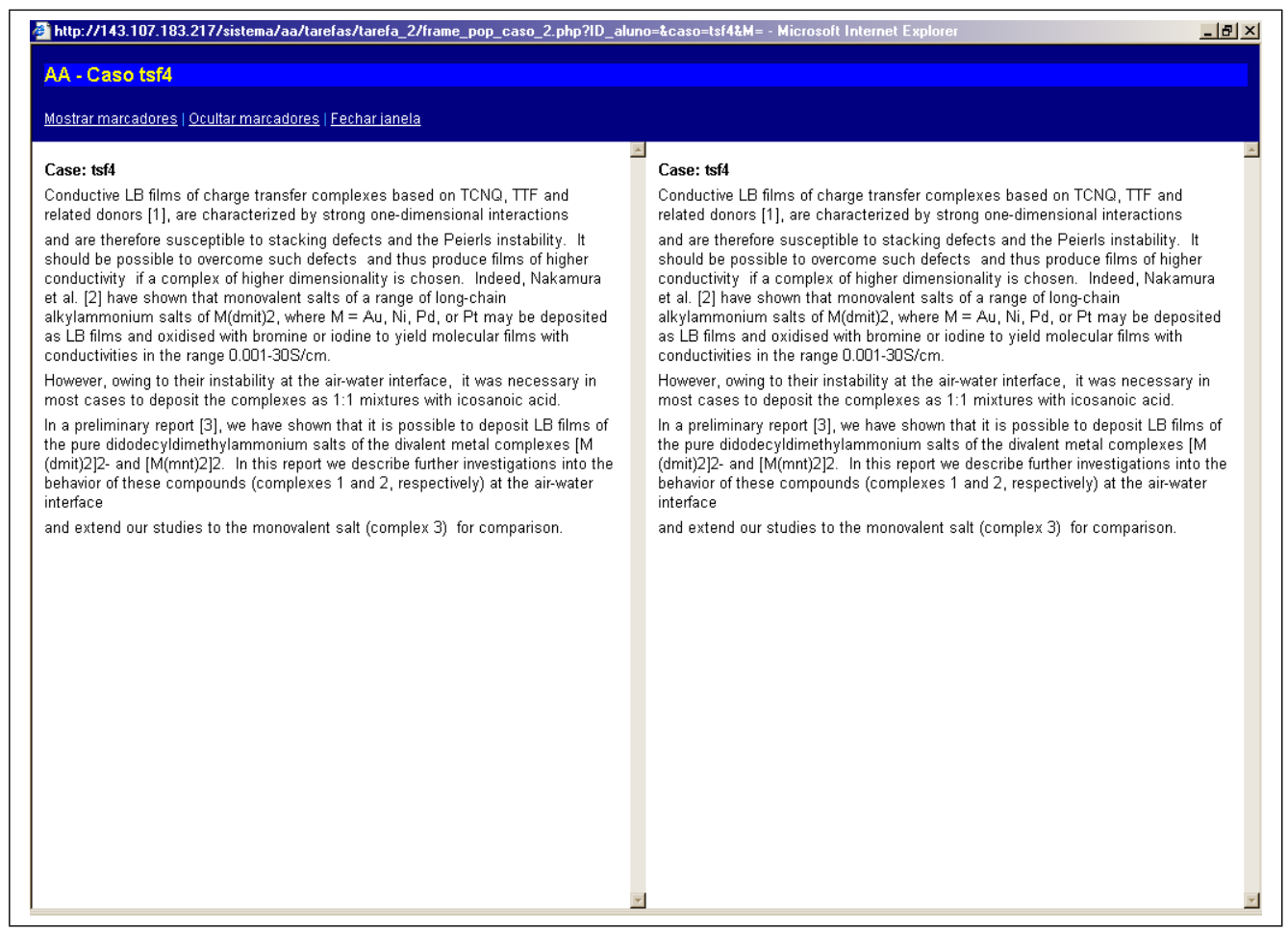

Figura 7.22: Tela 2 com a exibição do caso tsf4 para a Tarefa 2.

O aluno pode realizar novamente a tarefa e selecionar novas estratégias para a escrita de artigos científicos em inglês, ou finalizá-la (botão Fim de tarefa), que imediatamente o leva 
à reavaliação do $M 2$. Se o aluno atingir o critério para a inicialização da tarefa, novamente realizará T2. Caso contrário, será levado ao teste do Módulo 4 (M4) do EPI.

\subsubsection{Interação do Aluno com o CALEAP-Web na Tarefa 4}

A T4 trabalha com os conteúdos Setting e Review of Literature do M4. Para simular T4 escolheu-se um certo aluno $(A 4) \operatorname{com} \theta_{M 4}=0,370783$. A Tabela 7.4 mostra seus dados no decorrer do teste para o $M 4$.

Tabela 7.4: Dados do aluno 4 no ADEPT para o Módulo 4 do EPI.

\begin{tabular}{|c|c|c|c|c|}
\hline Questão & ID da Questão & Resposta & theta & $\mathrm{P}($ theta $)$ \\
\hline 10 & 51 & correta & 0,97747 & 0,914201 \\
\hline 11 & 56 & correta & 1,744692 & 0,915939 \\
\hline 12 & 46 & incorreta & 0,83444 & 0,421478 \\
\hline 13 & 59 & correta & 1,358763 & 0,836048 \\
\hline 14 & 57 & incorreta & 0,877287 & 0,458427 \\
\hline 15 & 60 & incorreta & 0,370783 & 0,440889 \\
\hline
\end{tabular}

$A 4$ é levado à $T 4$ (Figura 7.23), porque respondeu incorretamente a três questões pertencentes às partes Setting e Review of Literature do M4.

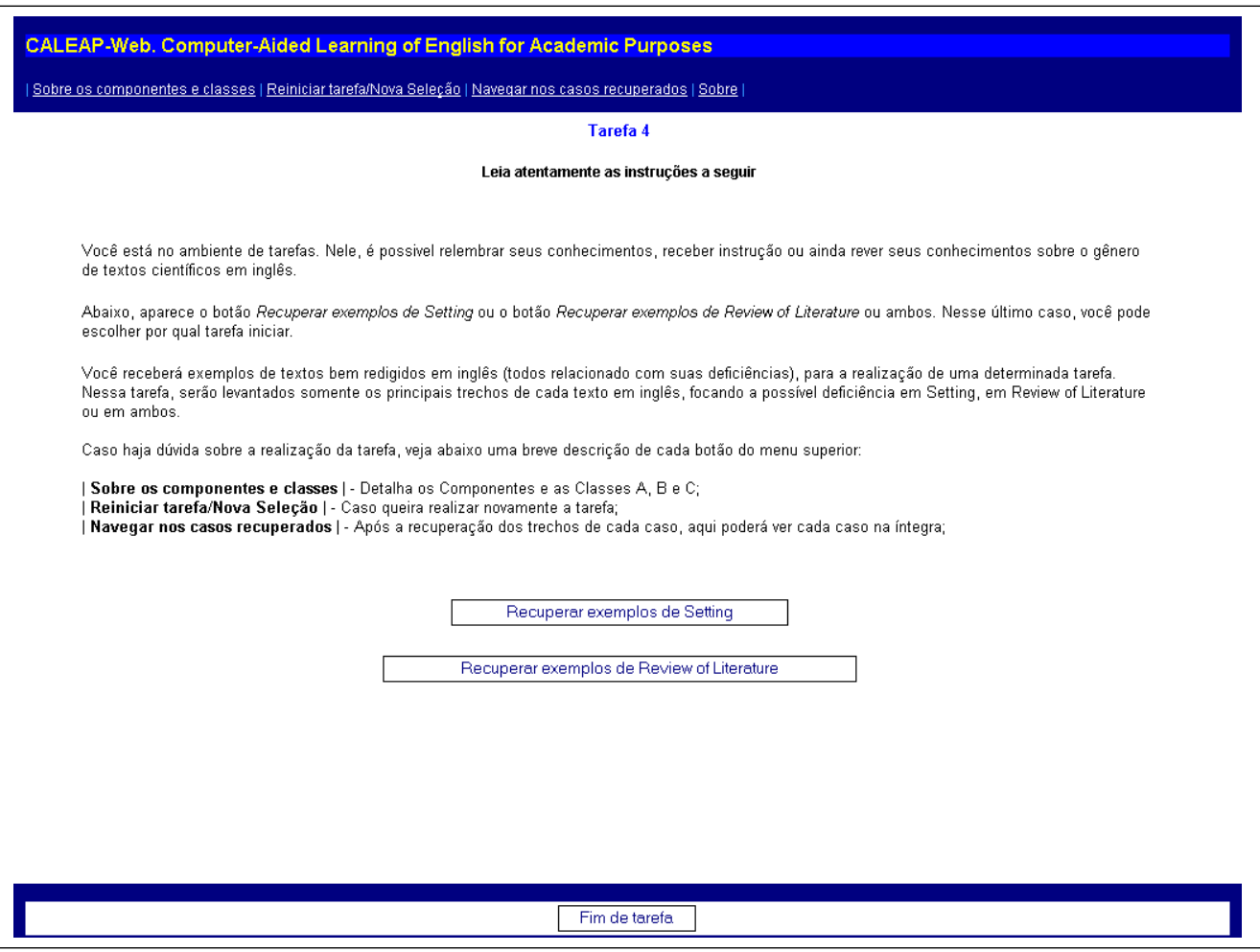

Figura 7.23: Tela com as instruções da Tarefa 4. 
Existem dois botões: Recuperar exemplos de Setting e Recuperar exemplos de Review of Literature. A4 poderá optar pelo primeiro ou segundo botão para iniciar a recuperação dos exemplos de textos bem redigidos em inglês. Se $A 4$ escolher realizar as tarefas relacionadas com o conteúdo de Gap, então é levado à tela de explicações da T4 (Figura 7.24).

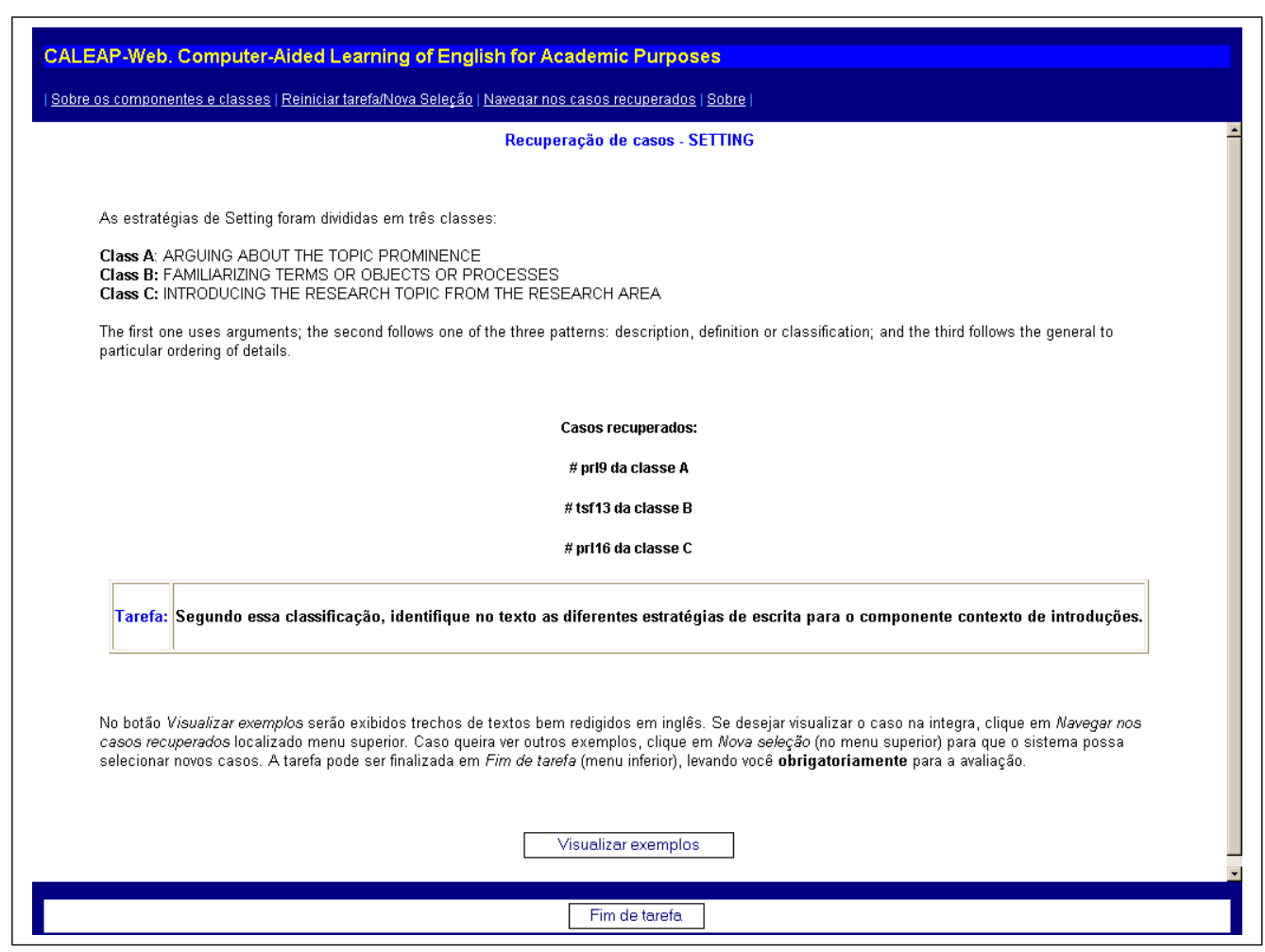

Figura 7.24: Tela com as explicações de Setting da Tarefa 4.

Os exemplos de Setting foram classificados em duas classes:

Class A: Arguing about the topic prominence: uses arguments;

Class B: Familiarizing terms or objects or processes: follows one of the three patterns: description, definition or classification;

Class C Introducing the research topic from the research area: follows the general to particular ordering of details.

O CALEAP-Web recuperará três casos de cada classe. Com isso, T4 de Setting, consiste em identificar no texto as diferentes estratégias de escrita para o componente contexto de introduções. Com um clique em Visualizar exemplos tem-se a tela na Figura 7.25. Nela são exibidos apenas os trechos de exemplos selecionados pelo ambiente. Na opção Navegar nos casos recuperados (ver Figura 7.14), pode-se visualizar o exemplo contextualizado no caso.

O A4 pode realizar a tarefa relacionada com o conteúdo Review of Literature. Os exemplos de Review of Literature (Figura 7.26) foram classificados em três classes: 


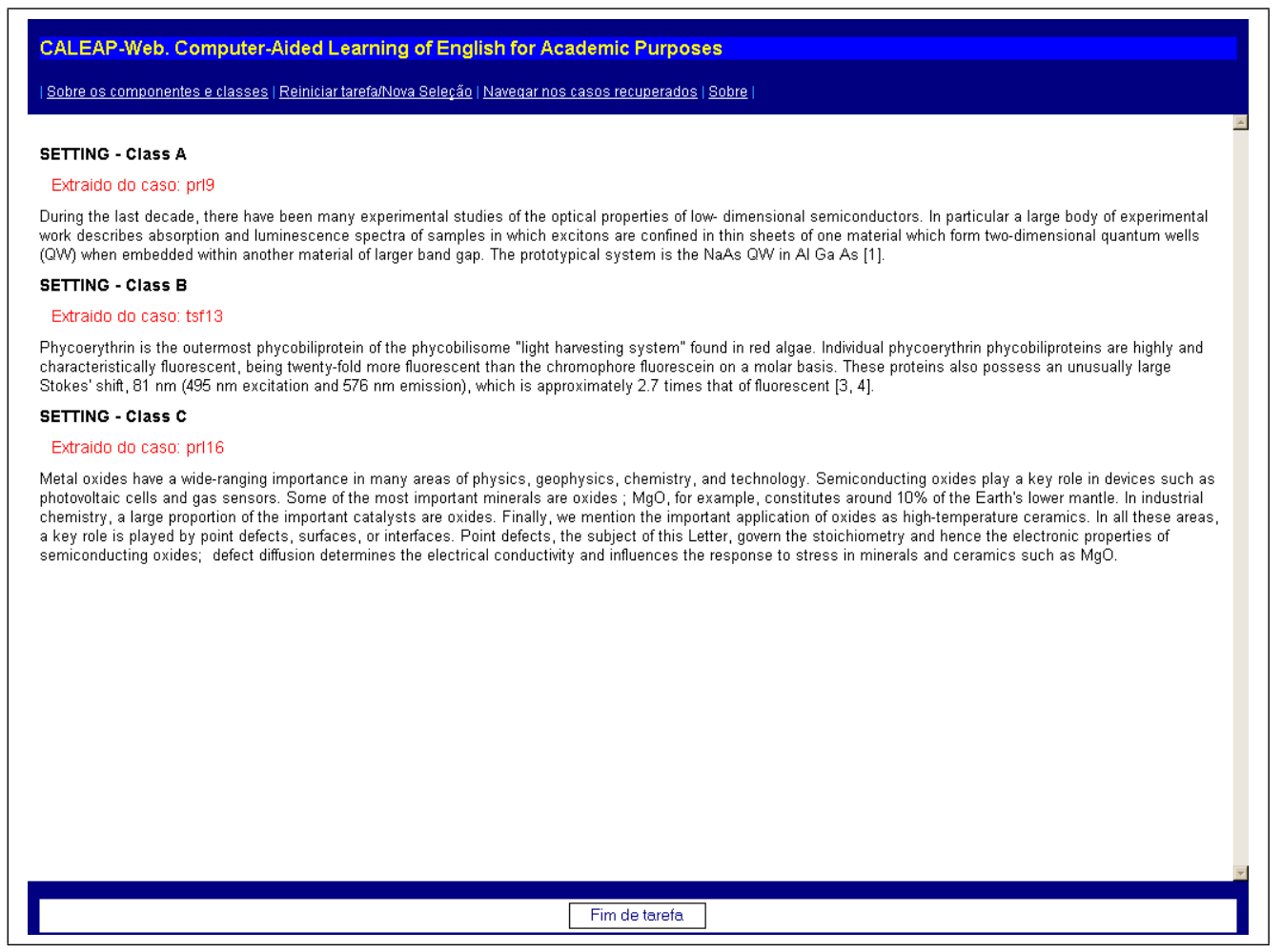

Figura 7.25: Tela da Tarefa 4 com os exemplos de Setting recuperados.

Class A: Citations grouped by approaches: is better suited for reviews of the literature which encompass different approaches;

Class B: Citations ordered from general to specific (General to particular ordering for citations): citations are organized in order from those most distantly related to the study to those most closely related;

Class C: Citations ordered chronologically (Historical Review): is used, for example, when describing the history of research in an area.

Recupera-se exemplos de três classes (Figura 7.27), sendo a T4 de Review of Literature: identificar no texto as diferentes estratégias de escrita para o componente revisão da literatura. As opções de Visualizar exemplos e Navegar nos casos recuperados também estão presentes.

O aluno poderá realizar novamente a mesma tarefa com a seleção de novos casos, ou terminar a tarefa clicando em Fim de tarefa, levando o $A 4$ à avaliação do $M 4$. Se no teste o $A 4$ atingir o critério para inicializar a tarefa, então realizará novamente a T4. Caso contrário, será levado ao Módulo 3 (M3) do EPI. 


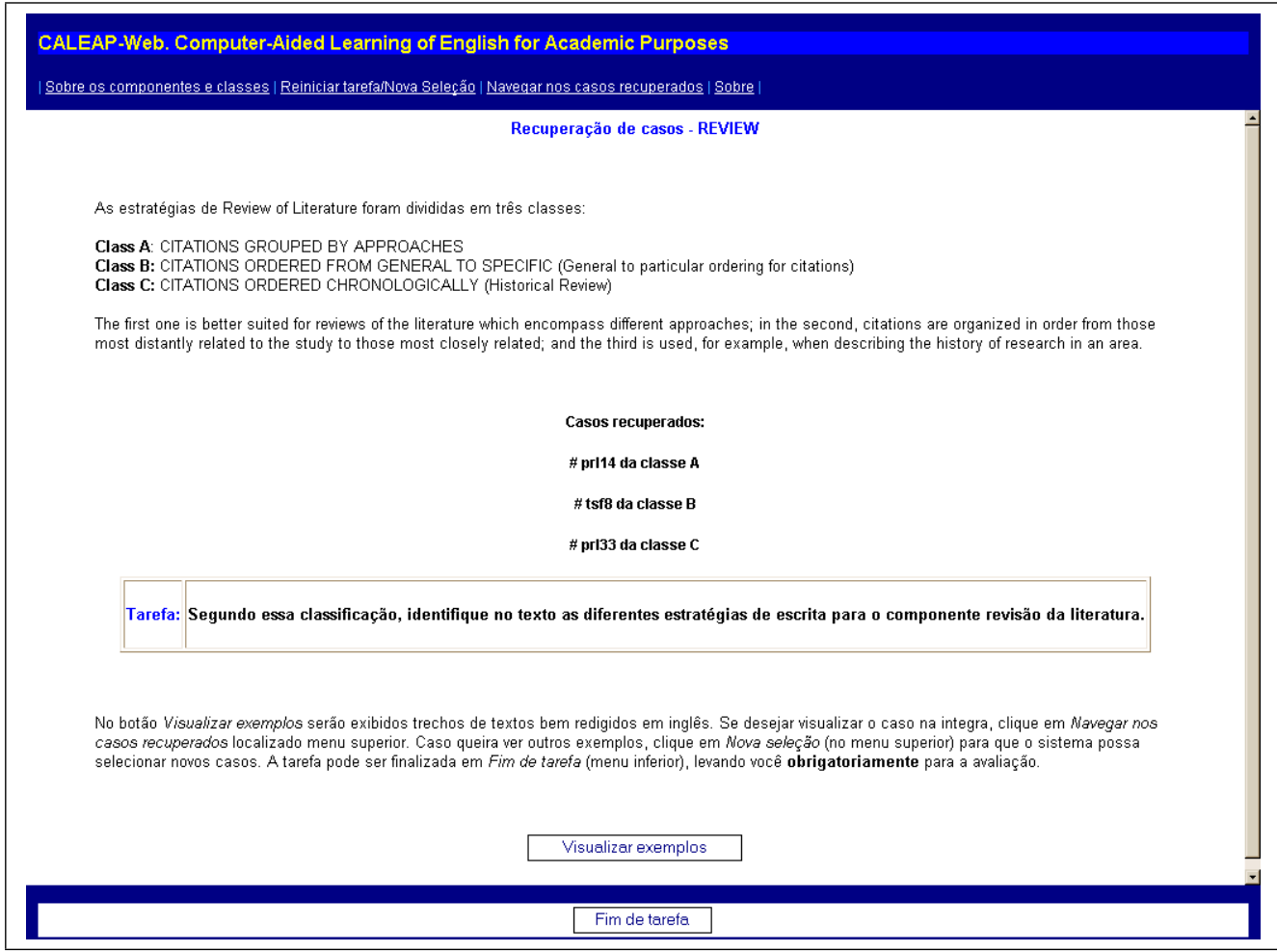

Figura 7.26: Tela com as explicações sobre Review of Literature da Tarefa 4.

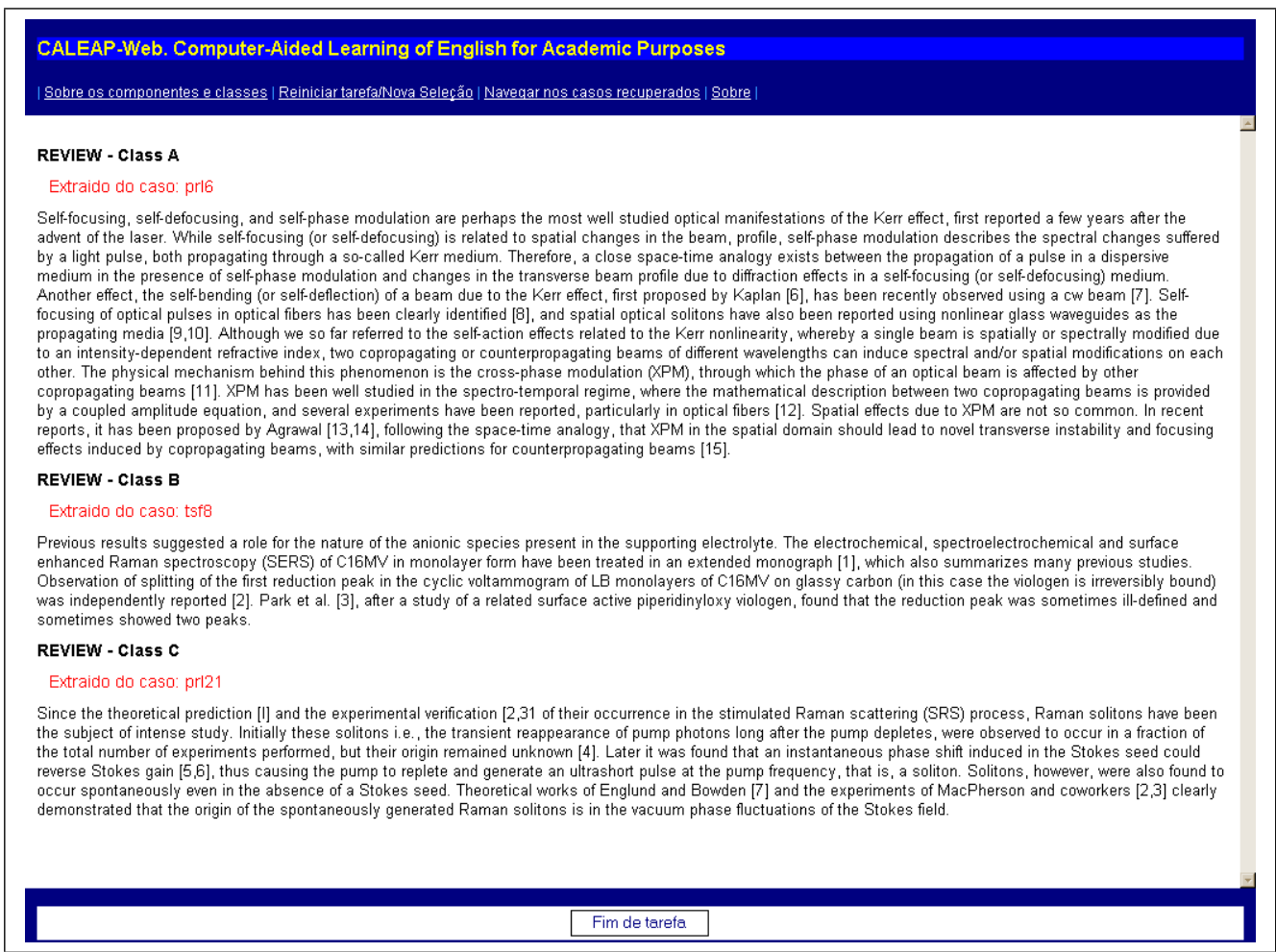

Figura 7.27: Tela da Tarefa 4 com os exemplos recuperados de Review of Literature. 


\subsubsection{Interação do Aluno com o CALEAP-Web na Tarefa 3}

O conteúdo Comprehension do M3 é ministrado pela T3. Para a interação elegeu-se um certo aluno $(A 3) \operatorname{com} \theta_{M 3}=0,348257$. A Tabela 7.5 mostra seus dados no decorrer do teste para o $M 3$.

Tabela 7.5: Dados do aluno 3 no ADEPT para o Módulo 3 do EPI.

\begin{tabular}{|c|c|c|c|c|}
\hline Questão & ID da Questão & Resposta & theta & $\mathrm{P}($ theta) \\
\hline 13 & 139 & incorreta & $-1,965543$ & 0,345112 \\
\hline 14 & 137 & correta & $-0,595272$ & 0,939528 \\
\hline 15 & 138 & correta & $-0,108067$ & 0,961335 \\
\hline 16 & 136 & incorreta & $-0,137163$ & 0,391113 \\
\hline 17 & 140 & correta & 0,093071 & 0,945767 \\
\hline 18 & 141 & correta & 0,348257 & 0,966676 \\
\hline
\end{tabular}

$A 3$ respondeu incorretamente a duas questões e devido a isso é levado à T3. Após a leitura das instruções (Figura 7.28), na tela seguinte (Figura 7.29) será fornecida a tarefa, que consiste em verificar os vários exemplos dos marcadores de cada função do discurso.

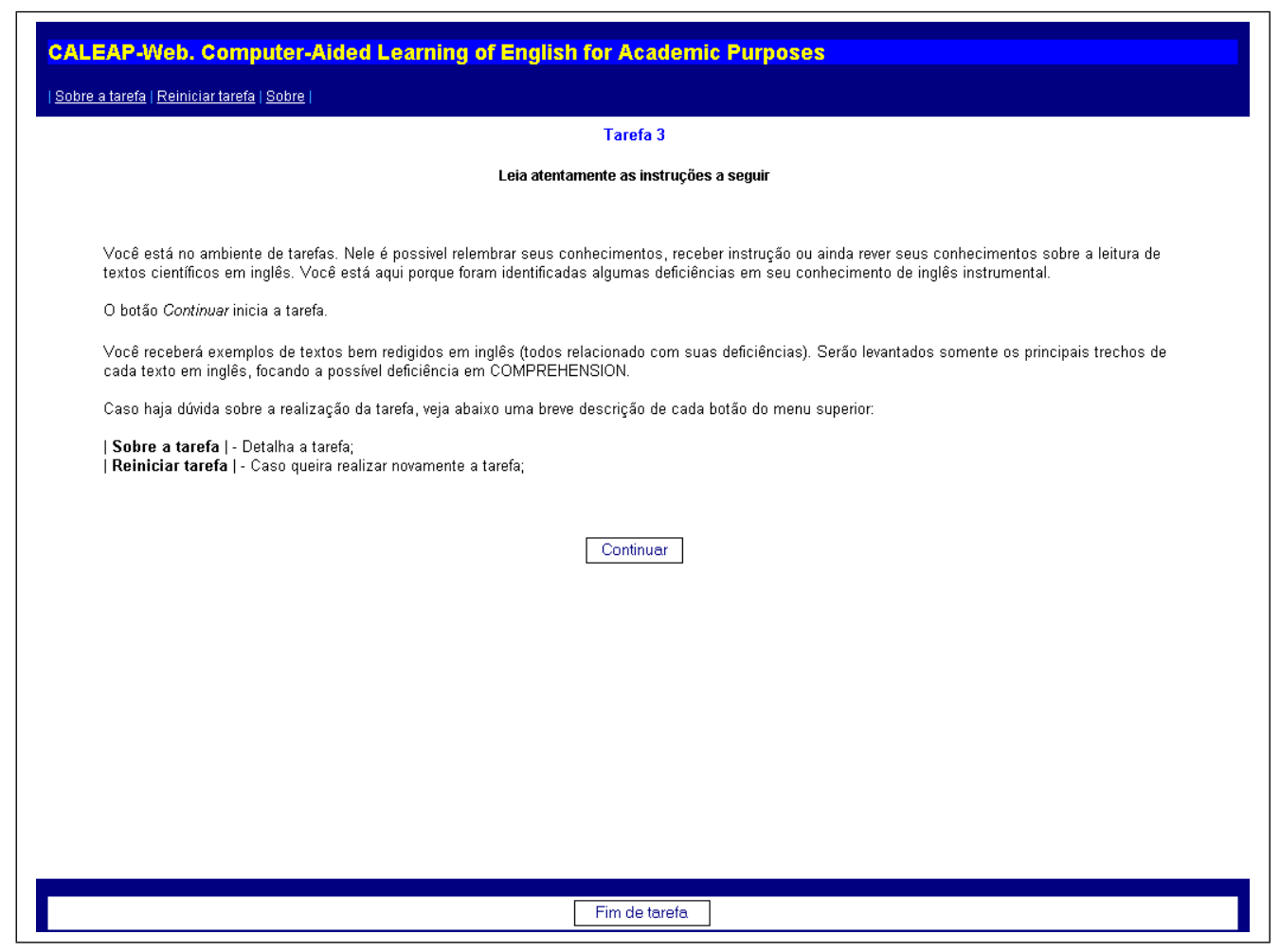

Figura 7.28: Tela com as instruções da Tarefa 3 .

Clicando em Ver marcadores de discurso será apresentada uma seqüência de marcadores, que são organizados pelas seguintes colunas: 


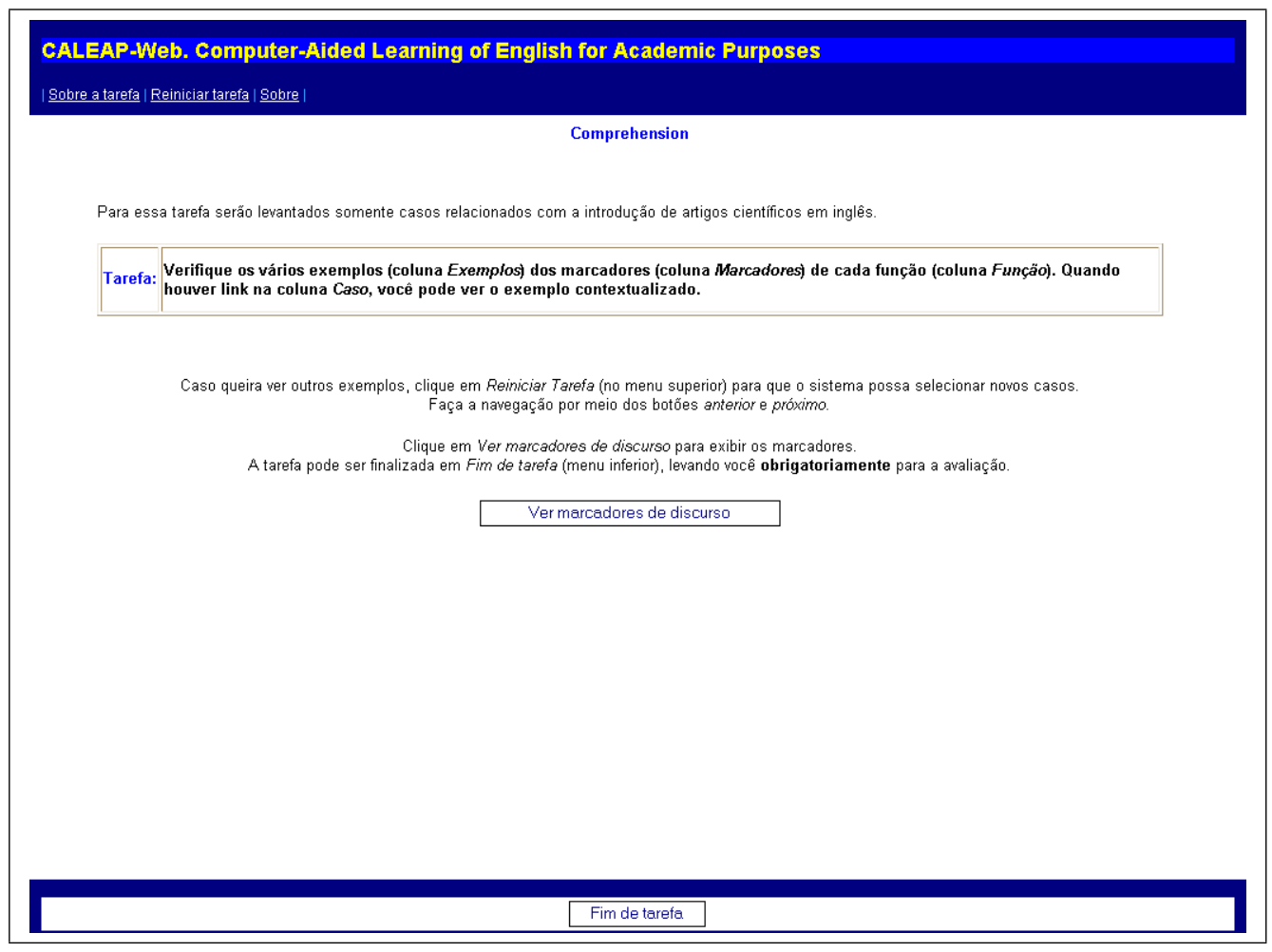

Figura 7.29: Tela com as explicações da Tarefa 3.

Função: é a função do marcador nas orações ou entre orações;

Marcadores: são os marcadores de ligando duas orações ou presente em uma;

Exemplos: são os exemplos selecionados da base de casos do CATESE, de artigos da URL IEEE ${ }^{3}$ ou da URL Online Concordancer (BNC Written) $4_{4}^{4}$

Caso: se houver um link, serão exibidos os exemplos contextualizados.

São um total de 9 marcadores de discurso, apresentados um por tela, conforme exemplos das Figuras 7.30 e 7.31 .

\footnotetext{
${ }^{3} \mathrm{http}: / / \mathrm{www}$.ieee.org

${ }^{4}$ http://132.208.224.131/Concord.htm
} 


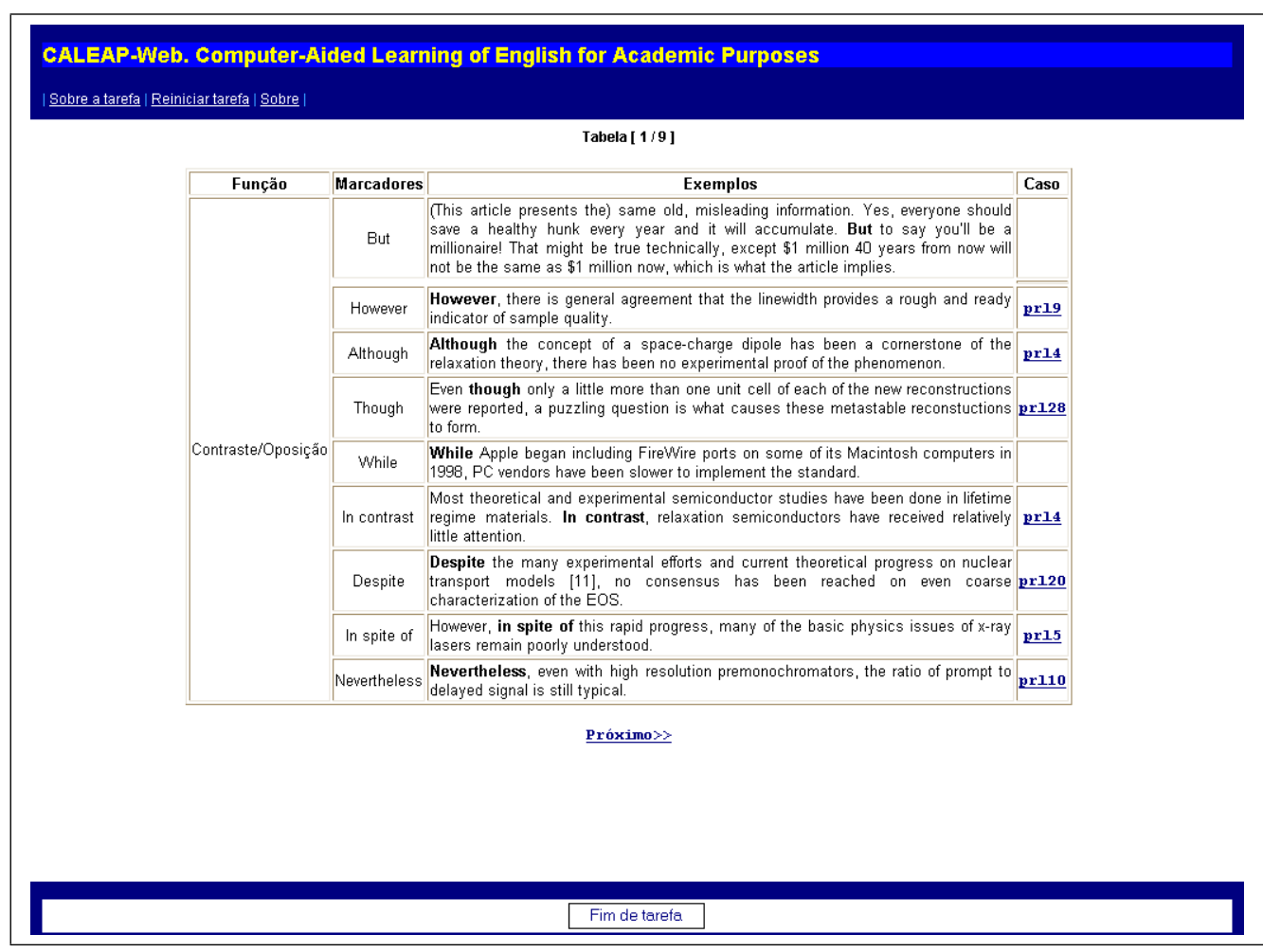

Figura 7.30: Tela com os marcadores da função contraste/oposição da Tarefa 3.

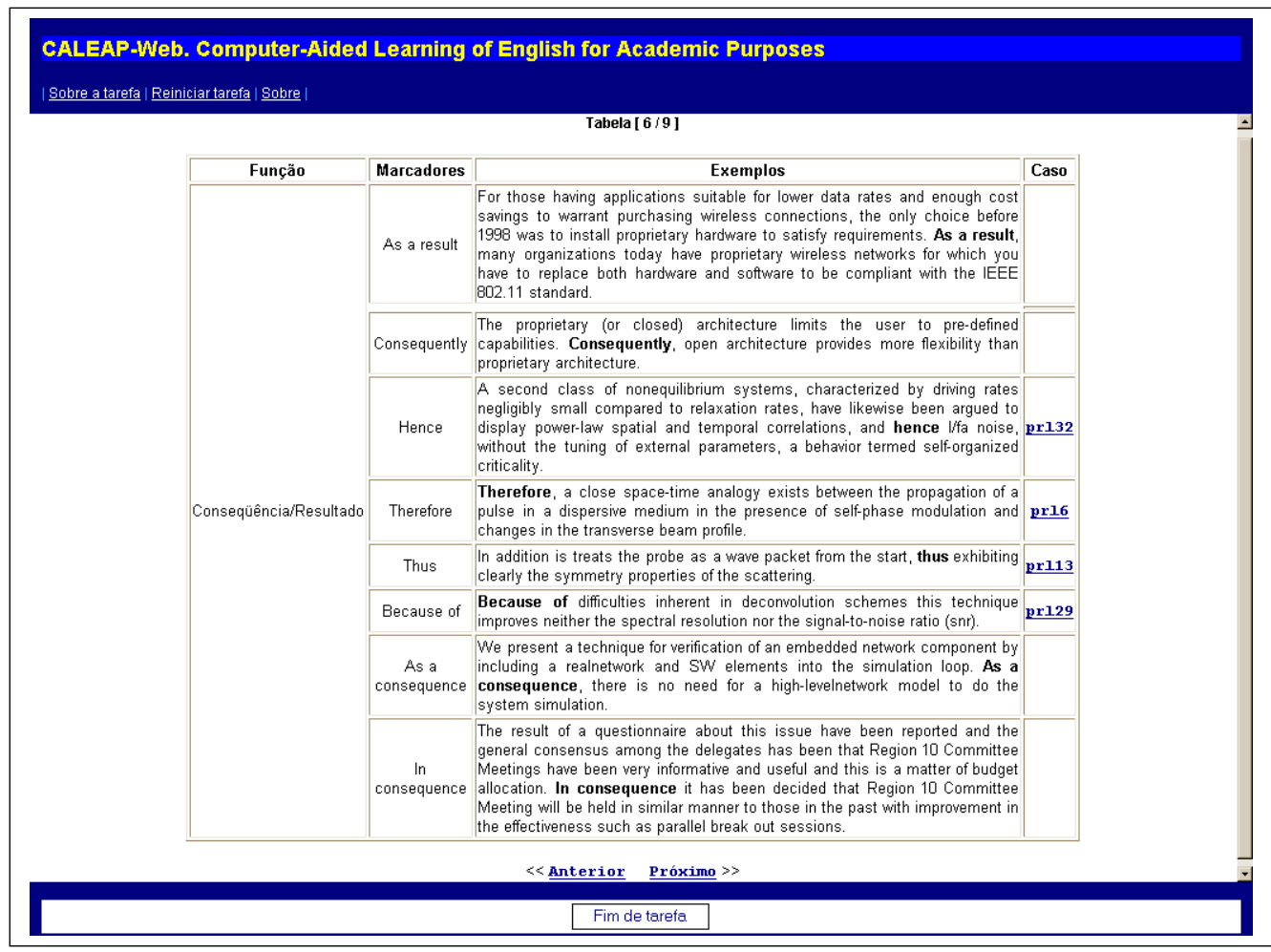

Figura 7.31: Tela com os marcadores da função consequiência/resultado da Tarefa 3. 
Após o aluno passar pelos quatro Módulos do EPI, receberá a tela apresentada na Figura 7.32, que irá finalizar o uso do ambiente. Nesse momento, espera-se que o aluno tenha aprendido os conteúdos sugeridos pelo CALEAP-Web para auxiliar a leitura e escrita de artigos científicos de sua área de pesquisa. Também, a partir desse momento, acredita-se que o aluno poderá realizar o EPI para o mestrado do ICMC-USP com maior segurança.

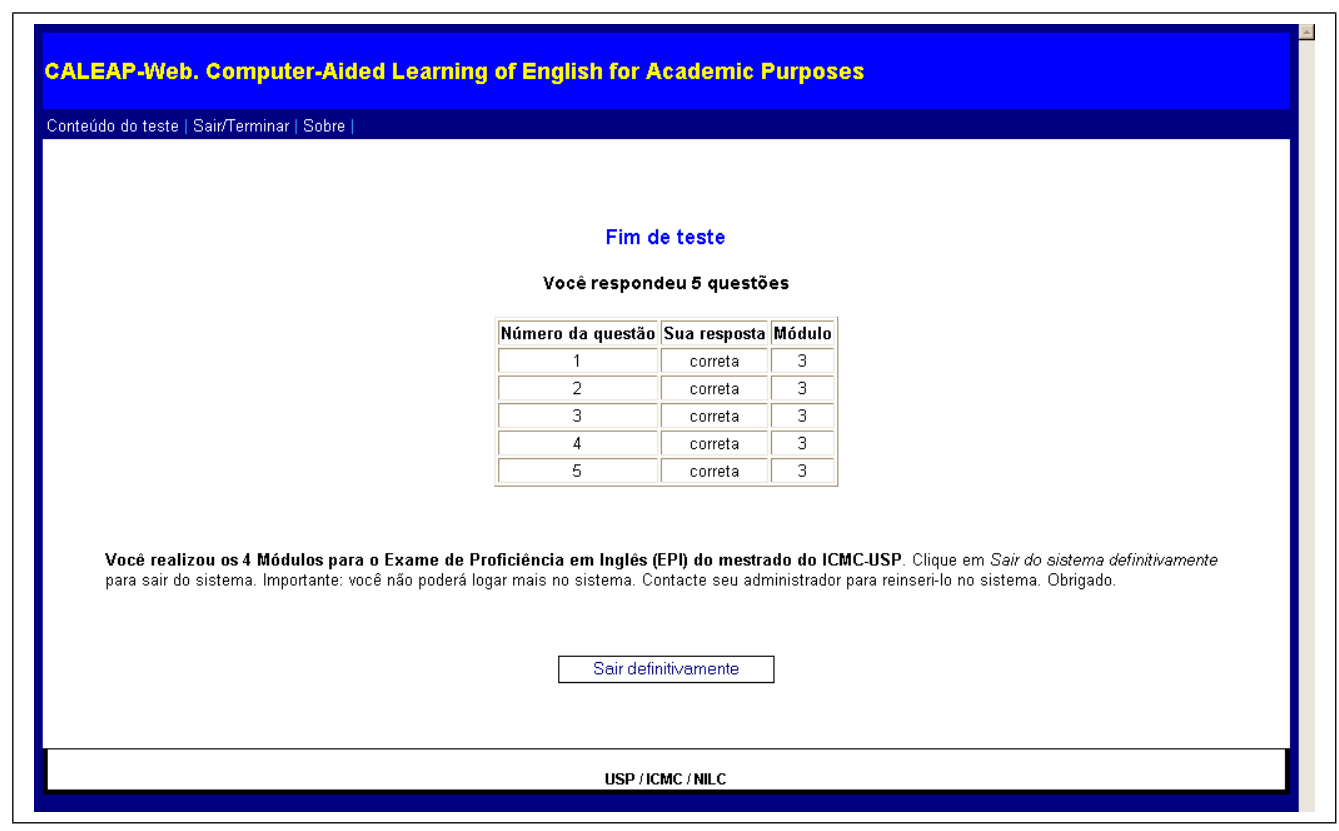

Figura 7.32: Término do uso do CALEAP-Web.

\subsection{Discussão dos Resultados}

O CALEAP-Web mostra-se como uma possível solução para pequenas instituições de ensino que avaliem a proficiência em lingua estrangeira e desejem incentivar seus alunos e jovens pesquisadores a lerem e escreverem com maior rapidez artigos em inglês. $\mathrm{O}$ ambiente foi desenvolvido sob as óticas da Lingüística Computacional (a base de casos), abordagem AprenderFazendo e Avaliação Formativa. O CALEAP-Web fornece um contexto de aprendizagem por meio de tarefas, que permite ao aluno selecionar, refletir e levantar conjecturas de seu próprio conhecimento de leitura e compreensão de textos científicos em inglês.

Este capítulo sobre a avaliação da operacionalidade do CALEAP-Web reforça a premissa que podem ser desenvolvidos ACA's que propiciem cenários favoráveis ao aprendizado de determinados conteúdos, que no caso dessa pesquisa são os quatro Módulos do EPI do programa de mestrado em Ciências da Computação e Matemática Computacional do ICMC-USP.

No CALEAP-Web, o aluno é levado, a partir do término de um teste (em um certo Módulo do EPI), para uma determinada tarefa sempre que responder incorretamente pelo menos a duas 
questões. Esse valor determinado não é incoerente, já que o aluno pode receber um número mínimo de 3 e no máximo 6 questões no TAI. O critério certamente poderia ser outro, por exemplo referenciado a partir do $\theta$ do aluno. Mas para isso, precisa-se de um estudo aprofundado sobre metodologias de avaliação baseados em processos de ensino/aprendizagem, que não é assunto tratado por essa pesquisa.

\subsection{Considerações Finais}

O CALEAP-Web é um ambiente fruto da integração de um TAI e um ACT, cobrindo os dois principais processos da aquisição de conhecimento: avaliar e aprender/estudar. O primeiro é realizado pelo ADEPT e o segundo pelo CATESE, integrados por logs em arquivo e por informações do BI. Quatro simulações das tarefas foram realizadas com o objetivo de descrever e mostrar que o CALEAP-Web está funcional e robusto e oferece:

- Interatividade entre usuário-computador;

- Tarefas que estão de acordo com os conteúdos abordados no teste;

- Uma avaliação adaptativa, possibilitando uma individualização do teste;

- Flexibilidade na realização das tarefas. Existe o "livre arbítrio" na execução de uma tarefa pelo aluno, pois a sua realização é opcional;

- Uma base de casos analisada e depurada para as tarefas, em que os casos são artigos científicos (ou parte deles). 


\section{Capítulo 8}

\section{Conclusão}

Nessa pesquisa foi abordado o desenvolvimento de um Ambiente Computacional de Aprendizagem, que propicia um contexto favorável para o aprendizado do inglês instrumental para o Exame de Proficiência em Inglês do mestrado em Ciências da Computação e Matemática Computacional do ICMC-USP. A hipótese que pretendíamos avaliar era se a integração de um Teste Adaptativo Informatizado e um Ambiente Computacional de Tarefas poderia gerar um Ambiente Computacional de Aprendizagem baseado na abordagem Aprender Fazendo que fosse útil para ensinar as convenções do gênero de textos científicos a jovens pesquisadores. Para avaliar a hipótese foi projetado, desenvolvido e avaliado tal ambiente.

A metodologia para o desenvolvimento do ambiente foi a implementação, em um primeiro momento, de um Teste Adaptativo Informatizado baseado no CBAT-2 seguido de avaliação com alunos de mestrado do ICMC-USP, e em um segundo momento, implementou-se um Ambiente Computacional de Tarefas que fornece tarefas para o aprendizado do aluno. O Ambiente Computacional de Tarefas foi avaliado juntamente com o ambiente de aprendizagem somente quanto a sua operacionalidade.

Para a realização dessa pesquisa de mestrado, foram necessárias muitas etapas. Inicialmente, houve um levantamento e revisão de literatura nas áreas de Informática na Educação (processos de ensino/aprendizagem, ambientes computacionais para o ensino e aprendizagem e avaliação de alunos), Ciência da Computação (Sistemas Tutores Inteligentes, Testes Informatizados, Testes Adaptativos Informatizados baseados na Teoria de Resposta ao Item, o algoritmo CBAT-2), Matemática (interpretação dos modelos, método de Newton-Raphson iterativo modificado) e escrita científica (o gênero de artigos científicos em inglês).

Para a implementação do Teste Adaptativo Informatizado baseado no CBAT-2, houve a necessidade de estabelecer um projeto de software, interpretação e análise da Teoria de Resposta ao Item. De fato, buscou-se a total compreensão do tema Teste Adaptativo Informatizado e do CBAT-2 para a implementação do ADEPT. 


\subsection{Contribuições}

A primeira contribuição dessa pesquisa foi a descrição detalhada da teoria necessária para a implementação do Teste Adaptativo Informatizado baseado na CBAT-2, e a avaliação do Teste Adaptativo Informatizado com alunos reais, presentes em um relatório técnico. Nesse documento há uma ampla análise de um Teste Adaptativo Informatizado baseado no CBAT-2, da estimativa da habilidade $\theta$ do aluno utilizando o método de Newton-Raphson iterativo modificado e da calibração do parâmetro $b$ dos items do Banco de Itens. Ressalta-se que o conteúdo das questões foram os quatro Módulos do Exame de Proficiência em Inglês para o mestrado do ICMC-USP.

Segundo os resultados obtidos da avaliação do Teste Adaptativo Informatizado, conclui-se que o conhecimento do aluno é o fator determinante para seu próprio sucesso ou fracasso em um Teste Adaptativo Informatizado, não ocorrendo a inferência do professor na calibração da base (salvo para a estimativa inicial). Isso permite uma maior adequação e individualização na avaliação de alunos, por causa da autocalibração do Teste Adaptativo Informatizado baseado no CBAT-2. De acordo com os resultados dos experimentos, pode-se afirmar que o Teste Adaptativo Informatizado com sistema de autocalibração é eficaz para a Avaliação Formativa. O sistema autocalibrativo ADEPT permite o uso de uma Avaliação Formativa em alunos de pequenas instituições, na medida em que necessita de um banco com poucos itens, diferentemente de outros modelos de Testes Adaptativos Informatizados que necessitam de uma pré-calibração com muitos itens, na maioria das vezes inexistentes nessas pequenas pequenas instituições.

A segunda contribuição foi a proposta do Ambiente Computacional de Tarefas baseado no conteúdo dos quatro Módulos do Exame de Proficiência em Inglês para o mestrado do ICMCUSP e em ferramentas para a escrita desenvolvidos no ICMC-USP.

A terceira foi o Ambiente Computacional de Tarefas e o Teste Adaptativo Informatizado formando o Ambiente Computacional de Aprendizagem proposto, cuja integração foi baseada nos trabalhos de Conejo et al. (1999), Conejo et al. (2000), Conejo et al. (2001), Papanikolaou et al. (2001) e Gouli et al. (2001) - projeto TREE e o INSPIRE. O propósito foi propiciar uma forma de ajudar os alunos de mestrado do ICMC-USP a estudarem para o EPI. Mas também fornecer um contexto de aprendizagem por meio de tarefas, que permite ao aluno selecionar, refletir e levantar conjecturas do seu próprio conhecimento de leitura e compreensão de textos científicos em inglês, propiciando sua autonomia em seu processo de aprendizagem. Tal fato é decorrente da liberdade que é dada ao aluno em executar as tarefas, tornando-se agente de seu próprio conhecimento. 


\subsection{Limitações}

O CALEAP-Web trabalha com quatro Módulos do Exame de Proficiência em Inglês do ICMC-USP que abrangem em parte o conhecimento inerente ao inglês instrumental. Por isso pode-se propiciar o aprendizado e avaliação do aluno somente nesse contexto dos Módulos do Exame de Proficiência em Inglês. Também o CALEAP-Web não trata do conteúdo abstract na Tarefa 2. Essa limitação é devido a ausência de uma base de casos analisada e classificada relacionada com abstracts de artigos científicos.

No CALEAP-Web, enquanto o aluno não responder todas as questões corretamente (com tolerância de uma questão), ele não será levado para o próximo Módulo. Aqui ressalta-se a necessidade de um estudo sobre outros critérios para a inicialização de uma tarefa, que de fato foi impossível no contexto dessa pesquisa, dada a necessidade de avaliação com alunos e análise.

Uma limitação da funcionalidade do CALEAP-Web é o esgotamento dos itens da base, visto que a cada nova realização de um teste, o aluno não receberá novamente as questões respondidas anteriormente. Uma solução para esse problema foi reestabelecer o status inicial do BI, ou seja, permitir a seleção de questões que já foram respondidas pelo mesmo aluno quando os itens se esgotaram.

Dentre todas as metas estabelecidas no cronograma do projeto de pesquisa desse mestrado, apenas uma não foi cumprida, que é a avaliação do CALEAP-Web com alunos reais. Tal fato é decorrente da dificuldade em trabalhar com usuários reais, ou seja, uma simples coleta de dados pode demorar meses. As dificuldades para se estabelecer esse cenário de avaliação são:

Motivação dos alunos: dificuldades foram encontradas para convocar os alunos de mestrado, pois muitos estavam atarefados com atividades de pesquisa;

Tempo de uso do sistema: para utilizar um Ambiente Computacional de Aprendizagem, tomase muito tempo do aprendiz, pois ele deverá realizar as tarefas tranqüilamente para que possa ocorrer a aquisição de conhecimento. Por exemplo, se o aluno realizar um Módulo por semana, são quatro semanas para passar por todos os Módulos do Exame de Proficiência em Inglês;

Tempo para análise: para analisar-se dados reais de alunos, necessita-se de um estudo aprofundado sobre processos de ensino/aprendizagem e outros parâmetros para análise, tais como idade, tempo de estudo na graduação, notas obtidas em outros exames de inglês, entre outros;

Monitoramento: no caso da realização das tarefas é interessante que o pesquisador monitore todos os passos do aluno, ou por captura de telas ou acompanhamento pessoal durante o 
uso do Ambiente Computacional de Aprendizagem, ou ainda gravação e análise de fita. Tais atividades demandam muito tempo do pesquisador.

\subsection{Trabalhos Futuros}

A proposta de elaborar cenários de aprendizado por meio de tarefas pode tornar o aprendizado mais interessante, pois o aluno determina o que e quando deseja aprender. Essa conjectura é reforçada na medida em que o aluno sente a necessidade de obter aquele conhecimento.

Um objetivo de continuação da pesquisa é utilizar-se o CALEAP-Web para o próximo Exame de Proficiência em Inglês para alunos de mestrado no ICMC-USP, podendo futuramente analisar-se os dados obtidos em situações reais com alunos.

Conforme dito na Seção 8.2, trabalhar com análise de dados de usuários reais é uma tarefa dispendiosa e trabalhosa. Por isso, pode-se em um trabalho de doutoramento futuro continuar essa análise, suportado por um trabalho direcionado na área de Ensino de Inglês Mediado por Computador. Também, pode-se melhorar o critério para a inicialização de uma tarefa, segundo critérios de Sistema Tutor Inteligente, pedagógicos ou de uma análise empírica a partir do uso do CALEAP-Web com usuários reais.

Acrescentar mais Partes nos Módulos do Exame de Proficiência em Inglês é também uma pretensão futura, com o objetivo de ter-se uma base de casos em inglês com todos os componentes necessários para a leitura e escrita de um bom artigo científico. 


\section{Referências Bibliográficas}

Abrantes, P. (1995). Avaliação e Educação Matemática (Primeira ed.). Rio de Janeiro, Brasil: Universidade Santa Úrsula, Série Reflexões em Educação Matemática MEM/USU-GEPEM.

Aluísio, S. M., I. Barcelos, J. Sampaio, \& O. N. O. Jr (2001, aug). How to learn the many unwritten "rules of the game" of the academic discourse: a hybrid approach based on critiques and cases to support scientifc writing. IEEE ICALT-Internetional Conference on Advanced Learning Tecnologies, 257-260.

Aluísio, S. M., V. T. de Aquino, R. Pizzirani, \& O. N. O. Jr (2003). High order skills with partial knowledge evaluation: Lessons learned from using a computer-based proficiency test of english for academic purposes. Journal of Information Technology Education 2(1), 185201.

Aluísio, S. M., N. Fontana, O. N. O. Jr, \& M. C. Ferreira (2003). Computer assisted writing - applications to english as a foreign languages. Assisted Language Learning Journal 6(2), 145-161.

Aluísio, S. M., N. Fontana, M. Oliveira, \& O. N. O. Jr (1993). Computer assisted writing applications to english as a foreign language. CALL-Computer Assisted Language Learning Journal 6(2), 145-161.

Aluísio, S. M. \& R. E. Gantenbein (1997). Towards the application of systemic functional linguistics in writing tools. Proceedings of International Conference on Computers and their Applications, 181-185.

Aluísio, S. M. \& O. N. O. Jr (1995). A case-based approach for developing writing tools aimed at non-native english users. Lecture Notes in Artificial Intelligence (1010), 121-132.

Aquino, V. T. (2001). Avaliação automática de exames de proficiência em inglês. Dissertação de mestrado, ICMC-USP, Instituto de Ciências Matemáticas e de Computação da Universidade de São Paulo, São Carlos, Brasil. 
Baker, F. (2001). The Basics of Item Response (Second ed.). College Park, MD: ERIC Clearinghouse on Assesment and Evaluation, University of Maryland. URL http: / / ericae. net/irt/baker/final.pdf, acessado em 18/11/2002.

Blandford, A. E. (1994). Teaching through collaborative problem solving. Journal of Artificial Intelligence in Education 5, 51-84.

Conejo, R., E. Millán, J. L. P. Cruz, \& M. Trella (2000, jun). An empirical approach to online learning in siette. ITS-Intelligent Tutorial Systems, 604-615.

Conejo, R., E. Millán, J. L. P. Cruz, \& M. Trella (2001). Modelado del alumno: um enfoque bayesiano. Inteligencia Artificial, Revista Iberoamericana de Inteligencia Artificial (12), 5058. URL http://tornado.dia.fi.upm.es/caepia/numeros/12/Conejo. pdf, acessado em 20/11/2002.

Conejo, R., A. Rios, M. T. Eva Millán, \& J. L. P. Cruz (1999). Internet based evaluation system. AIED-International Conference Artificial Intelligence in Education, IOS Press. URL http://www.lcc.uma.es/ eva/investigacion/papers/aied99a.ps.

Feltrim, V. D. (2003). Suporte computacional à escrita científica em português. Monografia de qualificação, ICMC-USP, Instituto de Ciências Matemáticas e de Computação da Universidade de São Paulo, São Carlos, Brasil. URLhttp://nilc.icmc.sc.usp.br/nilc/ download/VDFquali_corrigida.zip.

Feltrim, V. D. \& S. Teufel (2004). Automatic critiquing of novices scientific writing using argumentative zoning. Palo Alto, CA. AAAI Spring Symposium on Exploring Attitude and Affect in Text: Theories and Applications.

Gonçalves, J. P. \& S. M. Aluísio (2004, janeiro). Experimentos realizados com um teste adaptativo informatizado para o domínio do inglês instrumental. Relatório Técnico 224, ISSN 0103-2569, Publicações do ICMC-USP, Biblioteca Prof. Achille Bassi, São Carlos, Brasil. URL http: / / www . icmc.usp.br/ biblio/, disponível on-line.

Gonçalves, J. P. (2001). Uso de jogos computacionais educativos via internet na educação matemática - projeto formel. CNPQ-Conselho Nacional de Desenvolvimento Científico e Tecnológico, Anais do XVII Prêmio Jovem Cientista.

Gouli, E., H. Kornilakis, K. Papanikolaou, \& M. Grigoriadou (2001, December). Adaptive assessment improving interaction in an educational hypermedia system. PC-HCI Conference. URL http://hermes.di.uoa.gr/lab/CVs/papers/gouli/F51.pdf, acessado em 17/02/2003. 
Haydt, R. C. (1988). Avaliação do Processo Ensino-Aprendizagem. São Paulo, Brasil: Editora Ática, S.A.

Huang, S. X. (1996a, jul). A content-balanced adaptive testing. in computer aided learning and instruction in science and engineering. CALISCE-Computer Aided Learning and Instruction in Science and Engineering (3), 29-31.

Huang, S. X. (1996b, jun). On content-balanced adaptive testing algorithm for computer-based training systems. ITS-Intelligent Tutorial Systems, 12-14.

Lord, F. M. (1980). Application of Item Response Theory to Practical Testing Problems (first ed.). Hilsdale, New Jersey, EUA: Lawrence Erlbaum Associates.

McKenna, C. \& J. Bull (1999, June). Design effective objective test questions: an introductory workshop. Proceedings of the Conference at Loughborough University, Flexible Learning (Third), 253-257.

Miller, A., B. W. Imrie, \& K. Cox (1998, dec). Student Assessment in Higher Education, A Handbook for Assessing Performance (First ed.). 120 Pentonville Road, London, UK: Kogan Page.

Miskulin, R. G. S. (1999). Concepções Teórico-Medodológicas Sobre a Introdução e a Utilização de Computadores no Processo de Ensino/Aprendizagem da Geometria. Tese de doutorado, FE-Unicamp, Faculdade de Educação da Universidade Estadual de Campinas, Campinas, Brasil. URL http://www . cempem. fae.unicamp.br/lapemmec/ coordenacao/tese.pdf, acessado em 10/03/2003.

Morettin, P. \& W. Bussab (2003). Estatística Básica (Quinta ed.). São Vicente, Brasil: Editora Saraiva.

Neto, S. P. (1987). A Natureza da Aprendizagem e do Ensino (Primeira ed.). São Paulo, Brasil: EPU.

Olea, J., V. Ponsoda, \& G. Prieto (1999). Tests Informatizados Fundamentos y Aplicaciones. Ediciones Pirámede.

Oliveira, L. H. M. (2002). Testes adaptativos sensíveis ao conteúdo do banco de itens: uma aplicação em exames de proficiência em inglês para programas de pós-graduação. Dissertação de mestrado, ICMC-USP, Instituto de Ciências Matemáticas e de Computação da Universidade de São Paulo, São Carlos, Brasil. 
Papanikolaou, K., M. Grigoriadou, H. Kornilakis, \& G. D. Magoulas (2001, July). Inspire: An intelligent system for personalized instruction in a remote enviroment. Third Workshop on Adaptive Hypertext and Hypermedia Twelfth(Third), paper 3. URL http: / / wwwis . win. tue.nl/ah2001/papers/papanikolaou.pdf, acessado em 17/02/2003.

Ponte, J. P., A. M. Boavida, M. Graça, \& P. Abrantes (1997). Didáctica da Matemática, Ensino Secundário (Primeira ed.). Lisboa, Portugal: Editorial do Ministério da Educação, Departamento do Ensino Secundário.

Ramos, E. M. F. (1996). Análise Ergonômica do Sistema HiperNet Buscando Aprendizado da Cooperação e da Autonomia. Tese de doutorado, UFSC-Universidade Federal de Santa Catarina, Florianópolis, Brasil. URL http://www.inf.ufsc.br/ edla/tese/tese. htm, acessado em 7/01/2003.

Ruggiero, M. A. G. \& V. L. da Rocha Lopes (1997). Cálculo Numérico: Aspectos Teóricos e Computacionais (segunda edição ed.). São Paulo, Brasil: Makron Books.

Schank, R. (2002). Engines For Education (Hyperbook ed.). Chicago, USA: ILS-Institute for the Learning Sciences, Northwestern University. URL http: / / www . eng ines 4ed. org/hyperbook/index.html, acessado em 10/07/2003.

Schar, S. G. \& H. Krueger (2000, jul-sep). Using new learning tecnolggies with multimedia. IEEE Multimedia 7(3), 40-58.

Silva, A. R. M., C. Feltrin, J. Siqueira, L. U. Aguiar, \& W. T. Anjos (2000). John dewey. Universidade do Contestado. URL http://www.unc-mfa.rct-sc.br/Trabalhos/ Pedagogia/JOHN20DEWEY.doc, acessado em 20/09/2002.

Turine, M. A. S. (1994). Tegram: um sistema tutor de geometria plana baseado no tangram. Dissertação de mestrado, ICMC-USP, Instituto de Ciências Matemáticas e de Computação da Universidade de São Paulo, São Carlos, Brasil.

Varandas, J. M. (2000). Avaliação de investigações matemáticas: uma experiência. Dissertação de mestrado, DEFCUL, Departamento de Educação da Faculdade de Ciências, Universidade de Lisboa, Lisboa, Portugal. URL http://ia.fc.ul.pt/textos/jvarandas/ index.htm, acessado em 22/01/2003.

Wang, T. H. \& B. A. Hanson (2001, April). Developement and calibration of na item response model that incorporates response time. ACT Inc., Americam Educational Research Association in Seattle. 
Weiss, D. J. (1985). Adaptive testing by computer. Journal of Consulting and Clinical Psycho$\operatorname{logy} 53(6), 774-789$.

Witter, G. \& F. Romônaco (1984). A Natureza da Aprendizagem (Terceira ed.). São Paulo, Brasil: EPU. 


\section{Apêndice A}

\section{O Desenvolvimento do ADEPT}

Esse apêndice trata do desenvolvimento do Núcleo do Teste (Seção 6.1). Aqui descreve-se de forma algorítimica os processos para o desenvolvimento de um TAI baseado no CBAT-2. O principal requisito é a escolha de uma linguagem de programação que propicie melhores resultados com ponto flutuante. Para o caso do ADEPT, escolheu-se a linguagem $\mathrm{C}$ com código simples (sem orientação a objetos) para que tenha um bom desempenho.

Para melhor entendimento, foi realizado uma separação da execução do teste em 4 etapas:

1. Seleciona a questão ao aluno;

2. Aluno responde a questão;

3. Calibração do parâmetro $b$;

4. Estimativa da nova habilidade do aluno;

O processo é cíclico, sendo o fim determinado por um critério de parada do teste (Seção 6.1.2). As próximas seções tratam de cada etapa da execução do ADEPT, em processos de teor genérico. Para detalhes de cada fórmula, ver o Capítulo 4.

\section{A.1 Etapa 1 - Seleção da Questão ao Aluno}

Primeiramente, faz-se a seleção da questão $i$ ao aluno dentre as $N$ questões da base de itens $(0<i \leq N)$ por meio da Função de Informação de um Item (FII) dada pela seguinte fórmula:

$$
I_{i}(\theta)=\frac{\left(P_{i}^{\prime}(\theta)\right)^{2}}{P_{i}(\theta) Q_{i}(\theta)}
$$




$$
\begin{array}{r}
Q_{i}(\theta)=1-P_{i}(\theta) \\
P_{i}(\theta)=c+(1-c) \frac{1}{1+e^{-1.7 a(\theta-b)}}
\end{array}
$$

onde $\theta$ é a habilidade estimada do aluno, $P_{i}(\theta)$ é a probabilidade do aluno responder corretamente ao item $i$ (ver Seção 4.4.3), $P_{i}^{\prime}(\theta)$ é a derivada de primeira ordem da função $P_{i}(\theta)$.

Como cada questão possui os valores $a, b$ e $c$, então calcula-se a FII para todas as questões e seleciona-se o maior valor, ou seja, $I_{i}(\theta)=\max$. Essa será a questão $i$ selecionada ao aluno. No caso de existir valores para FII iguais, será selecionada a primeira ocorrência.

\section{A.2 Etapa 2 - Resposta à Questão}

Aqui existe somente a resposta do aluno à questão, que poderá ser correta $\left(r_{i}=1\right)$ ou incorrera $\left(r_{i}=0\right)$.

\section{A.3 Etapa 3 - Calibração do Parâmetro $b$ da Questão}

Primeiramente é necessário obter o parâmetro $b$ da $i$-ésima questão selecionada, com a finalidade de calibrar para um novo valor $\mu_{i}$. A seguir calcula-se o valor da função

$$
\mu_{i}=\frac{20 \omega_{0}+\Phi_{i}}{20+R_{i}+W_{i}}
$$

,onde $\mu_{i}$ é o novo $b$ calibrado e $\omega_{0}=b$. Mas para isso, precisa-se calcular

$$
\Phi_{i}=\sum_{j=1}^{n} k_{j} f\left(\theta_{j}^{\prime}\right)
$$

, que é a dificuldade acumulada por questão, dentre todas as questões respondidas até o momento. $n$ é o número de vezes que a questão $i$ foi respondida. $k_{j}$ é um valor que assume $k_{j}=0$ ou $k_{j}=2$ respectivamente se a $j$-ésima resposta à questão for correta ou incorreta. $R_{i}$ é o número de vezes que a questão atual foi respondida corretamente (de todos os testes anteriores); e $W_{i}$ é o número de vezes que a questão foi respondida incorretamente (de todos os testes anteriores).

$f\left(\theta_{j}^{\prime}\right)$ é uma função de normalização que converte o valor $\theta_{j}^{\prime}$ de um intervalo para outro. A escolha desse intervalo depende dos objetivos do teste. Para o ADEPT essa função converte do 
intervalo $[-4,4]$ para o intervalo $[0,1]$, segundo a fórmula

$$
f\left(\theta_{j}^{\prime}\right)=\frac{\theta_{j}^{\prime}+4}{8}
$$

Para essa etapa deve-se ter um histórico das respostas às questões de todos os alunos que passaram por ela, calibrando-se em tempo real o novo parâmetro $b=\mu_{i}$ para questão $i$.

\section{A.4 Etapa 4 - Estimativa da Habilidade do Aluno}

Na última etapa do ciclo, calcula-se o novo $\theta_{n+1}$ do aluno, baseado no atual $\theta_{n}$ do aluno, onde $n$ é o número de questões respondidas pelo aluno no teste (até o momento). O método de Newton-Raphson iterativo modificado (NR) é o modelo selecionado para a estimativa, que calcula o novo $\theta_{n+1}$ a partir da função

$$
\theta_{n+1}=\theta_{n}+\frac{\sum_{i=1}^{n} S_{i}\left(\theta_{n}\right)}{\sum_{i=1}^{n} I_{i}\left(\theta_{n}\right)}
$$

, e sendo

$$
S_{i}(\theta)=\left[r_{i}-P_{i}(\theta)\right] \frac{P_{i}^{\prime}(\theta)}{P_{i}(\theta)\left[1-P_{i}(\theta)\right]}
$$

, respectivamente $r_{i}=1$ ou $r_{i}=0$ se a resposta a questão estiver correta ou incorreta.

A função $S_{i}(\theta)$ é interpretada como um histórico da questão com relação à todos os alunos que responderam-na anteriormente. Um fato importante é que para essa última etapa, utiliza-se o valor $b$ não calibrado para $P_{i}(\theta)$ e $P_{i}^{\prime}(\theta)$, ou seja, $b=\omega_{0}$. 


\section{A.5 Ciclo das Etapas}

A Figura A.1 mostra o ciclo de etapas, que completado, tem-se a calibração no novo parâmetro dificuldade da questão (b) e o novo parâmetro habilidade do aluno $\theta$.

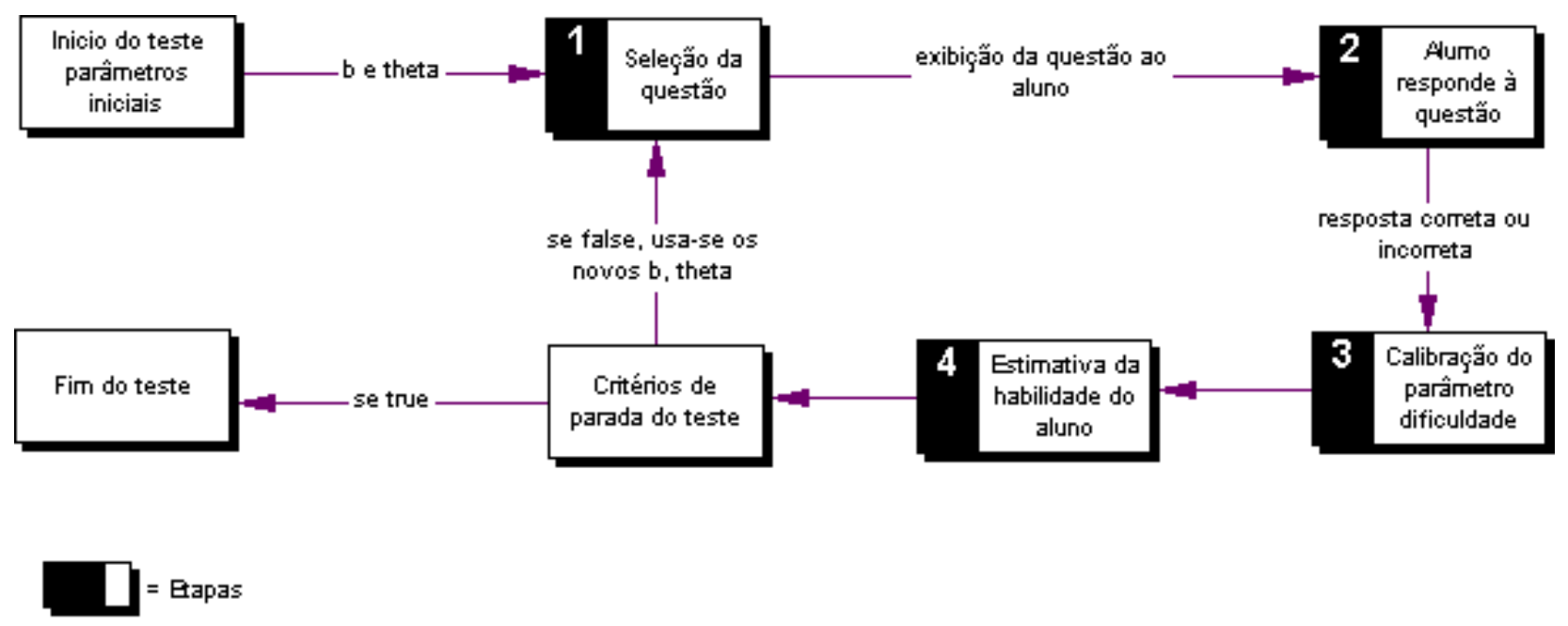

Figura A.1: Ciclo das Etapas para o desenvolvimento do ADEPT.

Finalizada a Etapa 4, segundo os critérios de para do teste, ou o aluno será remetido a uma nova questão ou o teste é terminado. 